\title{
Neurochemical and Behavioral Features in Genetic Absence Epilepsy and in Acutely Induced Absence Seizures
}

\author{
A. S. Bazyan ${ }^{1}$ and G. van Luijtelaar ${ }^{2}$ \\ ${ }^{1}$ Institute of Higher Nervous Activity and Neurophysiology, Russian Academy of Science, Russian Federation, \\ 5 A Butlerov Street, Moscow 117485, Russia \\ ${ }^{2}$ Biological Psychology, Donders Centre for Cognition, Donders Institute for Brain, Cognition and Behavior, \\ Radboud University Nijmegen, P.O. Box 9104, 6500 HE Nijmegen, The Netherlands
}

Correspondence should be addressed to G. van Luijtelaar; g.vanluijtelaar@donders.ru.nl

Received 21 January 2013; Accepted 6 February 2013

Academic Editors: R. L. Macdonald, Y. Wang, and E. M. Wassermann

Copyright (C) 2013 A. S. Bazyan and G. van Luijtelaar. This is an open access article distributed under the Creative Commons Attribution License, which permits unrestricted use, distribution, and reproduction in any medium, provided the original work is properly cited.

\begin{abstract}
The absence epilepsy typical electroencephalographic pattern of sharp spikes and slow waves (SWDs) is considered to be due to an interaction of an initiation site in the cortex and a resonant circuit in the thalamus. The hyperpolarization-activated cyclic nucleotide-gated cationic $I_{\mathrm{h}}$ pacemaker channels $(\mathrm{HCN})$ play an important role in the enhanced cortical excitability. The role of thalamic HCN in SWD occurrence is less clear. Absence epilepsy in the WAG/Rij strain is accompanied by deficiency of the activity of dopaminergic system, which weakens the formation of an emotional positive state, causes depression-like symptoms, and counteracts learning and memory processes. It also enhances $\mathrm{GABA}_{\mathrm{A}}$ receptor activity in the striatum, globus pallidus, and reticular thalamic nucleus, causing a rise of SWD activity in the cortico-thalamo-cortical networks. One of the reasons for the occurrence of absences is that several genes coding of $\mathrm{GABA}_{\mathrm{A}}$ receptors are mutated. The question arises: what the role of $\mathrm{DA}$ receptors is. Two mechanisms that cause an infringement of the function of DA receptors in this genetic absence epilepsy model are proposed.
\end{abstract}

\section{Introduction}

Absence seizures, typical for many different patients with absence epilepsy, principally differ from convulsive seizures. To illustrate, a number of widely used and efficient anticonvulsant drugs enhance absence seizures in patients and in the genetic absence models and ethosuximide is only effective in suppressing absence seizures and completely ineffective in other types of seizures [1-3]. Absence epilepsy is characterized by the occurrence of spontaneous occurring spikewave discharges (SWDs) and periods of reduced alertness or responsiveness. The SWDs are induced by hyperpolarization and they appear on an otherwise normal EEG. The spike of the SWD represents an excitatory postsynaptic potential and bursts of action potentials (Figure 1(b)) of thalamocortical and corticothalamic cells, the wave a slow wave in the EEG, is the subsequent inhibitory phase $[4,5]$. The generalized and widespread bilaterally synchronous SWDs are the result of highly synchronized oscillations in corticothalamocortical networks. SWDs, as can be found in WAG/Rij rats, have a local cortical origin in the perioral region of the somatosensory cortex [6-12], which is now confirmed in GAERS $[13,14]$, another well validated and often used strain of rats with absence epilepsy $[15,16]$. Local injections in the perioral region of the somatosensory cortex of the T-type $\mathrm{Ca}^{2+}$ channel blocker ethosuximide was rather effective in suppressing SWDs [17], but also in Long-Evans rats with SWDs, and in Wistar rats treated with a low dose of PTZ [18]. The cortex is part of a network in which the reticular thalamic nucleus (RTN) is an essential part. The RTN is responsible for the initiation of sleep spindles not only in rats, but also in other species $[19,20]$. It needs to be acknowledged that previously the RTN was considered as the pacemaker for SWDs as well [21, 22]. Nowadays the origin of the initiation site of SWDs is the subject of quite some research efforts, in rats as well as in humans and it is widely assumed that 


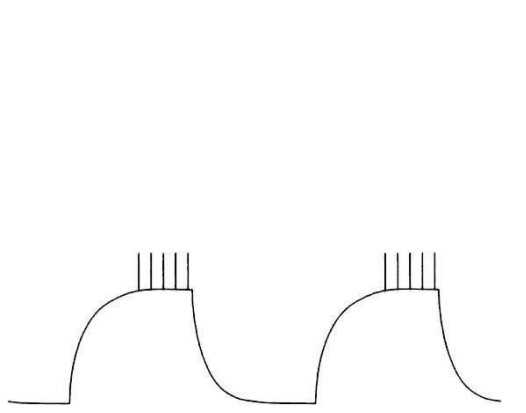

(a)

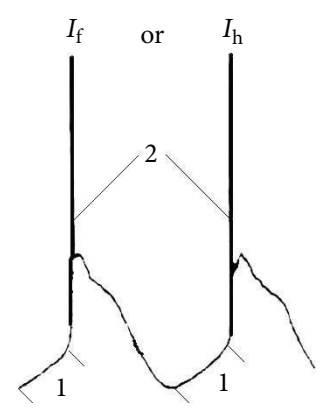

(b)
FIgURE 1: The schematic representation of two types of epileptic discharges. (a) The gradual increase in potential reaches the threshold level followed by the generation of epileptic discharges. This is typical for the EEG hallmarks accompanying convulsive seizures. (b) The spike-wave discharge. It consists of an inhibitory phase and an action potential. The inhibitory phase (1) appears as a slow wave on the EEG, excitation (a series of action potentials) of the cells appears as a spike (2). A rebound peak appears at the end of this phase and the cycle repeats itself many times. The discharge possesses the same profile as spike-wave discharges (with permission from Springer; [30]).

the cortex contains a focal hyperexcitable region in which SWDs have their origin, although the initiation site and the number of foci might be different among patients and between humans and rats [10, 14, 23-29].

The genetic rodent models are most widely used as models of absence epilepsy. They allow the investigation of the neurobiological underpinning of this type of epilepsy and the accompanying SWDs $[9,16,31-36]$. The mice have often spontaneous mutations such as in lethargic and tottering mice and transgenic and gene replacement models are also often used (for review see $[35,36]$ ). These mice have spontaneous epileptic seizures of which the behavioral and electrographic features and anticonvulsant sensitivity might sometimes be similar to those of human absence seizures [2]. Acutely induced absence seizures can also be studied in acute pharmacological models, $\gamma$-hydroxybutyrate (GHB), penicillin but most often a low dose of pentylenetetrazole (PTZ) is used [37]. There are two pharmacological models for atypical absence epilepsy. These are the AY-9944 [38, 39] and the methylazoxymethanol acetate (MAM)-AY-9944 [40] models in rats. Administration of the 7-dehydrocholesterol reductase inhibitor, AY9944, early in life to either rats or mice results in the spontaneous recurrent occurrence of atypical absence seizures which last throughout the animal's lifetime. The MAM-AY9944 model is a double hit model of medically refractory atypical absence epilepsy since cortical dysplasias are first induced in rat by prenatal administration of MAM and then AY9944 is administered during the first 3 weeks postnatally [41].

The WAG/Rij model is one of the well documented models $[9,10,16,34,42]$. The SWDs of WAG/Rij rats start to appear in the EEG when the rats are about 2-3 months. At the age of six months, all rats of this fully inbred strain have several hundred SWDs per day. The model has some features, which further increase the interest.

(i) WAG/Rij have a changed expression of genes coding for the low threshold T-type $\mathrm{Ca}^{2+}$ channel $\left(I_{\mathrm{Ca}, \mathrm{T}}\right)$ compared to ACI control rats [43] and absence epileptic patients have a mutation of genes coding for $I_{\mathrm{Ca}, \mathrm{T}}[44-46]$.

(ii) Reduction of expression of the $\alpha 3$ subunit protein in $\mathrm{GABA}_{\mathrm{A}}$ receptors in the RTN [47] of WAG/Rij rats and mutation of genes coding for subunits of $\mathrm{GABA}_{\mathrm{A}}$ receptors in people with absence epilepsy were found $[48,49]$.

(iii) WAG/Rij rats have complex phenotype: they are comorbid for depression [50-52].

We assume that the $I_{\mathrm{h}}$ pacemaker channels localized in the somatosensory cortex contribute to the initiation of the occurrence of SWDs and that a second set of pacemaker channels can be found in the thalamus. The latter is responsible for the occurrence of thalamic delta activity and sleep spindles, as can be assumed from the classical studies of the firing pattern in thalamic relay cells, tonic and burst firing modes $[53,54]$. A small portion of thalamic relay cells show bursting during SWDs, in which $I_{\mathrm{h}}$ might also play a role. The thalamus, a recipient of many cortical efferents, is also part of a resonant circuitry for SWDs that can be activated by the somatosensory cortex. In this way, the RTN and its widespread connections to other thalamic nuclei form a pathway in the propagation of cortically triggered SWDs and sustain oscillations.

\section{Hyperpolarization-Activated $I_{\mathrm{h}}$ Pacemaker Channel in the Mammalian Brain}

The pacemaker channels in the mammalian brain are named $I_{\mathrm{h}}$ channels, the pacemaker channels in other tissue are named $I_{\mathrm{f}}[30,55]$. Both are cationic pacemaker channels.

2.1. The Features of $I_{\mathrm{f}}$ and $I_{\mathrm{h}}$ Pacemaker Channels. Hyperpolarization-activated cyclic nucleotide-gated cationic $I_{\mathrm{f}}$ or $I_{\mathrm{h}}$ pacemaker channels maintain spontaneous periodic activation, and they were discovered in heart $\left(I_{\mathrm{f}}\right)$ and brain $\left(I_{\mathrm{h}}\right)$. Four isoforms of this channel are known (HCN1HCN4, hyperpolarization-activated and cyclic nucleotidegated) [56-61]. HCN channels resemble voltage-dependent $\mathrm{K}^{+}$channels; they are tetrameric and consist of monomeric subunits, each of which contains six transmembrane domains (S1-S6) with a P-loop (Figure 2) between the S5 and S6 domains [60, 62]. Four HCN1 subunits join and form a $\mathrm{HCN} 1$ homotetrameric channel, four HCN2 subunits form a HCN2 homotetrameric channel, and so forth. Different HCN subunits may also join to form a heteromultimeric complex, this substantially increases the diversity of $I_{\mathrm{f}}$, or $I_{\mathrm{h}}$ channels [62-64].

The primary analysis of the HCN channel sequence [56$58,60,62]$ indicated the presence of five endogenous cysteine residues in the transmembrane domains. Three of these are 


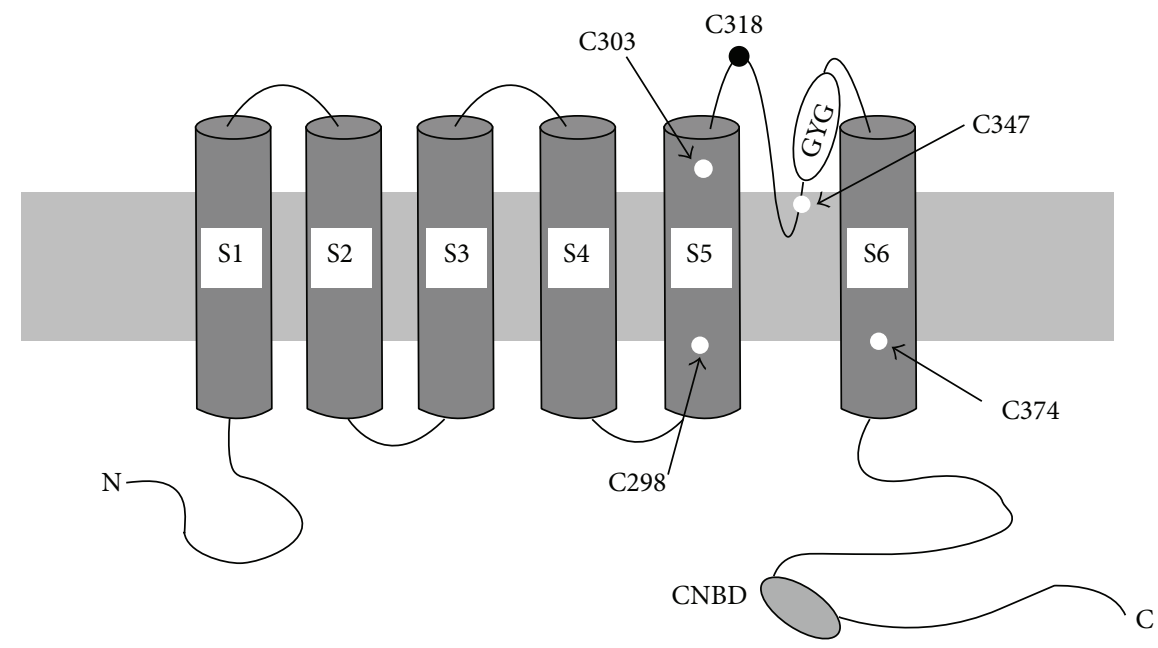

Figure 2: Probable transmembrane topology of HCN channels. Six transmembrane domains (S1-S6) of monomeric of the HCN1 subunit are presented. Five endogenous cysteine residues are localized in transmembrane domains of all four isoforms of HCN channels. Three of them in the 303, 318, and 347 position (Cys303, Cys318, and Cys347) are localized closer to the extracellular space, whereas the two remaining ones (Cys298 and Cys374) are probably closer to the cytoplasmic or inner side. The cyclic nucleotide-binding domain (CNBD) is localized on the C-terminus. The glycine-tyrosine-glycine amino-acid sequence forms a channel pore between the S5 and S6 domains (with permission from Springer, [30]).

localized closer to the extracellular side, the Cys303 residue in the S5 transmembrane domain, the Cys318 residue in the aminoacid chain connecting S5 and S6, and Cys347, which is in direct proximity to the glycine-tyrosine-glycine (GYG) sequence that forms the channel pore. Two other cysteine residues are localized closer to the cytoplasmic, or inner, side (Cys298 in S5 and Cys374 in S6) (Figure 2). It is known that cysteine has a hydrosulphate group and its reduced form may easily participate in chemical reactions, like alkylation, acylation, and arylation, or even cross-inking with another nearby cysteine to form a disulphide bridge $[65,66]$. These chemical reactions are essential for association of subunits and channel formation.

The HCN channel is open at an average membrane potential of $-80 \mathrm{mV}$ [67]. However, different subunits of the HCN channel possess different functional properties. To illustrate, $\mathrm{HCN} 1$ and $\mathrm{HCN} 2$ subunit isoforms, coexpressed in the cerebral cortex and hippocampus, are substantially different in their biophysical features. HCN1 channels become five to ten times faster activated than HCN2 channels. Also, HCN1 channels become activated at a membrane potential that is $20 \mathrm{mV}$ more positive than the potential required for HCN2 activation $[68,69]$. The HCN2 channel demonstrates a clear response $(+17 \mathrm{mV})$ to cAMP binding at the cyclic nucleotide binding domain (CNBD) on the $\mathrm{C}$-terminus, the HCN1 channel demonstrates a minimal response to cAMP $(+4 \mathrm{mV})$. Therefore it can be safely assumed that $\mathrm{HCN} 1$ and $\mathrm{HCN} 2$ perform quite different functions in the brain regions where they predominate [70]. Heteromultimeric channels with new properties can be found throughout the central nervous system $[68,69]$. Coexpression of $\mathrm{HCN} 1$ and $\mathrm{HCN} 2$ with heteromultimeric channel formation leads to $I_{\mathrm{h}}$ currents, which are kinetically activated via a voltage-dependent mechanism and tend to possess functional properties that are intermediate between $\mathrm{HCN} 1$ and $\mathrm{HCN} 2$ homomeric channels. Coexpressed heteromultimeric channels demonstrate a relatively larger shift in response to cAMP $(+14 \mathrm{mV})$ than the monomeric HCN1 channel. Neither the kinetic curve nor dose-effect curve in response to cAMP of coexpressed heteromultimeric $I_{\mathrm{h}}$ channels are a linear summation of the independent populations of $\mathrm{HCN} 1$ and $\mathrm{HCN} 2$ homomeric channels. These heteromeric channels have unique and new properties [63].

Several chimers of HCN1 and HCN2 homomeric channels have been created with a modified $\mathrm{NH}_{2}$ terminus, transmembrane domain, and different areas of the $\mathrm{COOH}$ terminus. CNBD exchange between $\mathrm{HCN} 1$ and $\mathrm{HCN} 2$ results in only a small influence on the main gating mechanism, and exerts a relatively poor effect on cAMP modulation. The difference in the cAMP modulatory effect depends instead on the interaction between CNBD and the aminoacid sequence (80 amino acids) that connects the last transmembrane domain (S6) and CNBD.

The glycine-tyrosine-glycine (GYG) sequence found between the S5 and S6 domains forms the channel pore (Figure 2). The pore is formed by this aminoacid sequence originating from all four subunits when they are united in the tetrameric channel. The same amino acid sequence forms a pore in many $\mathrm{K}^{+}$selective channels [62]. The pore of the HCN channel is permeable not only for $\mathrm{K}^{+}$but also for $\mathrm{Na}^{+}$ ions.

2.2. $I_{\mathrm{h}}$ Channels and Absence Epilepsy. The main diagnostic sign of absence epilepsy is the presence of SWDs in human or animal electroencephalogram (EEG). The similarity in morphology of SWDs $[32,71]$ and discharges generated by $I_{\mathrm{h}}$ channel (Figure 1(b)) suggests that the $I_{\mathrm{h}}$ channel is 
a contributing factor to the morphology of the spike and wave complex. Several other authors have already hypothesized that this nonselective $I_{\mathrm{h}}$ channel plays also a crucial role in the age-dependent development in the occurrence in SWDs [70, 72-76]. Considering that different subtypes are differently present in cortex and thalamus, HCN1 is expressed selectively in specific brain regions, among others the neocortex and certainly on the large pyramidal neurons [58, 77, 78], while HCN2 is more widely expressed throughout the brain, including the thalamus; these different parts will be discussed separately.

2.2.1. $I_{\mathrm{h}}$ in Cortex. Studies aimed at elucidating the role of $I_{\mathrm{h}}$ channel activity in absence epilepsy compared $I_{\mathrm{h}}$ channels in cortical neurons of epileptic and control strains of rats: WAG/Rij, Wistar (of the same genetic background as WAG/Rij but less prone to absence epilepsy) and ACI rats (an inbred strain practically devoid of epileptic activity) $[73,79,80]$. The cortex was targeted since it contains the focal onset zone of SWDs. Patch-clamp recording from the whole cell of the second-third cortical layer of pyramidal neurons was supplemented by immunohistochemical, Western blot, and PCR studies of HCN1-HCN4 subunits of the $I_{\mathrm{h}}$ channel. The fast component of $I_{\mathrm{h}}$ activation in neurons of WAG/Rij rats was significantly reduced (a 50\% decrease in the current density) and was four time slower than in the neurons of nonepileptic Wistar or ACI rats. The results of Western blot and PCR analysis corresponded to a decreased $I_{\mathrm{h}}$ current. A decrease by $34 \%$ was found in the level of the HCN1 subunit protein in the cerebral cortex of WAG/Rij rats as compared to Wistar rats, but HCN1 mRNA expression was not different. The protein and mRNA levels of the other three $I_{\mathrm{h}}$ channel subunits (HCN2-HCN4) were not altered [73]. This loss of neocortical HCN1 function may contribute to an increased cortical excitability since there are substantially fewer HCN1 subunits in the combined complex of the $I_{\mathrm{h}}$ channel in the cortical zone containing the focal region in WAG/Rij strain compared to the two control strains.

A loss of HCN1 was also found during ontogeny: it occurs primarily in the apical dendrites of layer 5 pyramidal neurons in the cortex, leading to a spatially uniform 2-fold reduction in dendritic $\mathrm{HCN}$ current throughout the entire somatodendritic axis [76]. Dual whole-cell recordings from the soma and apical dendrites demonstrate that loss of HCN1 increases somatodendritic coupling and significantly reduces the frequency threshold for generation of dendritic $\mathrm{Ca}^{2+}$ spikes by back propagating action potentials. As a result of increased dendritic $\mathrm{Ca}^{2+}$ electrogenesis, a large population of WAG/Rij layer 5 neurons showed intrinsic high-frequency burst firing. Using morphologically realistic models of layer 5 pyramidal neurons from control Wistar and WAG/Rij animals, it was shown that the experimentally observed loss of dendritic $I_{\mathrm{h}}$ recruits dendritic $\mathrm{Ca}^{2+}$ channels to amplify action potential-triggered dendritic $\mathrm{Ca}^{2+}$ spikes and increase burst firing. Thus, loss of function of dendritic HCN1 channels in layer 5 pyramidal neurons provides a somatodendritic mechanism for increasing the synchronization of cortical output, and is therefore likely to play an important role in the generation of SWDs accompanying absence seizures [76].

It has been shown that neonatal handling and maternal deprivation postnatally (1-21 days) resulted in reduced number of absences, decreased interspike interval, and changes in power of the frequency spectrum of SWDs in adult WAG/Rij rats [81]. Whole cell patch-clamp recordings from the cells of the fifth pyramidal layer, in situ hybridization, and Western blot analysis of the cortex of adult WAG/Rij rats [74] showed an increase in the HCN1 protein level in the somatosensory cortex of handled and mother-deprived rats as compared to control rats. This increase was selective for the HCN1 subunit and did not affect the expression of HCN2-HCN4 subunit proteins; neither did expression of the mRNA of any subunit ( $\mathrm{HCN} 2, \mathrm{HCN} 3$, and $\mathrm{HCN} 4)$. These results indicate that relatively mild changes in the environment of neonatal rats have long-lasting consequences for the occurrence of paroxysmal activity later in life and suggest that increased concentration or better, an increased proportion of $\mathrm{HCN} 1$ subunits in $I_{\mathrm{h}}$ channel composition in a small area of the somatosensory cortex is related to a reduction in the number of SWDs. An increased number of HCN1 subunits in the channel due to their extensive expression (increased $\mathrm{HCN} 1$ protein level without changes in $\mathrm{HCN} 2, \mathrm{HCN} 3$, and HCN4 mRNA levels), and consequently, a decreased number of HCN2, HCN3, and HCN4 subunits in the channel complex, as mentioned above $[68,69]$, result in impaired activity of the $I_{\mathrm{h}}$ channel, reduced cortical excitability, and less SWDs, as it has been demonstrated experimentally $[73,74,81]$.

Besides the age-dependent decrease in the number of $\mathrm{HCN} 1$ subunits and in protein expression in the deep layers of the focal region [76], a chronic drug treatment aimed at antiepileptogenesis in the same model confirmed that the reduction of SWDs was accompanied by an increase in HCN1, producing levels that resemble nonepileptic controls [82]. In addition, neonatal manipulations [74] increased the number of HCN1 subunits and decreased SWDs, providing evidence for the negative correlation between SWDs on the one side and this $I_{\mathrm{h}}$ channel otherwise.

Blocking the $I_{\mathrm{h}}$ channels of Layer V neurons by ZD7288 (4-ethylphenylamino-1,2-dimethyl-6-methyl-aminopyrimidinium chloride), as well as a loss of $\mathrm{HCN} 1$ subunits, increases somatodendritic coupling, increases $\mathrm{Ca}^{2+}$ conductance by reducing the frequency threshold for induction of dendritic $\mathrm{Ca}^{2+}$ electrogenesis, increasing synchronization of cortical output and burst firing [76]. Therefore, ZD7288 when administered in the cortex can enhance SWDs. It is, however, possible that this property of $I_{\mathrm{h}}$ channels is only present in neurons of the the subgranular layers, since $I_{\mathrm{h}}$ channels of thalamic neurons have different biophysical properties.

It can be concluded that an age-dependent loss of neocortical HCN1 function contributes to an increased cortical excitability in the form of more and longer spontaneous occurring SWDs and that various early manipulations, such as maternal deprivation but also treatments aiming at antiepileptogenesis confirm the negative relation between HCN1 and SWDs. 
2.2.2. $I_{\mathrm{h}}$ in Thalamus: Its Role in Delta, Sleep Spindles, and SWDs. The in vitro studies done in the late eighties and in the nineties of the last century were influential for the ideas than have been developed on the role of the interaction between $I_{\mathrm{h}}$ and $I_{\mathrm{Ca}, \mathrm{T}}$ [83]. Basically, the interaction of $I_{\mathrm{h}}$ and $I_{\mathrm{Ca}, \mathrm{T}}$ channels has been assumed to be the basis for burst firing in thalamocortical (TC) cells [84]. Briefly, upon hyperpolarization of the TC cell membrane by a reduction of depolarizing inputs beneath the resting membrane potential, $I_{\mathrm{h}}$ is activated and produces a slow pacemaker depolarization until the threshold voltage of activation of $I_{\mathrm{t}}$ is reached. The hyperpolarization concomitantly deinactivated $I_{\mathrm{t}}$ and the pacemaker depolarization subsequently activates $I_{\mathrm{t}}$ that leads to the generation of a low-threshold $\mathrm{Ca}^{2+}$ potential, bringing the membrane potential positive to firing threshold. This evokes high-frequency burst of action potentials. The transient nature of $I_{\mathrm{t}}$ will then terminate the depolarization and hyperpolarize the cell. Less $I_{\mathrm{h}}$ (less inward current) than at the beginning of the $\mathrm{Ca}^{2+}$ spike will be activated because $I_{\mathrm{h}}$ partly deactivated during the depolarization associated with the $\mathrm{Ca}^{2+}$ potential. As a consequence, the membrane potential will hyperpolarize to a potential more negative than the $I_{\mathrm{t}}$ activation threshold. The cell will thus reach the peak of the hyperpolarization and reactivate $I_{\mathrm{h}}$, restarting the cycle. Thus, while $I_{\mathrm{t}}$ is responsible for the large-amplitude depolarizations, $I_{\mathrm{h}}$ mediates both the slow pacemaker depolarization necessary to activate $I_{\mathrm{t}}$ and the hyperpolarization that follows low-threshold $\mathrm{Ca}^{2+}$ potentials [85]. The burst firing mode is activated during drowsiness, with TC and CT cells undergoing a progressive hyperpolarization from drowsiness and the early stages of sleep to the late sleep stage of deep slow wave sleep. The frequency of the burst firing mode is determined by the amount of hyperpolarization, such that sleep spindle oscillations $(7-12 \mathrm{~Hz})$ occur at more depolarized membrane potentials than delta oscillations [86]. It has been assumed based on in vitro studies that this thalamic burst firing mode can also be the physiological correlate of SWD. However, studies in GAERS have demonstrated that TC relay cells were not associated with rhythmic IPSPs, $\mathrm{Ca}^{2+}$ currents, or burst discharges, but only with the occasional firing of a single action potential $[87,88]$, and that during SWDs a minor portion of TCR cells (7\% in GAERS, [87]) show $\mathrm{Ca}^{2+}$ currents and burst discharges. The bursting of such a small portion of TCR cells appears to be sufficient for the sustainment of SWDs. In agreement with this finding is that local injections of the low-threshold $\mathrm{Ca}^{2+}$ blocker ethosuximide are not very active when injected in the thalamus [17]. Moreover, there are no in vivo studies in genetic models which investigated the role of thalamic $I_{\mathrm{h}}$.

However, burst firing in TC cells is crucial for the presence of delta waves. In in vitro rat, cat, and ferret studies, isolation of TC relay cells from synaptic input from CT and RTN leads to a hyperpolarization of the cells and onset of selfsustained oscillations in the delta $(0.5-4 \mathrm{~Hz})$ frequency band $[85,89,90]$. Likewise hyperpolarization of TC neurons by means of hyperpolarizing current injection leads to burst firing of the neurons also in the delta frequencies [85], and this goes together with the activation of $I_{\mathrm{h}}[85,89]$. In vivo studies which confirmed this were, however, not done.

Studies on the role of $I_{\mathrm{h}}$ in spindle oscillations have been performed in thalamic slices with neurons that either show spontaneous spindling, such as in the ferret LGNd [91], or where thalamic spindle activity is evoked by applying hyperpolarizing current pulses mimicking IPSPs arriving during spindle waves in the intact RTN/PGN-TC network [92]. Induced spindle activity in TC neurons has been shown to go together with $I_{\mathrm{h}}$ activation, lending evidence for an involvement of $I_{\mathrm{h}}$ in spindle generation [93, 94]. Further evidence for a role of $I_{\mathrm{h}}$ in spindle oscillations comes from $I_{\mathrm{h}}$ manipulation studies in thalamic slices. Intracellular injection of depolarizing current into spindling LGNd neurons resulted in inactivation of $I_{t}$, abolition of rebound $\mathrm{Ca}^{2+}$ spikes and cessation of the spindle oscillations [95]. The type of burst firing oscillation (delta and spindle oscillations) is determined by the membrane potential [86], that is on its turn set by $I_{\mathrm{h}}[70,93] . I_{\mathrm{h}}$ thus plays an important role in setting the membrane potential that determines the type of burst firing oscillation present in the TC cells. But different from delta oscillations, $I_{\mathrm{h}}$ and the pacemaker potential created by lowthreshold $\mathrm{Ca}^{2+}$, does not seem to be of critical importance for spindles since blockade of $I_{\mathrm{h}}$ does not lead to the cessation of the oscillation, as seen in delta oscillations [85, 89, 96, 97], but to a failure in spindle termination $[89,92]$. This questions the exact role of $I_{\mathrm{h}}$ in spindle generation; moreover in vivo studies towards the role of $I_{\mathrm{h}}$ in sleep spindle generation are lacking as well.

It can be concluded that the interaction of $I_{\mathrm{h}}$ and $I_{\mathrm{t}}$ seems critical for the generation of delta oscillations, $I_{\mathrm{h}}$ seems involved in sleep spindle generation, and however its exact mechanisms are beyond the scope of this paper. A dominant role for $I_{\mathrm{h}}$ in thalamic bursting underlying SWD can also be doubted since a small portion of TC cells show this behavior. However, the possibility exists that $I_{\mathrm{h}}$ and $I_{\mathrm{t}}$ interact in the portion of TC cells that do show bursting in which the $I_{\mathrm{h}}$ and $I_{\mathrm{t}}$ interact as a tandem.

2.2.3. $I_{\mathrm{h}}$ in Thalamus: A Different Role. The role of thalamic $I_{\mathrm{h}}$ was investigated in WAG/Rij rats: high HCN1 mRNA and protein expression without alterations in HCN2-HCN4 expression was found in thalamic neurons [98]. These authors found also that that burst discharges in thalamocortical neurons locked to SWDs were prolonged during blockade of $\mathrm{I}_{\mathrm{h}}$ by Cs ${ }^{+}$and ZD7288, similar as has been found for sleep spindles. This was associated with hyperpolarizing shift in $I_{\mathrm{h}}$ activation, a decrease in cAMP responsiveness of $I_{\mathrm{h}}$ in TC neurons and resulting impairment to shift from burst to tonic firing, which in turn produced long burst activity after recruitment of $I_{\mathrm{h}}$ during SWDs. On the basis of these results and shifts of $I_{\mathrm{h}}$ channel reactivity induced by high concentrations of cAMP, Budde et al. [98] hypothesized that increased HCN1 expression in the epileptic thalamus is associated with decreased $I_{\mathrm{h}}$ channel reactivity to cAMP in thalamic neurons and leads to a loss of control over the channel, which, in turn, prolongs high $I_{\mathrm{h}}$ channel activity during absence seizures. 
Interesting results [75] were also obtained during the study of the regulation of the pacemaker $I_{\mathrm{h}}$ channel in the thalamus of GAERS rats; the function of the $I_{\mathrm{h}}$ channel and subunit composition in TC-neurons were studied before (presymptomatic) and when (symptomatic) SWDs were present in the EEG. The voltage-dependent $I_{\mathrm{h}}$ current remained unaltered in mature somatosensory neurons, both in vivo and in vitro. However, an increase in $I_{\mathrm{h}}$ current by the phasic, practically physiologic, impulse of cAMP was diminished by approximately $40 \%$ and the half-maximal cAMP concentration was approximately fivefold increased. This diminished sensitivity of $I_{\mathrm{h}}$ current to its main cellular modulator preceded the beginning of epilepsy, lasted during its chronic phase, and accompanied the elevated expression of mRNA of the cAMP-insensitive HCN1 subunit of the channel $(>50 \%)$ without alterations in $\mathrm{HCN} 2-\mathrm{HCN} 4 \mathrm{mRNA}$ expression.

Changes in excitability of TC neurons were analyzed by measuring the delayed upregulation of the $I_{\mathrm{h}}$ current. This current was caused by $\mathrm{Ca}^{2+}$-triggered cAMP synthesis and is essential for finishing synchronized oscillations in vitro. Repeated recovery of the $\mathrm{Ca}^{2+}$ spike induced the normal deceleration of upregulation of the $I_{\mathrm{h}}$ current in mature GAERS neurons, sufficient to reduce the spontaneous rhythmic burst discharges. These adaptive mechanisms take place despite cAMP turnover and involve increased intracellular $\mathrm{Ca}^{2+}$ concentration in response to repeated low-threshold $\mathrm{Ca}^{2+}$ discharges. Thus, HCN channels may play an ambient role in absence epilepsy. The weakening of the binding of cAMP to HCN channels in the thalamus proceeds, and likely promotes, epileptogenesis in GAERS rats, whereas compensatory mechanisms stabilizing the function of $I_{\mathrm{h}}$ channels contribute to the completion of the SWDs in chronic absence epilepsy [75].

A quantitative model (Figure 3 ) describes how $I_{\mathrm{h}}$ and $I_{\mathrm{t}}$ cooperate and how the subcompositions of the subunits determine the net effect (depolarization) of hyperpolarizing inputs. It is based on Kuisle et al. [75]. The tandem consisting of $I_{\mathrm{h}}$ and $I_{\mathrm{Ca}, \mathrm{T}}$ works as follows: the hyperpolarization of the cell membrane opens a $I_{\mathrm{h}}$ channel and the membrane is depolarized by an amount $N$. Next the hyperpolarization opens the $I_{\mathrm{Ca}, \mathrm{T}}$ channel and $\mathrm{Ca}^{2+}$ enters the cell, increases activity of adenylate cyclase, and increases cAMP concentration as the result of selective activation of PKA (cAMP-dependent protein kinase-A) isoforms. The cAMP binds to the CNBD domain and enhances the ion flow and amount of membrane depolarization (gating mechanism) to a value $M$. The total amount of depolarization $I_{\mathrm{h} \text { Dep }}=N+M$.

When the $I_{\mathrm{h}}$ channel consists of four HCN1 subunits, as the case in the cortex for the large pyramidal cells, then the interaction of cAMP with the CNBD HCN1 subunit strengthens the gating mechanism and the depolarization is increased by $4 \mathrm{mV}$ [63]. In this case, $4(\mathrm{HCN1}) ; I_{\mathrm{h} \text { Dep }}=N+$ $(4 \times 4) \mathrm{mV}=N+16 \mathrm{mV}$.

When cAMP interacts with CNBD of an HCN2 subunit, as is the case in the thalamus, then the gating mechanism is amplified and the depolarization is increased by $17 \mathrm{mV}$ [63]. The subunit composition can be either:

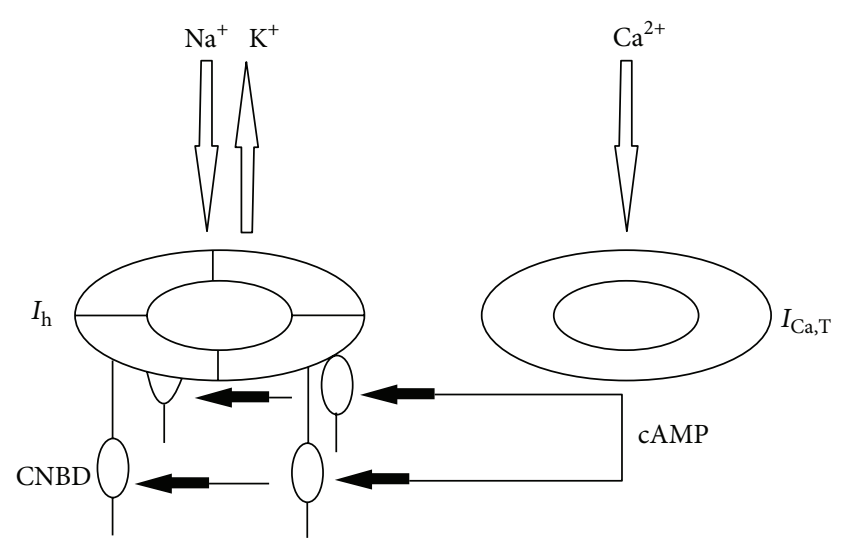

FIGURE 3: Schematic representation of the functional interaction between $I_{\mathrm{h}}$ and $I_{\mathrm{Ca}, \mathrm{T}}$ channel, for explanation see text.

$$
\begin{aligned}
& 3(\mathrm{HCN} 1)+1(\mathrm{HCN} 2) ; I_{\mathrm{h} \text { Dep }}=N+(3 \times 4) \mathrm{mV}+ \\
& (1 \times 17) \mathrm{mV}=N+29 \mathrm{mV} \\
& 2(\mathrm{HCN} 1)+2(\mathrm{HCN} 2) ; I_{\mathrm{h} \text { Dep }}=N+(2 \times 4) \mathrm{mV}+ \\
& (2 \times 17) \mathrm{mV}=N+42 \mathrm{mV} \\
& 1(\mathrm{HCN} 1)+3(\mathrm{HCN} 2) ; I_{\mathrm{h} \text { Dep }}=N+(1 \times 4) \mathrm{mV}+ \\
& (3 \times 17) \mathrm{mV}=N+55 \mathrm{mV} \\
& 4(\mathrm{HCN} 2) ; I_{\mathrm{h} \text { Dep }}=N+(4 \times 17) \mathrm{mV}=N+68 \mathrm{mV} .
\end{aligned}
$$

This implies that the composition of the heteromeric $I_{\mathrm{h}}$ channel, as can be found for example, in the thalamus, determines the amount of depolarization and the subsequent activation of voltage-activated $\mathrm{Ca}^{2+}$ channels. With age, the contribution of $\mathrm{HCN} 1$ subunits decreases (through a process called trafficking) and is replaced by HCN2 subunits. It does also explain that during aging the reaction to hyperpolarizing inputs might increase the amount of depolarization; in other words, during aging the thalamus will react with larger depolarizations upon the same hyperpolarizing inputs.

Our hypothesis that burst firing in TC neurons is caused by (tandem) hyperpolarization-activated $I_{\mathrm{h}}$ channel and hyperpolarization-activated $\left(I_{\mathrm{Ca}, \mathrm{T}}\right)$ channel and that burst firing of at least some TC cells plays a role in SWD occurrence, is supported by pharmacological studies indicating that increased GABAergic inhibition in the ventral basal (VB) complex of the thalamus, as induced by local injections of GABA-agonists, enhances SWDs. Remember that opposite effects (a decrease in SWDs) were obtained by injections of GABA agonists in the focal zone of the cortex $[15,99,100]$, suggesting that here depolarization rather than hyperpolarization promotes burst firing $[76,101]$.

The literature reviewed in this paragraph suggests that $I_{\mathrm{h}}$ and low-threshold T-type $\mathrm{Ca}^{2+}$ channels in TC cells work in tandem in order to generate burst-like activity, the assumed neurophysiological firing pattern that forms the basis of delta waves, sleep spindles and perhaps SWDs. The latter remains uncertain since the vast majority of TC cells do not show burst firing activity during SWDs. Hyperpolarization opens the $I_{\mathrm{h}}$ channel, and cationic current depolarizes the membrane to the threshold and induces a $\mathrm{Ca}^{2+}$ spike. Hyperpolarization also opens the $I_{\mathrm{Ca}, \mathrm{T}}$ channels. The entrance of $\mathrm{Ca}^{2+}$ ions into 
the cell induces $\mathrm{Ca}^{2+}$-dependent cAMP synthesis, and cAMP dramatically increases channel activity through binding to the CNBD locus of HCN subunits. The HCN1 subunit responds weakly to cAMP binding; therefore, a decrease in the proportion of HCN1 subunits in the channel increases pacemaker activity and an increase in the proportion of HCN1 subunits in the channel decreases pacemaker activity. The analysis of experimental data shows that one of the basic mechanisms of the long-term regulation of $I_{\mathrm{h}}$ pacemaker activity is modification and consolidation of a number of HCN1 subunits in the pacemaker channel by the help of the transduction signal.

\section{GABAergic Inhibitory System}

3.1. Pharmacological Investigations. The GABAergic system has two types of receptors. The first type of receptors mediating fast postsynaptic GABA reactions (IPSP's) are ionotropic $\mathrm{GABA}_{\mathrm{A}}$ receptors, including in its structure a chlorine channel. The second type of receptors mediating slow GABA reactions is metabotropic $\mathrm{GABA}_{\mathrm{B}}$ receptors. $\mathrm{GABA}_{\mathrm{B}}$ receptors are coupled indirectly to $\mathrm{K}^{+}$channels. When activated, these receptors can decrease $\mathrm{Ca}^{2+}$ conductance and inhibit cAMP production via intracellular mechanisms mediated by $G$ proteins. $G_{A B A}$ receptors can mediate both pre- and postsynaptic inhibition. Presynaptic inhibition may occur as a result of $\mathrm{GABA}_{\mathrm{B}}$ receptor binding on nerve terminals causing a decrease in the influx of $\mathrm{Ca}^{2+}$, thereby reducing the release of neurotransmitters. Postsynapticaly, the $\mathrm{G}$ proteingated inwardly rectifying $\mathrm{K}^{+}$(GIRK) channels are activated by stimulation of $\mathrm{G}_{\mathrm{i} / \mathrm{o}}$-coupled $\mathrm{GABA}_{B}$ receptors and provide an important mechanism for the slow inhibitory modulation of cellular excitability in the brain [102-104].

3.1.1. $G A B A_{A}$ Receptors. The $\mathrm{GABA}_{\mathrm{A}}$ receptors can be allosterically facilitated (increase of chlorine current) by benzodiazepines [105-107]. Pharmacological studies with specific agonists and antagonists of the benzodiazepine (BDZ) receptor focused on the $\mathrm{GABA}_{\mathrm{A}}$ receptor complex. A series of drugs belonging to the class of the $\beta$-carbolines were evaluated, mainly partial agonists such as ZK 91296 and ZK 112119 (abecarnil) and compared with the full agonist diazepam [108-110]. Diazepam showed all behavioral and electrophysiological changes characteristic for the BDZ, ZK 91296 reduced seizure activity without inducing signs of sedation, sleepiness, myorelaxation, and changes in behavior or EEG spectral content. Another member of the $\beta$-carboline family, the partial inverse agonist FG 7142, aggravated epileptic activity, with slightly enhanced immobile behavior, suggesting anxiogenic properties. The results not only demonstrate that the multiple effects of the BDZ could be separated by these compounds, but also that the antiepileptic activity is not related to changes in spectral content of the EEG. Because of its selective activity, ZK 91296 appears to be more suitable than diazepam in reducing seizure activity. Finally, FG 7142 seems a genuine partial inverse agonist which has some, but not all, of the inverse effects of a full agonist [108]. Next the effects of the $\beta$-carboline (abecarnil,
ZK 112119) were determined in two experiments: in the first the antiabsence profile of abecarnil was evaluated in WAG/Rij rats. In the second experiment, effects on sleep and behavior were investigated in nonepileptic Wistar rats. It was found that, similarly to classical BDZ, abecarnil possessed a strong antiepileptic character and also changed the background EEG to more high-frequency waves and less spindle activity. It also produced more immobile behavior. Abecarnil induced only small, marginally significant increases in slow-wave sleep while reducing REM sleep as a proportion of total sleep. It also reduced the number of REM periods. These observations are consistent with the proposed partial agonist activity of abecarnil, a drug with interesting therapeutic implications [111]. Rather similar results on the antiabsence action of the full agonists of BDZ receptors have been found in GAERS [112], emphasizing the similarities in the pharmacological profile of the two genetic absence models.

Hypnotic drugs are known to possess antiepileptic activity. Therefore, the effects of the BDZ hypnotic midazolam and the imidazopyridine hypnotic Zolpidem (both $10 \mathrm{mg} / \mathrm{kg}$ ) on sleep-wake states and on the number of SWDs were evaluated in WAG/Rij rats. Both hypnotics reduced the number and duration of SWDs. The initial decrease of SWDs after midazolam, however, was followed by a rebound. The antiabsence activity of zolpidem mimics that of midazolam and is well correlated with the equipotent hypnotic action and anticonvulsant effect in the isoniazid test [113].

The assumed tolerance to $\mathrm{BDZ}$ was investigated by injecting diazepam $(5 \mathrm{mg} / \mathrm{kg})$ twice daily for 23 days in WAG/Rij rats. After this, the rats received the agonist, diazepam, or the antagonist, flumazenil (Ro 15-1788). Acutely administered, diazepam reduced SWDs, while flumazenil was without clear effects. The effects were rather different after chronic administration: both compounds increased the number of SWDs [114], suggesting that repeated administration of diazepam abolished its antiepileptic action and even reversed its action. Also Flumazenil produced an increase in SWDs after chronic diazepam treatment. The antiepileptic effect of diazepam, acutely administrated, has been found also by others in GAERS [115].

The next allosteric facilitator of GABA inhibition at the $\mathrm{GABA}_{\mathrm{A}}$ receptor is the group of neurosteroids [116]. They have clinical relevance partly because the ovarian hormones acting as neurosteroids are held responsible for the variation of seizure frequency during the menstrual cycle, around puberty, and menopause. The variations in seizure frequency have been attributed partly to the antiepileptic action of progesterone: it reduces seizures during the luteal phase. However, studies on catamenial epilepsy (derived from the Greek word katomenios, meaning "monthly"), clusters of seizures around specific points in the menstrual cycle, have not always distinguished between patients with focal and generalized seizures. Grünewald et al. [117] described a patient whose absence seizures exacerbated when she was given progesterone. This indicates that, in contrast to the well-known anticonvulsant and antiepileptic properties of progesterone in most animal models and in almost all seizure types, absence epilepsy might be an exception in the sense that progesterone increases absence seizures [118]. 
The role of the sex hormones, but also of ganaxolone and other neurosteroids, has been thoroughly investigated in the genetic and pharmacological absence models. Ganaxolone ( $3 \alpha$-hydroxy- $3 \beta$-methyl- $5 \alpha$-pregnan-20-one) is a synthetic neurosteroid with anticonvulsant properties in a number of seizure models as well as the ability to enhance function of the $\mathrm{GABA}_{\mathrm{A}}$ receptor complex via the neurosteroid binding site. The effect of ganaxolone on absence seizures was assessed in the low-dose PTZ and the GHB model. Ganaxolone resulted in a significant prolongation of absence seizure in both models and in doses above $20 \mathrm{mg} / \mathrm{kg}$ it produced bilaterally synchronous SWDs associated with behavioral arrest. These data suggest that augmentation of $\mathrm{GABA}_{\mathrm{A}}$ receptor complex function by neurosteroids has the potential to result in or exacerbate absence seizures [119]. Systemic administration of the neurosteroids allopregnanolone and pregnenolone sulfate was studied in WAG/Rij rats. Allopregnanolone is also a positive modulator of the $\mathrm{GABA}_{\mathrm{A}}$ receptor, it increased dose dependently the number and total duration of SWDs. Pregnenolone sulfate, also a positive modulator of NMDA receptors, also increased those parameters, though only at the highest dose used $(100 \mathrm{mg} / \mathrm{kg})$ and only in the first hour postinjection. The obtained data indicate that both these neurosteroids aggravate SWD activity. These proepileptic activities of these neurosteroids contrasts with the anticonvulsant effects of many of these neurosteroids and they point to a different pharmacological profile of epilepsy with convulsive or nonconvulsive seizures [120]. In the next experiment the influence of endogenous neurosteroids on SWDs was investigated in female WAG/Rij rats in a chronic EEG study during a complete ovarian cycle [121]. A circadian pattern emerged for the number of SWDs: a nadir during the first hours of the light period, and an acrophase during the first hours of the dark period. This daily maximum was increased at proestrus day compared with the other days of the cycle, coinciding with an increased progesterone plasma level specifically at these hours of this day. This clearly suggests that even shifts in physiological concentrations of progesterone are already large enough to enhance SWDs. The results are presented in Figure 4.

There was no difference in the first few hours of the light period in the number of SWDs between proestrus and the three other days, suggesting that estradiol has no effect on SWDs. In the second study, the effects of systemic administration of progesterone and $17 \beta$-estradiol on SWDs and spontaneous behavior were investigated. It was confirmed what was found in the long term EEG study: progesterone increased the number and total duration of SWDs; $17 \beta$-estradiol was completely ineffective. The administration of RU 38486, an antagonist of intracellular progesterone receptors, had no effect on SWDs and did not block the stimulatory effect of progesterone. The intracellular estrogen receptor antagonist tamoxifen did not evoke alterations in the number or duration of SWDs either. The results indicate that estradiol is not affecting SWDs and that progesterone aggravates SWDs, but the progesterone effect is not mediated through intracellular receptors. Since progesterone is rapidly metabolized in the brain to the positive modulator of $\mathrm{GABA}_{\mathrm{A}}$ receptor allopregnanolone, which is also known

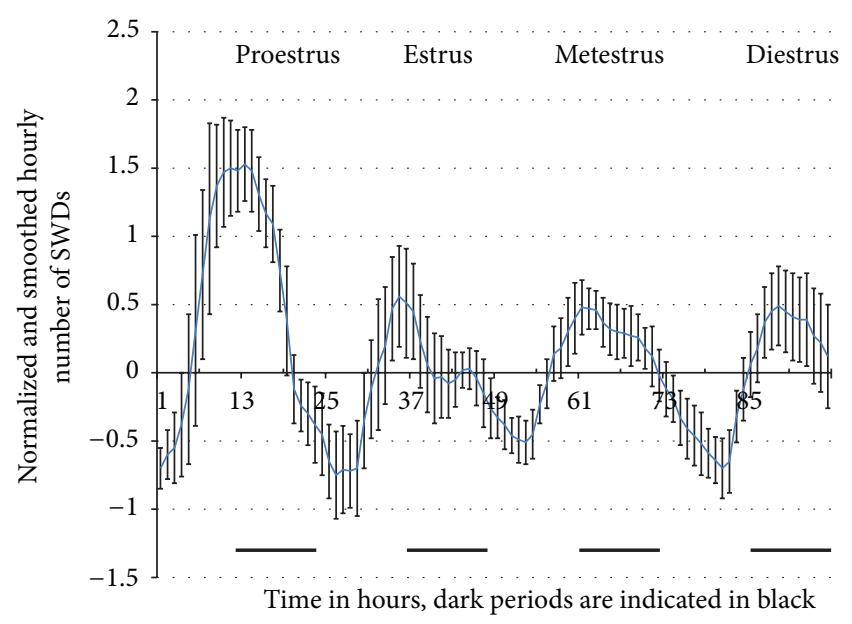

FIGURE 4: Hourly number of SWDs (mean and sem) in female WAG/Rij rats across the ovarian cycle. Note the circadian pattern across all four days and the increase in SWDs at the last hours of the light and first hours of the dark period of the proestrus day. It is at specifically these hours that progesterone levels are increased (adapted, [121]).

to increase SWDs in WAG/Rij rats, it is rather likely that the epileptoformic effects of progesterone are mediated through this metabolite [121]. In order to elucidate whether the regulatory effect of progesterone depends indeed on its conversion to allopregnanolone, the effect of finasteride, a $5 \alpha$-reductase inhibitor, on progesterone-induced increase in SWDs was studied. Progesterone dose dependently increased the number of SWDs during the first hour after injection. Finasteride alone had no effect on the number of SWD, up to $24 \mathrm{~h}$ following its administration. Pretreatment of rats with finasteride, however, blocked the progesteroneinduced enhancement of SWD. This indicates that the action of progesterone is mediated by its neuroactive metabolite allopregnanolone, through strengthening of $\mathrm{GABA}_{\mathrm{A}}$ receptor activity [122].

The administration of both progesterone and allopregnanolone exacerbated seizures in the AY model (an atypical absence epilepsy model) in agreement with the outcomes in WAG/Rij rats, whereas $17 \beta$-estradiol attenuated SWDs (this ovarian hormone does not modulate absences in the typical absence model). Neither mifepristone nor tamoxifen blocked the effects of progesterone and $17 \beta$-estradiol, respectively, on SWDs duration in the atypical absence model, suggesting that these two sex hormones are working in a manner independent of their intracellular neurosteroid receptor [123]. Anyway, the differential role of estradiol in typical and atypical absence seizures emphasizes the differences between these types of epilepsy [41].

The effects of neurosteroids on SWDs in WAG/Rij rats were also studied by local microinjections [99]. Allopregnanolone and ganaxolone (the two positive allosteric modulators of the $\mathrm{GABA}_{\mathrm{A}}$ receptor complex acting on the steroid recognition site) and pregnenolone sulphate, (the negative 
allosteric modulator of $\mathrm{GABA}_{\mathrm{A}}$ receptors and a positive modulator of NMDA receptors) were investigated. Focal bilateral microinjection of the two $\mathrm{GABA}_{\mathrm{A}}$ positive modulators into some thalamic nuclei (nucleus ventralis posteromedialis, NRT, nucleus ventralis posterolateralis) increased SWDs. Both compounds reduced number and duration of SWDs when microinjected into the perioral region of the primary somatosensory cortex, the focal region. This demonstrates that there is not a general increase in inhibition, instead there seems to be an increased inhibition on the level of the $\mathrm{VB}$, not a decrease in inhibition in the RTN [15] and the focal zone in the cortex. The effects of pregnenolone sulphate were more complex and depended on the dose and the site of administration: generally, at low doses in RTN and focal cortical region an increase in number and mean duration was found, and a reduction at high doses. The effects in the ventralis posteromedialis and posterolateralis were a decrease and no effect, respectively, on SWDs. It was concluded that neurosteroids might play a role in absence epilepsies and that their action depends on the activity in specific neuronal areas. More specifically, the results show that a lack of inhibition at the focal cortical site may be a cause of the increased excitability.

Some researchers have studied the role of the $\mathrm{GABA}_{\mathrm{A}}$ receptor site. The effects of specific $\mathrm{GABA}_{\mathrm{A}}$ receptor agonist and antagonist, muscimol and bicuculline, respectively, were studied by intracerebroventricular injections. EEG registrations and behavioral observations showed that muscimol dose dependently increased the nonconvulsive absence seizures. Besides this, it induced EEG spikes and body twitches. Bicuculline induced spikes and body twitches as well but decreased the nonconvulsive epilepsy. All effects of muscimol were blocked by bicuculline and vice versa, which suggests that the observed effects are genuine $\mathrm{GABA}_{\mathrm{A}}$ effects [124]. The other agonists of $\mathrm{GABA}_{\mathrm{A}}$ receptors such as 4,5,6,7-tetrahydroisooxazolo(5,4-c)pyridin-3-ol (THIP), Lbaclofen $[115,125]$ enhanced the duration of SWDs in a dosedependent fashion.

All these described results implicate that nonconvulsive epilepsy can be caused by a $\mathrm{GABA}_{\mathrm{A}}$ receptor hyperfunction, although this is an oversimplification. In general, the opposite action of GABAmimetic drugs points to a pharmacological difference between convulsive and absence types of epilepsy. The local injection studies demonstrated that there is $\mathrm{GABA}_{\mathrm{A}}$ hyperfunction in the $\mathrm{VB}$, but a $\mathrm{GABA}_{\mathrm{A}}$ hypofunction in the focal cortical region.

3.1.2. $G A B A_{\mathrm{B}}$ Receptor. The $\mathrm{GABA}_{B}$ receptor antagonist CGP 35348 was intraperitoneally given in doses of 100,300 , and $900 \mathrm{mg} / \mathrm{kg}$ to old Wistar rats, endowed with similar SWDs as WAG/Rij rats and GAERS. The effects on sleep and behavior were investigated as well. The low and middle dose of the drug produced an increase in the duration of REM sleep, the REM sleep latency was correspondingly reduced. NonREM sleep and total sleep duration increased and an sshaped dose-response relationship was found. Explorative behavior was diminished. Number and duration of SWDs were reduced after all doses of CGP 35348, confirming the strong suppressive action of this $\mathrm{GABA}_{\mathrm{B}}$ antagonist on absences [126]. Others have described similar effects in GAERS [127] and in the lethargic (lh/lh) mutant mice model [128]. Antagonists of the $\mathrm{GABA}_{\mathrm{B}}$ receptors suppressed SWDs whereas agonists of $\mathrm{GABA}_{\mathrm{B}}$ receptors exacerbated them. Furthermore, $\mathrm{GABA}_{\mathrm{B}}$ receptor binding and synaptically evoked $\mathrm{GABA}_{\mathrm{B}}$ receptor-mediated inhibitions of NMDA responses were selectively increased in $\mathrm{lh} / \mathrm{lh}$ mice. Therefore, enhanced $\mathrm{GABA}_{\mathrm{B}}$ receptor-mediated synaptic responses may underlie absence seizures in the $\mathrm{lh} / \mathrm{lh}$ mice, and $\mathrm{GABA}_{\mathrm{B}}$ receptor antagonists hold promise as antiabsence drugs [128]. The microinjections of the $\mathrm{GABA}_{\mathrm{B}}$ agonist [(-)-baclofen] and the antagonist CGP 35348 in anterior ventral lateral thalamic nucleus, RTN and nucleus reunions decrease and increase, respectively, absence seizures in (lh/lh) mice [129]. Next the antiabsence effect of the $\mathrm{GABA}_{\mathrm{B}}$ receptor antagonist SCH 50911 was investigated in the lethargic (lh/lh) mutant mouse and in two rat models in which absence seizures were induced by administration of either GHB or a low-dose $(20 \mathrm{mg} / \mathrm{kg})$ PTZ. SCH 50911 abolished seizures in all three models in a dose-dependent fashion. In each model SCH 50911 was more potent than the $\mathrm{GABA}_{\mathrm{B}}$ receptor antagonist CGP 35348, ethosuximide, trimethadione, and valproic acid. $\mathrm{SCH} 50911$ was equipotent as the $\mathrm{GABA}_{\mathrm{B}}$ antagonist CGP 46381 in the $\mathrm{lh} / \mathrm{lh}$ mouse model [130]. Further experiments examined the effectiveness of a range of specific $\mathrm{GABA}_{\mathrm{B}}$ receptor agonists and antagonists of varying specificity, as well as the specific GHB-receptor antagonist NCS 382, in the GHB and low-dose PTZ models. All specific $\mathrm{GABA}_{\mathrm{B}^{-}}$ receptor antagonists as well as the specific GHB-receptor antagonist produced blockade of absence seizures in both models; pretreatment with $\mathrm{GABA}_{\mathrm{B}}$ receptor agonists resulted in generalized absence status epilepticus lasting for hours. These data confirm that specific $\mathrm{GABA}_{\mathrm{B}}$-receptor antagonists have antiabsence activity, that the same holds for specific GHB-receptor antagonists, and raise the possibility that both GHB- and $\mathrm{GABA}_{\mathrm{B}}$-antagonist drugs have the potential to be useful therapeutic agents in generalized absence seizures [131].

Systemic injections of the $\mathrm{GABA}_{\mathrm{B}}$ receptor antagonists suppress completely SWDs in GAERS [127]. In the same strain, bilateral injections of the selective $\mathrm{GABA}_{\mathrm{B}}$ receptor agonist R-baclofen into the specific relay nuclei and the RTN increased SWDs dose dependently, whereas injections of a $\mathrm{GABA}_{\mathrm{B}}$ antagonist CGP 35348 into the same sites decreased these seizures dose dependently.

The effect of R-baclofen on SWDs could be blocked by a subsequent injection of CGP 35348 at the same site. Injections of R-baclofen or CGP 35348 in the midline thalamus had no effect. Bilateral injections of R-baclofen into the specific relay nuclei of nonepileptic rats induced synchronized rhythmic oscillations on the cortical EEG. These results suggest that $\mathrm{GABA}_{\mathrm{B}}$ receptors in the ventrolateral thalamus and in the RTN are involved in an oscillatory activity which underlies SWDs [132]. SWDs in GAERS were also dose dependently suppressed by i.p. administration of the $\mathrm{GABA}_{\mathrm{B}}$ receptor antagonists CGP 36742 and CGP 56999, and by bilateral microinjections of the same compounds into the lateral nuclei of the thalamus. In rats susceptible to 
audiogenic seizures, intraperitoneal administration of both $\mathrm{GABA}_{\mathrm{B}}$ receptor antagonists, at doses which suppressed absence seizures, facilitated the elicitation of sound-induced tonic seizures. In nonepileptic control rats, intraperitoneal injections of higher doses of CGP 36742 and CGP 56999 induced delayed clonic convulsions, which were suppressed by pretreatment with baclofen. c-Fos protein was expressed after $\mathrm{GABA}_{\mathrm{B}}$ receptor antagonist-induced clonic seizures in the cortex, hippocampus, amygdala, perirhinal, and piriform cortex. Intracortical and hippocampal microinfusion of both $\mathrm{GABA}_{\mathrm{B}}$ receptor antagonists produced focal seizures. The authors concluded that $\mathrm{GABA}_{\mathrm{B}}$ receptor antagonists induce convulsions in cortical and limbic structures but suppress nonconvulsive absence seizures by blocking thalamic $\mathrm{GABA}_{\mathrm{B}}$ receptors [133].

Somewhat different conclusions were drawn by Staak and Pape [22] in WAG/Rij rats: their in vivo studies in anesthetized WAG/Rij rats in combination with single-unit recordings and microiontophoretic techniques in the ventrobasal thalamic complex showed that the application of the $\mathrm{GABA}_{\mathrm{B}}$ receptor antagonist CGP 55845A exerted a statistically insignificant modulatory effect on neuronal activity during spontaneous SWDs but significantly attenuated the bicuculline-evoked aggravation of SWD-related firing. This indicates that $\mathrm{GABA}_{\mathrm{A}}$ receptor-mediated events are recruited with each SWD and that SWD-related activity can be evoked with no significant contribution of $\mathrm{GABA}_{\mathrm{B}}$ receptors. It is obvious that their results voted against a predominant or even exclusive contribution of $\mathrm{GABA}_{\mathrm{B}}$ receptors to spontaneous SWDs in thalamic relay nuclei in the WAG/Rij strain, but rather point to a critical role of $\mathrm{GABA}_{\mathrm{A}}$ receptor activation. Whether this difference is due to the neurolept anaesthetic is not immediately clear.

The $\mathrm{GABA}_{\mathrm{B}}$ receptor antagonists CGP55845A and CGP62349 suppressed the development of the absence syndrome to a larger extent in mice than in rats with GHBLinduced absence epilepsy in a chronic treatment protocol in which both $\mathrm{GHBL}$ and the $\mathrm{GABA}_{\mathrm{B}}$ antagonists were given for 33 days. The absence syndrome was observed after 3 weeks of treatment in the saline group. A third antagonists CGP71982 suppressed it later than the other two antagonists (fifth week) [134], suggesting that $\mathrm{GABA}_{\mathrm{B}}$ receptors are also involved in epileptogenesis.

The effects of combined and single administration of the $\mathrm{GABA}_{\mathrm{B}}$ receptor antagonist CGP 36742 and $\alpha$-amino-3hydroxy-5-methyl-4-isoxazolepropionic acid (AMPA) receptor antagonist, 7,8-methylenedioxy-1-(4-aminophenyl)-4methyl-3-acetyl-4,5-dihydro-2,3-benzodiazepine (LY 300164) on SWDs were also investigated in WAG/Rij rats in order whether the combined treatment might yield additive effects. CGP 36742 was effective as it reduced the number and mean duration of SWDs dose dependently. LY 300164 had minor effects: only the highest dose $(16 \mathrm{mg} / \mathrm{kg})$ reduced the number of SWDs in a short time window. The $\operatorname{ED}(50)$ values for the inhibition of SWDs by LY 300164 and CGP 36742 in a time window $30-60$ min after injection were 15.5 and $16.6 \mathrm{mg} / \mathrm{kg}$, respectively. The $\mathrm{ED}(50)$ of CGP 36742 was reduced to $8.0 \mathrm{mg} / \mathrm{kg}$ when this antagonist was administered in combination with LY $300164(6 \mathrm{mg} / \mathrm{kg})$.

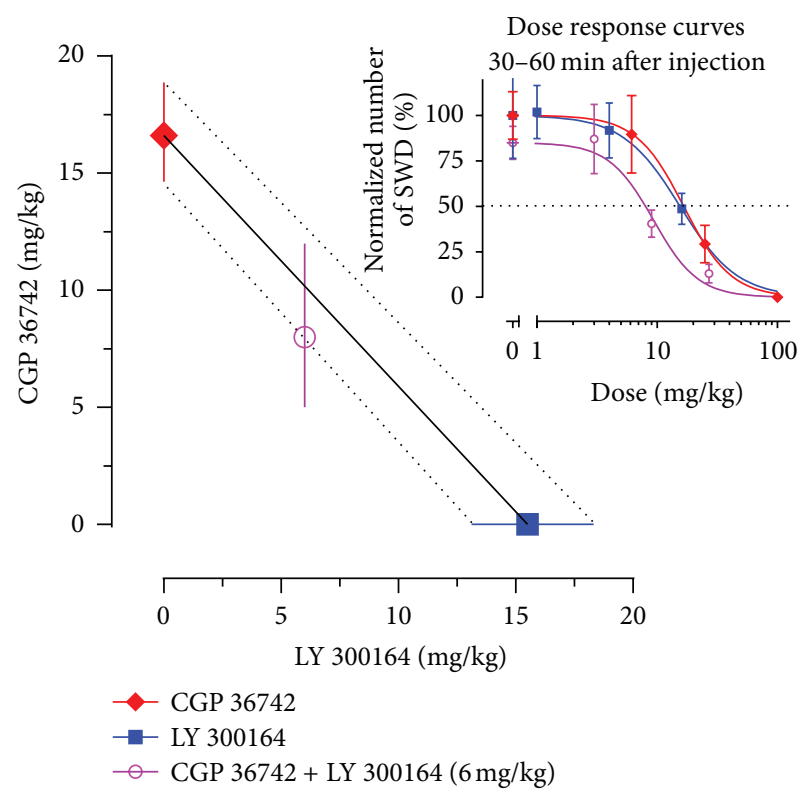

FIGURE 5: Isobologram for the antiabsence interaction between the $\mathrm{GABA}_{\mathrm{B}}$ antagonist CGP 36742 and the AMPA receptor antagonist LY 300164 . The $\mathrm{ED}_{50}$ value of CGP 36742 is plotted on the ordinate (closed diamond) and that of LY 300164 on the abscissa (closed square). The $\mathrm{ED}_{50}$ values (for the inhibition of SWD) were obtained by fitting data to the sigmoid $E_{\max }$ model, for the data from the time period 30-60-min after injection (see graph insert and Materials and Methods section of [135]). The straight line connecting the two plotted $\mathrm{ED}_{50}$ values is the isobolographic line, while dotted lines represent 95\% confidence intervals (CIs). The experimental $\mathrm{ED}_{50}$ of the combination of CGP 36742 and LY $300164(6 \mathrm{mg} / \mathrm{kg})$ is plotted as the open circle and $95 \%$ CIs as the solid vertical line. If the experimentally determined $\mathrm{ED}_{50}$ lies on the isobolographic line, then the drug effects are additive. If the $\mathrm{ED}_{50}$ lies below this line, supra-additivity is assumed and when the $\mathrm{ED}_{50}$ lies above the isobolographic line, there is infra-additivity. However, when $95 \%$ CIs of the experimentally obtained combination overlap with the respective intervals of the isobolographic line, then the interaction is regarded as statistically nonsignificant. In such case, the observed interaction seems to be additive (reprinted with permission from Elsevier, [135]).

The interaction between the two antagonists appeared to be additive according to isobolographic analysis. The data are presented in Figure 5.

Importantly, CGP 36742 and LY 300164 administered either alone or in combination had no apparent effects on behavior. Their isobolographic method used may provide information for a rational approach to polytherapy in general and specifically for the treatment of generalized absence epilepsy [135].

A similar effect for specific antagonist of $\mathrm{GABA}_{\mathrm{B}}$ receptor has been received in the AY-9944 model of atypical absence epilepsy [136]. The $\mathrm{GABA}_{\mathrm{B}}$ receptor antagonist CGP 35348, administered i.p., decreased dose dependently the mean burst times. SWDs were suppressed for at least $4 \mathrm{~h}$ after injection of CGP 35348. 
3.1.3. Physiological Inactivation of GABA. There are two mechanisms of the physiological inactivation of GABA: high affinity reuptake of GABA by specific GABA transporters and enzymatic inactivation of GABA by GABA-transaminase. The inhibition of both mechanisms of GABA inactivation by specific agents leads to a substantial increase of GABA concentration in the synaptic cleft.

In a series of clinical reports the development of nonconvulsive status epilepticus (NCSE) with electroclinical features consistent with those of atypical absence seizures after adjunctive antiepileptic therapy of tiagabine (an inhibitor of GABA reuptake) was described. The patient, a boy of 7 years, suffered from frequent myoclonic seizures and rare atypical absences, tonic, atonic, and simple partial seizures of unknown etiology. The interictal EEG showed generalized sharp waves and/or $2-2.5 \mathrm{~Hz}$. NCSE developed when rapid dosage increase and high dose of tiagabine was given [137]. In two other reports, it was described that tiagabine induced NCSE in patients with focal epilepsies and in one patient with juvenile myoclonic epilepsy. A 32-year-old patient with absence epilepsy and primary generalized tonic-clonic seizures since 11 years of age was described, who developed her first NCSE while treated with $45 \mathrm{mg}$ of tiagabine daily [138]. Three other cases with focal lesional epilepsy had nonconvulsive status epilepticus induced by treatment with tiagabine [139].

These clinical cases were predicted based on results in the genetic absence models: effects of tiagabine in various doses were investigated on EEG, two types of SWDs, and behavior of WAG/Rij rats. WAG/Rij rats have two types of SWDs, the most common ones, bilateral symmetrical and generalized (type I), and more occipital, shorter lasting SWDs (type II). According to expectations from other GABAmimetics, Tiagabine enhanced in a dose-related way both the number and mean duration of both types of SWDs. The low dose of $1 \mathrm{mg} / \mathrm{kg}$ had almost no effects, but doses of 3 and $10 \mathrm{mg} / \mathrm{kg}$ were effective. Furthermore, tiagabine in the latter two doses increased the power in the higher $\beta$ band of the background EEG, whereas no significant changes in behavior of the rats were found. In general, this experiment supports that nonconvulsive epilepsy is associated with a GABA hyperfunction. It also underlines the biochemical differences of convulsive and nonconvulsive animal models of epilepsy since tiagabine is rather effective in blocking convulsive seizures; it belongs to the category of drugs effective in convulsive animal models and not in nonconvulsive models of epilepsy [1].

The limbic system is generally not included in any theory (for review see [7]) about the pathogenesis of absence seizures. However, some data demonstrated that the alterations in the limbic system attribute to the expression of absence epileptic phenotype in genetic models of absence epilepsy [140]. Tolmacheva and van Luijtelaar [141] investigated whether local intrahippocampal administration of the neurosteroid progesterone and the GABA reuptake inhibitor tiagabine might affect the occurrence of SWDs. WAG/Rij rats received intracerebral injections of progesterone, $45 \% \beta$ cyclodextrin $(\mathrm{CD})$, saline, or tiagabine. EEG recordings made before and after injection showed that progesterone, CD, and tiagabine administration to the hippocampus reduced
SWDs for $60 \mathrm{~min}$ following administration without behavioral or electroencephalographic side-effects. Both progesterone administration into the cortex and saline injection into the hippocampus yielded no changes in the occurrence of SWDs. These data suggest that activation of GABAergic transmission in the hippocampus has an inhibitory effect on corticothalamocortical circuits underlying the generation of SWDs and might be critically involved in the regulation of absence seizures in the corticothalamocortical network.

Tiagabine increases absence seizures also in the other genetic absence models such as after systemic administration in GAERS and in the lethargic mouse models [2, 142].

The intensification of the efficiency of the GABAergic system by vigabatrin, a GABA-transaminase inhibitor, causes also an increase of absences. Vigabatrin but also carbamazepine and phenytoin are contraindicated in typical absence seizures [143]. Yang et al. [144] presented three patients with de novo absence epilepsy after administration of carbamazepine and vigabatrin with different types of epilepsy. In a second clinical study 14 patients (seven male), aged 15-46 years, and with a mean duration of epilepsy of 16.4 years were identified. Video-EEG demonstrated typical absence status epilepticus in five, atypical status epilepticus in five, atypical myoclonic status epilepticus in three and typical myoclonic status epilepticus in one. Epilepsy had been misclassified as cryptogenic partial in eight cases and cryptogenic generalized in four. The correct diagnosis proved to be juvenile absence epilepsy in six patients, juvenile myoclonic epilepsy in four, epilepsy with generalized tonicclonic seizures on awakening in two, and childhood absence epilepsy in two. All patients had been treated with carbamazepine (CBZ) and had experienced seizure aggravation or new seizure types before referral. Seven patients had polytherapy with phenytoin, vigabatrin, or gabapentin. Potential precipitating factors included dose increase of carbamazepine or of carbamazepine and phenytoin; initiation of carbamazepine, vigabatrin, or gabapentin; decrease of phenobarbital. Withdrawal of the aggravating agents and adjustment of medication resulted in full seizure control. This series shows that severe pharmacodynamic aggravation of seizures in idiopathic generalized epilepsy may result in absence status epilepticus or myoclonic status epilepticus, often with atypical features [145].

The effects of vigabatrin on type II SWDs in the EEG of $\mathrm{ACI}$ rats were studied in order to learn more about the effects of altering GABA concentration on SWDs. The incidence and mean duration of type II SWDs increased after vigabatrin as compared to saline. This effect appeared with a halftime of $100 \mathrm{~min}$. The peak frequency of the type II SWDs decreased after vigabatrin $(5.6 \mathrm{~Hz})$ as compared to saline treatment $(7.5 \mathrm{~Hz})$. Thus, vigabatrin alters the type II SWD morphology. These results are in agreement with predictions of Destexhe's theoretical model, modulating both $\mathrm{GABA}_{\mathrm{A}}$ and $\mathrm{GABA}_{\mathrm{B}}$ conductance's [146]. The effect of vigabatrin on the starting and the stopping mechanisms (the latter was determined by the hazard function) was also investigated in WAG/Rij rats. This experiment showed that a high GABA level changed the stopping mechanism of the absence epileptic seizures, creating much better conditions for very long seizures to 
occur. With respect to the starting mechanism, it was found that both with a high and a low GABA level, there was evidence for a recovery mechanism that decreases the probability that a new seizure starts. Another possibility is that the brain protects itself from a subsequent absence seizure, an endogenous protection mechanism; this has been described for the hippocampus by Kelly and McIntyre [147] and for acute PTZ seizures [148]. Initially this probability is lower with high GABA concentrations, but gradually it converges to the same constant baseline probability as in the condition with a low GABA concentration [149].

Other inhibitors of GABA catabolism such as $\gamma$-vinyl GABA (GVG) also increase SWDs, as demonstrated in GAERS $[115,125,150]$.

Thus, pharmacological research of $\mathrm{GABA}_{\mathrm{A}}$ and $\mathrm{GABA}_{\mathrm{B}}$ receptors and of GABA inactivation mechanisms specifies the basic strengthened role of the GABAergic system on absence seizures. Such conclusion can be made on the basis of that in the overwhelming majority agonists of GABA receptors after systemic injections increase SWD activity (an exception are the benzodiazepines), and antagonists reduce them. Besides strengthening of GABAergic neurotransmission, a more exact prolongation of GABA effects by inhibition of GABA inactivation mechanisms also increases absences. Local injections of GABA mimetic drugs may show opposite effects, so that one can conclude that absence seizure is not due to a global increase in inhibition, but to localized increased and decreased sites of inhibition. The increase of SWDs by GABA agonists confirms our assumption that the hyperpolarization-induced $I_{\mathrm{h}}$ pacemaker in the thalamus contributes to the occurrence of SWDs. The composition of the $I_{\mathrm{h}}$ channel isoforms in the focal region of the cortex, the putative presence of $I_{\mathrm{h}}$ on GABA interneurons in different part of the brain, together with the found opposite actions of GABA agonists in cortex and thalamus, might give room for another collaboration between $I_{\mathrm{h}}$ and $\left(I_{\mathrm{Ca}, \mathrm{T}}\right)$.

3.2. Measurement of GABAergic System Efficiency. One of the methods to estimate the efficiency of neurotransmitter systems is to determine the binding constants of a labeled ligand with a receptor; it characterizes the activity of a receptor. By the help of specific concentration-dependent kinetic reactions and equations describing them, the dissociation constant $\left(K_{\mathrm{d}}\right)$ and density of a receptor $\left(B_{\max }\right)$ type are defined. Rate of direct and reverse reactions of interaction (i.e., rate of association and dissociation) depends on the concentration of the ligand. The dissociation constant $\left(K_{\mathrm{d}}\right)$ is the concentration ligand at which the rate of direct and reverse reactions is equal, then the rate of association is equal to the rate of dissociation. The $K_{\mathrm{d}}$ defines the affinity of a ligand with a receptor. The general pool of receptors in a membrane can be in two states: closed state (receptors immerse in the cell membrane, with such type of receptors binding is not carried out) and in open state, when receptor binding takes place. An increase of receptor density $\left(B_{\max }\right)$ implies an increase in the quantity of the active centers of binding. Based on $K_{\mathrm{d}}$ and $B_{\max }$, it is possible to characterize receptors. A reduction of $K_{\mathrm{d}}$ (without changes in $B_{\max }$ ) means increase in affinity of receptors, strengthening of efficiency of the reaction of the receptors to the most sensitive and intensive part of a receptor. An increase of $B_{\max }$ (without change in $K_{\mathrm{d}}$ ) means strengthening of receptors reaction efficiency to all concentrations tested.

In vitro, the binding parameters of ${ }^{3} \mathrm{H}$-Ro 5-4864, a ligand labeling the peripheral benzodiazepine receptor, were determined for brain homogenates of WAG/Rij and ACI rats. No difference in $K_{\mathrm{d}}$, but a significant decrease $(25 \%)$ in WAG/Rij rats receptors $B_{\max }$, was found [151]. Autoradiography was used to study the binding of $\left[{ }^{3} \mathrm{H}\right]-\mathrm{GABA}$ with $\mathrm{GABA}_{\mathrm{A}}$ and $\mathrm{GABA}_{\mathrm{B}}$ receptors in brains from GAERS: both the density of $\mathrm{GABA}_{\mathrm{A}}$ or $\mathrm{GABA}_{\mathrm{B}}$ receptors and affinity of these receptors to $\mathrm{GABA}$ were determined. No difference in the density of $\mathrm{GABA}_{\mathrm{A}}$ and $\mathrm{GABA}_{\mathrm{B}}$ receptors and affinity of these receptors to GABA between control and epileptic animals were found [152]. The regional distribution of radioactive ligand binding for different receptors of the $\mathrm{GABA}_{\mathrm{A}}$-benzodiazepine-picrotoxin chloride channel complex was measured on tissue section by autoradiography in brains taken from GAERS and controls. The ligands employed included $\left[{ }^{3} \mathrm{H}\right]$ muscimol for high affinity GABA agonists sites; $\left[{ }^{3} \mathrm{H}\right] \mathrm{SR} 95531$ for the low-affinity GABA sites; $\left[{ }^{3} \mathrm{H}\right]$ flunitrazepam for the benzodiazepine sites; and $\left[{ }^{35} \mathrm{~S}\right] \mathrm{t}$ butyl bicyclophosphorothionate (TBPS) for the picrotoxin site. There were no significant differences between GAERS and control animals in $\left[{ }^{3} \mathrm{H}\right]$ flunitrazepam and $\left[{ }^{35} \mathrm{~S}\right] \mathrm{TBPS}$ binding. However, there was a decreased $\left[{ }^{3} \mathrm{H}\right]$ muscimol and $\left[{ }^{3} \mathrm{H}\right] \mathrm{SR} 95531 B_{\max }$ in the CA2 region of the hippocampus in GAERS. It is necessary to note once more that the hippocampus is traditionally not considered as a structure in which SWDs can be measured [4, 21, 153], although recent data in GAERS and WAG/Rij rats point towards alternations in the limbic system as a consequence of the hundreds daily SWDs [41, 140]. Another study explored a possible role of $\mathrm{GABA}_{\mathrm{B}}$ receptors in absence seizures in lethargic (lh/lh) mice. $\left[{ }^{3} \mathrm{H}\right]$ baclofen binding to neocortical plasma membranes prepared from $\mathrm{lh} / \mathrm{lh}$ and wild $(+/+)$ agematched congenic mice was measured. The $B_{\max }$ of $\mathrm{GABA}_{\mathrm{B}}$ receptors was $20 \%$ larger in $\mathrm{lh} / \mathrm{lh}$ than in $+/+$ mice in an ageindependent manner. Interestingly, the subset of $\mathrm{lh} / \mathrm{lh}$ mice with larger seizure frequency (40-70 seizures/15 $\mathrm{min}$ ) had a significantly greater $B_{\max }$ than the subset with lower seizure frequency (1-10 seizures/15 min). The increase of $\mathrm{GABA}_{\mathrm{B}}$ receptor density was selective, because binding to glutamate receptors $\left(\left[{ }^{3} \mathrm{H}\right]\right.$ glutamate binding) and to $\mathrm{GABA}_{\mathrm{A}}$ receptors $\left(\left[{ }^{3} \mathrm{H}\right]\right.$ muscimol binding) was not significantly different in the two strains. The authors suggest that higher density of $\mathrm{GABA}_{\mathrm{B}}$ receptors in $\mathrm{lh} / \mathrm{lh}$ mice underlies the expression of absence seizures in this model [154]. GABA and the enzyme of its synthesis, glutamic acid decarboxylase (GAD), was investigated in cortex and thalamus of GAERS by immunocytochemistry; the $\mathrm{GABA}_{\mathrm{A}}$ receptors were evaluated by autoradiography of ${ }^{3} \mathrm{H}$-flunitrazepam binding and by immunocytochemistry using specific antibodies against the $\beta 2-\beta 3$ subunits of $\mathrm{GABA}_{\mathrm{A}}$ receptor protein. GABA and GAD immunocytochemistry did not show any difference in density or distribution of immunoreactive elements (fibers, terminals 
and neurons) between epileptic and control animals, but autoradiographic and immunocytochemical studies showed a decreased enhancement of ${ }^{3} \mathrm{H}$-flunitrazepam binding and of $\beta 2-\beta 3$ subunits of $\mathrm{GABA}_{\mathrm{A}}$ receptor in the sensory-motor cortex and anterior thalamic areas of the epileptic strain. No differences were found in benzodiazepine receptors in the two strains. $\mathrm{GABA}_{B}$ receptors were measured as ${ }^{3} \mathrm{H}$-baclofen binding in a crude synaptic membrane preparation and there was no difference between epileptic and control animals. The data suggest an impairment of the "GABA ${ }_{\mathrm{A}}$ system" in studied brain regions of epileptic rats, due to a reduction of receptor $\beta 2-\beta 3$ subunits and coupling to benzodiazepine receptors despite the normal synthesis and location of the neurotransmitter [155]. The effect of GHBA-induced SWDs on the function of various components of the $\mathrm{GABA}_{\mathrm{A}}$ receptor complex in the cortex of the rat was determined in a series of in vitro experiments. GHBA itself without SWDs had no effect on the binding of $\left[{ }^{3} \mathrm{H}\right]$ muscimol, $\left[{ }^{3} \mathrm{H}\right]$ flunitrazepam, and $\left[{ }^{35} \mathrm{~S}\right] \mathrm{TBPS}$ or on the uptake of ${ }^{36} \mathrm{Cl}^{-}$into synaptoneurosomes in the in vitro studies. However, at the onset of GHBA-induced SWDs, there was a significant decrease in the binding of $\left[{ }^{35} \mathrm{~S}\right] \mathrm{TBPS}$, associated with a significant decrease in muscimol-stimulated uptake of ${ }^{36} \mathrm{Cl}^{-}$with no other biochemical change. One minute after onset of GHBAinduced absence seizures, a significant increase in the binding of $\left[{ }^{3} \mathrm{H}\right]$ muscimol was noted. Ten minutes later the decrease in muscimol-stimulated uptake of ${ }^{36} \mathrm{Cl}^{-}$had normalized, while the changes in binding of $\left[{ }^{3} \mathrm{H}\right]$ muscimol and $\left[{ }^{35} \mathrm{~S}\right] \mathrm{TBPS}$ persisted [156]. The analysis of extra- and intracellularly recorded synaptic responses revealed an intracortical hyperexcitability which was accompanied by a significant reduction in the efficiency of GABAergic inhibition. These data indicate that the imbalance between intracortical excitatory and inhibitory mechanisms may at least contribute to the expression and augmentation of SWDs in WAG/Rij rats, and this was also found in an in vitro neurophysiologic study [157]. Leaning on the known fact, that postsynaptic $\mathrm{GABA}_{\mathrm{B}}$ receptor-mediated events are reduced after prior treatment with pertussis toxin (PTx), the influence of PTx (0.4 microg), denatured-PTx or vehicle saline bilaterally injected into the relay nuclei of the thalamus in anesthetized GAERS were studied for up to 6 days, following which the brains were removed and $G_{A B A}$ or $\mathrm{GABA}_{\mathrm{A}}$ receptor autoradiography was performed. By 6 days the SWD of the rats treated with PTx was suppressed by $96 \%$ compared with vehicle-injected rats with a significant (62\%) reduction even after 1 day. Denatured toxin had no effect. After 6 days $\mathrm{GABA}_{\mathrm{B}}$, but not $\mathrm{GABA}_{\mathrm{A}}$, receptor binding was significantly reduced by $70-80 \%$ in the ventrolateral and ventral posterolateral thalamic nuclei [158]. In the same model, the high affinity binding of $\mathrm{GABA}_{\mathrm{A}} / \mathrm{BZD}$ receptors with $\left({ }^{3} \mathrm{H}\right) \mathrm{RO}$ 15-1788 in the brain of naive rats and after administration of FG 7142 did not differ in GAERS and nonepileptic control rats [112]. The authors suggested that the hypersensitivity of GAERS to various inverse agonists of the $\mathrm{GABA}_{\mathrm{A}} / \mathrm{BDZ}$ receptor involves cortical $\mathrm{GABA}_{\mathrm{A}}$ receptors and is not related to differential activity of a subunit-selective receptor.
Miniature $\mathrm{GABA}_{\mathrm{A}}$ IPSCs recorded in the VB complex of the thalamus, and in cortical layer II/III neurons were similar in GAERS and nonepileptic controls, whereas in GAERS RTN neurons had a 25\% larger amplitude and $40 \%$ faster decay. In addition, baclofen was significantly less effective in decreasing the frequency of RTN mIPSCs in GAERS than in control, whereas no difference was observed for cortical and VB mIPSCs between the two strains. Pairedpulse depression was $45 \%$ smaller in GAERS RTN, but not in $\mathrm{VB}$, and was insensitive to $\mathrm{GABA}_{B}$ antagonists. These results point to subtle, nucleus-specific, $\mathrm{GABA}_{\mathrm{A}}$ receptor abnormalities underlying SWDs rather than a full block of these receptors across the whole corticothalamocortical network. Their occurrence prior to seizure onset suggests that they might be critically involved in epileptogenesis [160].

We have studied muscimol-induced ${ }^{36} \mathrm{Cl}^{-}$conductivity in synaptoneurosomes prepared from the frontal and somatosensory cortex of rats with three types of epileptic activity: tonic-clonic pentylenetetrazole kindling in Wistar rats, nonconvulsive absence PTZ kindling in Wistar rats (an absence seizure model), WAG/Rij and Wistar control rats [159]. We used two concentrations of muscimol: 30 and $100 \mu \mathrm{M}$. The occurrence of kindling prior to tonic-clonic seizures in the Wistar rats decreased the muscimol-induced ${ }^{36} \mathrm{Cl}^{-}$conductivity compared to control (Figure 6(a)). Development of nonconvulsive kindling considerably increased ${ }^{36} \mathrm{Cl}^{-}$conductance into the neocortical synaptoneurosomes. WAG/Rij rats showed an increase in ${ }^{36} \mathrm{Cl}^{-}$conductance in neocortical synaptoneurosomes as compared to the control Wistar rats (Figure 6(b)). The decrease in muscimol-induced ${ }^{36} \mathrm{Cl}^{-}$conductivity after development of tonic-clonic kindling was in agreement with a quite some amount of data regarding the decrease in the activity of $\mathrm{GABA}_{\mathrm{A}}$ receptor during tonicclonic kindling [55, 161-165]. The high level of muscimolinduced ${ }^{36} \mathrm{Cl}^{-}$conductivity in the neocortical synaptoneurosomes of the WAG/Rij rats supported the concept that the SWDs originating from the somatosensory cortex are induced by hyperpolarization. The high level of ${ }^{36} \mathrm{Cl}^{-}$conductivity during nonconvulsive PTZ kindling suggests that the activity of the $\mathrm{GABA}_{\mathrm{A}}$ receptor was similar in the genetic absence epilepsy model and PTZ absence seizure model.

The binding of $\left[{ }^{11} \mathrm{C}\right]$ flumazenil at the $\mathrm{BDZ}$ site of the $\mathrm{GABA}_{\mathrm{A}}$ receptor was studied in five patients with idiopathic generalized epilepsy with positron emission tomography. No evidence was found for a change in $\left[{ }^{11} \mathrm{C}\right]$ flumazenil binding with absence seizures [166]. However, these early studies were not aimed at the cortex, the most likely location of the origin of SWDs.

Except for binding constants of labeled ligands with $G_{A B A}$ and $G_{A B A}$ receptors defining efficiency of GABAergic, other parameters defining efficiency of GABAergic transmission have been used. Levels of extracellular GABA and other amino acids in the ventrolateral thalamus in GAERS have been monitored with in vivo microdialysis. It was shown that the basal extracellular levels of GABA and, to a lesser extent, taurine were increased when compared with values in nonepileptic controls. However, modifying 


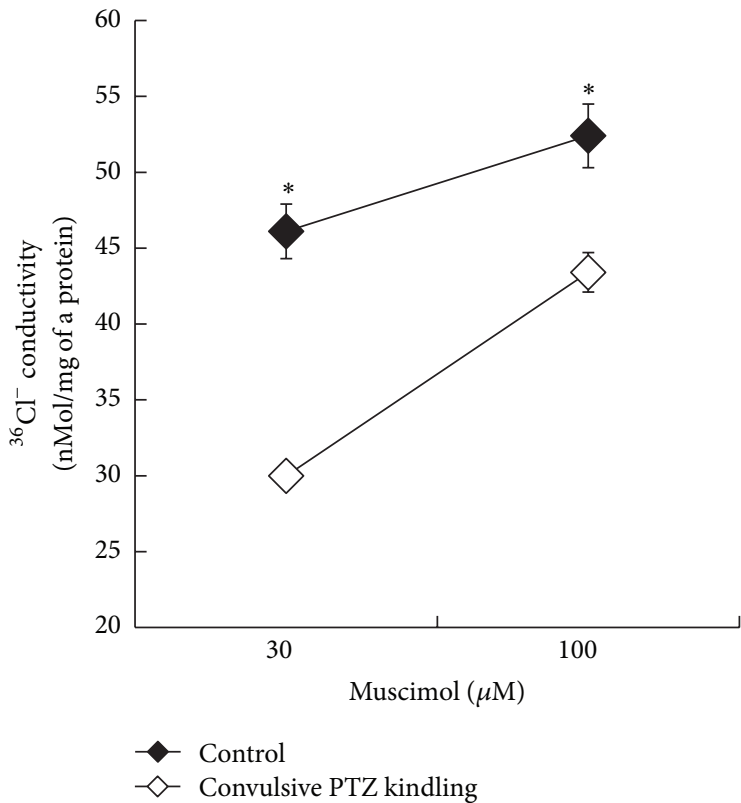

(a)

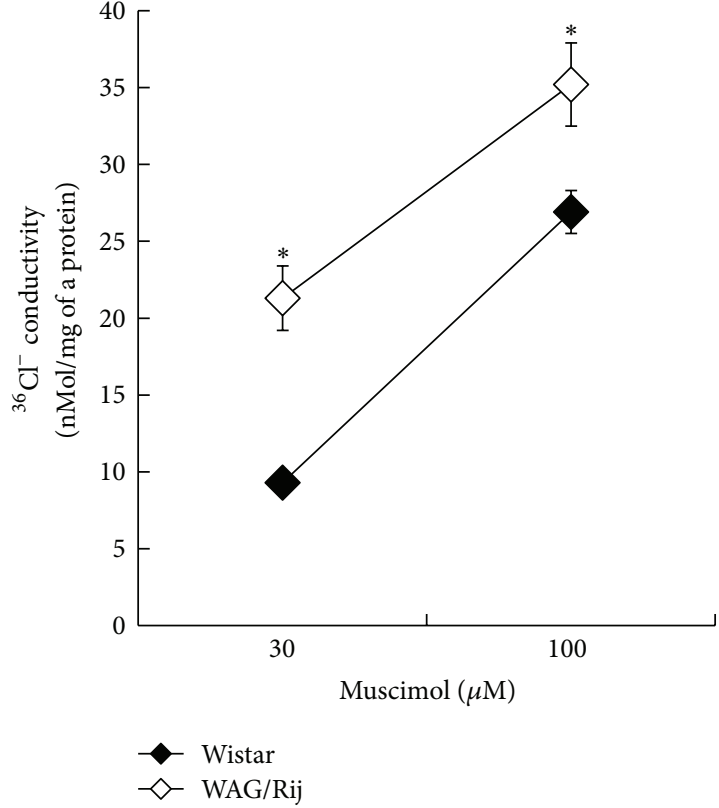

(b)

Figure 6: Muscimol-induced ${ }^{36} \mathrm{Cl}^{-}$conductivity (nmole/mg of protein) inside synaptoneurosomes prepared from the neocortex of 3-4month-old control Wistar rats (a) and Wistar rats with PTZ-induced convulsive kindling and 5-6-month-old control Wistar and WAG/Rij rats (b). ${ }^{*} P<0.05$ (with permission from Springer, [159]).

GABAergic transmission with the $\mathrm{GABA}_{\mathrm{B}}$ agonist (-)baclofen, the $\mathrm{GABA}_{\mathrm{B}}$ antagonist CGP-35348, or the GABA uptake inhibitor tiagabine did not produce any further alteration in extracellular GABA levels [167]. Another study was performed to test the hypothesis that presynaptic $\mathrm{GABA}_{\mathrm{B}}$ receptors in $\mathrm{lh} / \mathrm{lh}$ mice inhibit $\left[{ }^{3} \mathrm{H}\right] \mathrm{GABA}$ release to a greater degree than nonepileptic littermates (designated $+/+$ ). Synaptosomes isolated from neocortex and thalamus of age-matched $\mathrm{lh} / \mathrm{lh}$ and $+/+$ mice were similar in uptake of $\left[{ }^{3} \mathrm{H}\right] \mathrm{GABA}$. In the neocortical preparation, baclofen dose dependently inhibited $\left[{ }^{3} \mathrm{H}\right] \mathrm{GABA}$ release evoked by $12 \mathrm{mM}$ $\mathrm{KCl}$, an effect mediated by $\mathrm{GABA}_{\mathrm{B}}$ receptors. The maximal inhibition $\left(I_{\max }\right)$ value was significantly greater $(80 \%)$ in lh/lh than in $+/+$ mice, whereas the IC50 ( 3 microM) was unchanged. The effect of baclofen ( 50 microM) was $58 \%$ less robust in thalamic preparation of the $\mathrm{lh} / \mathrm{lh}$ mice. Other effects mediated by $\mathrm{GABA}_{\mathrm{B}}$ receptors (inhibitions in $\mathrm{Ca}^{2+}$ uptake and CAMP formation) were also significantly reduced in thalamic synaptosomes from $\mathrm{lh} / \mathrm{lh}$ mice. It is possible that selective effects of presynaptic $\mathrm{GABA}_{\mathrm{B}}$ receptors or GABA release in neocortex and thalamic nuclei of $\mathrm{lh} / \mathrm{lh}$ mice may contribute to mechanisms underlying absence seizures [168]. $\mathrm{K}^{+}$conductance of $\mathrm{GABA}_{\mathrm{B}}$ receptor activation by baclofen was subsequently studied. Whole-cell voltage-clamp recordings were made from thalamic ventrobasal neurons of age-matched lethargic (lh/lh) and wildtype $(+/+)$ mice. No essential distinctions were found [169]. GABA release and uptake were examined in GAERS and in nonepileptic control animals, using crude synaptosomes prepared from the cerebral cortex and thalamus. Uptake of $\left[{ }^{3} \mathrm{H}\right] \mathrm{GABA}$ over time was reduced in thalamic synaptosomes from epileptic rats, compared to controls. The affinity of the uptake process in thalamic synaptosomes was lower in epileptic animals. NNC-711, a ligand for the GAT-1 uptake protein, reduced synaptosomal uptake by more than 95\%; $\beta$-alanine, an inhibitor selective for the uptake proteins GAT-2 and GAT-3, did not significantly reduce synaptosomal uptake. These results indicate that GABA uptake in the thalamus of GAERS rats was reduced compared to control animals. The lower level of uptake in the epileptic animals corresponds to higher efficiency of GABA system in these rats [170].

Progesterone and estradiol serum levels were investigated in WAG/Rij rats before, during, and after pregnancy following parturition. The serum concentration of progesterone increased after the 3rd day of pregnancy. Levels of estradiol changed less. Progesterone is kept high until the 18th day of pregnancy and drastically decreased before the parturition. Common duration of absences-spontaneous SWD, frequency, and the duration of every SWD decreased from 3rd to 19th days of pregnancy before parturition. On the basis of these data and regulation of $\mathrm{GABA}_{\mathrm{A}}$ receptor efficiency by neurosteroids [116], it can be assumed that the changes in the parameters of SWD are possibly correlated with changes in progesterone in serum during pregnancy $[171,172]$.

A time course study that examined the effects of the female estrous cycle on the more slow atypical SWDs, GABA receptor binding, and $\mathrm{GABA}_{\mathrm{B}}$ receptor protein expression was conducted in the AY9944 model in Long-Evans rats. There was a significant increase in both the duration of 
SWDs and $\mathrm{GABA}_{\mathrm{B}}$ receptor binding during the proestrus stage of the estrus cycle, the stage during which the levels of progesterone are at their highest. No changes in $\mathrm{GABA}_{\mathrm{B}} \mathrm{R} 1$ or R2 protein levels were observed. These data suggest an important role for steroid hormones and its interaction with GABA receptors in the regulation and maintenance of AY9944-induced atypical absence seizures [123]. Brain cholesterol synthesis inhibition (CSI) at a young age in rats has been shown to be a faithful model of the symptomatic generalized epilepsies, in this case acquired absence epilepsy, a devastating condition for which few therapies or models exist. The CSI model was used to study cellular mechanisms. Patch-clamp and whole-cell recordings were compared from neurons acutely dissociated from the RTN in Long-Evans Hooded rats treated and untreated with the cholesterol synthesis inhibitor U18666A. In U18666A-treated animals, 91\% of rats developed SWDs. Relevant is also that mutations of the $\gamma 2$ subunit of the $\mathrm{GABA}_{\mathrm{A}}$ receptor abolish natural sensitivity to BDZ [173]. Patch-clamp results revealed that although there was no remarkable change in $\mathrm{GABA}_{\mathrm{A}}$ receptor affinity, both a loss of ability of benzodiazepines to enhance $\mathrm{GABA}_{\mathrm{A}^{-}}$ receptor responses and an increase of $\mathrm{Zn}^{2+}$ inhibition of $\mathrm{GABA}_{\mathrm{A}}$-receptor responses of RTN neurons occurred in this model. This change was specific, since no significant changes were found in neurons exposed to the GABA allosteric modulator pentobarbital. Taken collectively, these findings provide evidence for abnormalities in $\mathrm{BDZ}$ and $\mathrm{Zn}^{2+}$ modulation of $\mathrm{GABA}_{\mathrm{A}}$ receptors in the cholesterol synthesis inhibition model and suggest that decreased $\gamma_{2}$ subunit expression may underlie important aspects of generation of TCSWDs in atypical absence seizures. The present results are also consistent with recent findings that mutation of the $\gamma 2$ subunit of the $\mathrm{GABA}_{\mathrm{A}}$ receptor changes benzodiazepine modulation in families with generalized epilepsy syndromes [174].

It is known that basket cells typically express two calciumbinding proteins, parvalbumin (PV) and calbindin. $\mathrm{PV}$ is coexpressed with GABA in $90 \%$ of the GABAergic neurons $[175,176]$, and PV-immunostaining is an appropriate way to mark basket cells [177]. Quantification of PV-positive cells showed clear reductions in the parietal and forelimb area of the somatosensory cortex in WAG/Rij rats compared to nonepileptic control ACI rats. These results are interpreted as deficiency of $\mathrm{Ca}^{2+}$-binding protein in corresponding structures of the brain of WAG/Rij rats [178], or as deficiency of GABAergic cells [9].

Thus, the measurement of efficiency of the GABAergic system in various absence models leads to the conclusion that a huge variety of experiments demonstrate a large role for deficiencies in the GABAergic system. However, there are also diverse results, among others with the role of $G_{A B A}$. We see three reasons for this; different seizure or epilepsy models were used. It is possible that different deficiencies and different mechanisms may all lead to the same phenotype: SWDs. The second reason of the diverse results is the socalled process of uncertainty of the nervous system [179]. The analysis of several works has shown that increase or decrease of general activity of the neurotransmission system at different animals can be carried out by different ways and depends on specific features of these animals. The third reason for the occurrence of diverse results can be processes of indemnification (protection against injury). To illustrate, in our study of synaptoneurosomes, samples from cortex of Wistar and WAG/Rij rats were leveled on protein [159] and on concentration of $\mathrm{GABA}_{\mathrm{A}}$ receptors. In these conditions conductivity of chlorine was higher in WAG/Rij rats. In brain tissue, in which GABA systems have been reduced [9], a reduction of the quantity of $\mathrm{GABA}_{\mathrm{A}}$ receptor can be found and a reduction of inhibition. In this case strengthening of conductivity of chlorine through $\mathrm{GABA}_{\mathrm{A}}$ receptors can be considered as compensation for the reduced functioning of GABA systems.

\subsection{Subunit Composition and Mutation of $G A B A_{A}$ Receptor}

3.3.1. Molecular Structure of $G A B A_{A}$ Receptor. GABA $_{A}$ receptors concern an ionotropic super family of receptors representing a pentahedron [180]. Five subunits of $\mathrm{GABA}_{\mathrm{A}}$ receptor surround the $\mathrm{Cl}^{-}$channel $[105-107,181,182]$. $\mathrm{GABA}_{\mathrm{A}}$ receptor subunits are a long polypeptide which penetrates a membrane in four places, that is why subunits possess four transmembrane domains. The so-called $\mathrm{N}$ - and C-terminals of the polypeptide are located on the extracellular surface. It is supposed that the second domain of $\mathrm{GABA}_{\mathrm{A}}$ receptor subunit covers a wall of the chloride channel [183]. Between the third and fourth domains, there is a large intracellular fragment to which sites of protein kinase phosphorilation are concentrated and with which the basic differences in primary structure between various subunits are connected $[181,184]$. On the $\mathrm{N}$-terminal of the polypeptide leaving the first domain is the active center of a receptor or the sites connecting with ligands [105, 185-187].

Some specific binding sites are located on the $\mathrm{GABA}_{\mathrm{A}}$ receptor $[105,182]$. The first site is the GABA site where binding to GABA and its specific agonists such as gaboxadol, ibotenic acid, muscimol, and progabide takes place and to antagonists such as bicuculline and gabazine. Next there is the site of positive allosteric modulators such as barbiturates, benzodiazepines, carisoprodol, ethanol (alcohol), etomidate, glutethimide, kavalactones [188], meprobamate, methaqualone, neuroactive steroids $[189,190]$, niacin/niacinamide, nonbenzodiazepines, propofol, theamine, valerenic acid, and volatile/inhalation anesthetics. There is also the site of negative allosteric modulators such as flumazenil, Ro15-4513 and sarmazenil [191-193] and the site of noncompetitive channel blockers such as cicutoxin, oenanthotoxin, pentylenetetrazol, picrotoxin, and thujone. According to the definition, allosteric modulators which bind with $\mathrm{GABA}_{\mathrm{A}}$ receptors in places which do not overlap with a binding site of an agonist, cause conformation reorganizations and change of receptor efficiency [194]. The chloride channel opens when two GABA molecules interact with their own site. Other sites only strengthen or reduce this interaction. GABA itself is an allosteric regulator for other sites. Next, the neurosteroid site will be discussed in more details. 
After interaction of neurosteroids with the $\mathrm{GABA}_{\mathrm{A}}$ receptor, an intracellular process, oxygenation, is started; it transforms some intracellular metabolites in steroid receptors ligands [116]. After binding of these ligands with intracellular steroid receptors, the gene expression is modified. As the GABA site is an allosteric modulator of neurosteroid site, the interaction of GABA with its own site, allosterically modified by the neurosteroid site, initiates a cascade of events leading to the start of signal transduction. The transduction signal started through receptors processes of intracellular phosphorilation which terminate in updating the expression of genes. It means that the $\mathrm{GABA}_{\mathrm{A}}$ receptor is an ionotropic receptor, but that it also initiates simultaneously signal transduction. Why is signal transduction so important? The modification of genes expression is a unique mechanism of an encoding process called memory consolidation, that is the transfer of information from short-term into long-term memory. Hence, signal transduction plays an important role at the long-term storage of information, in learning and memory, in training, in neuroplasticity in general, and in pathological states.

The $\mathrm{GABA}_{\mathrm{A}}$ receptor has 22 subunits: $\alpha-6$ subtypes, $\beta-4$ subtypes, $\gamma$-3 subtypes, $\delta$ - 1 subtype, $\varepsilon$ - 3 subtype, $\pi$ - 1 subtype, $\rho-3$ subtype, and $\theta-1$ subtype $[181,195,196]$. It is necessary to notice that some isoforms of $\mathrm{GABA}_{\mathrm{A}}$ receptor subunits have various variants. So, for $\gamma 2$ subunit, two variants were revealed [197, 198], differing in length of an intracellular fragment between 3 and 4 domains. Similar distinctions are known for $\beta 2, \beta 4$ subunits for which the presence of two variants has also been shown $[199,200]$. Each of such sequences $(\gamma 2, \beta 2$ and $\beta 4)$ has in the designation an additional letter L or S (accordingly, long and short) [181]. Two splays variant have been found for the $\beta 3$ subunit [201]. It is supposed, those three splays variants exist for the $\alpha 5$ subunit [202]. A product of alternative splicing is the $\alpha 6$ subunit, truncated with an N-terminal [203]. The 18 types of $\mathrm{GABA}_{\mathrm{A}}$ receptor subunits are expressed in a mammalian brain: $\alpha$ subunits (1-6), $\beta$ subunits (1-3), $\gamma$ subunits (1-3), $\varepsilon$ subunits (1-3) and on 1 subunits $\delta, \pi$ and $\sigma$ [204].

Different confirmations of the $\mathrm{GABA}_{\mathrm{A}}$ receptor are found throughout the brain, and the most common mammalian subunits composition is two $\alpha 1$ subunits, two $\beta 2$ subunits, and one $\gamma 2$ subunit assembling in a pentahedron- $(\alpha 1)_{2}(\beta 2)_{2}(\gamma 2)$. Two molecules of GABA interact with two sites, each of which is located on two $\mathrm{N}$-terminuses from the first domain of $\alpha 1$ and $\beta 2$ subunits. The benzodiazepine site is located on two $\mathrm{N}$-terminus from the first domain of $\alpha 1$ and $\gamma 2$ subunits. Efficiency of allosteric regulation depends on the subunit composition of $\mathrm{GABA}_{\mathrm{A}}$ receptors [205]. Table 1 describes the degree of allosteric regulation. For example, $80 \%$ of brain $\mathrm{GABA}_{\mathrm{A}}$ receptors are highly sensitive for diazepam, $10 \%$ of receptors have a low sensitivity for diazepam. The latter is the case if the subunit compositions of $\mathrm{GABA}_{\mathrm{A}}$ receptor contain $\gamma 1$ or $\gamma 3$ subunits. The $10 \%$ of receptors not sensitive for diazepam have subunit compositions of $\mathrm{GABA}_{\mathrm{A}}$ receptor containing $\alpha 4$ or $\alpha 6$ subunits. From the $80 \%$ of receptors that are highly sensitive for diazepam, $10 \%$ is insensitive for zolpidem. This is the case if the subunit composition of $\mathrm{GABA}_{\mathrm{A}}$ receptor contains a $\alpha 5$ subunit.
TABLE 1: Density of $\left[{ }^{3} \mathrm{H}\right]$ SCH 23390 binding sites in different brain areas of $A C I$ and WAG/Rij rats $\left(D_{1}\right.$ receptors).

\begin{tabular}{lccc}
\hline Brain regions & ACI rats & WAG/Rij rats & $P<0.05$ \\
\hline Nucleus accumbens (core) & $7.12 \pm 0.61$ & $5.86 \pm 0.79$ & \\
Nucleus accumbens (shell) & $10.51 \pm 0.33$ & $8.96 \pm 0.36$ & 0.013 \\
Caudate nucleus (head) & $11.14 \pm 0.25$ & $8.35 \pm 0.23$ & 0.00004 \\
Caudate nucleus (ventral) & $11.09 \pm 0.56$ & $12.14 \pm 0.67$ & \\
Caudate-putamen & $7.75 \pm 0.70$ & $8.70 \pm 0.36$ & \\
\hline
\end{tabular}

The other $90 \%$ of receptors are zolpidem sensitive. The composition $\alpha 1 \beta 2 \gamma 2$ possesses high affinity for zolpidem, and compositions $\alpha 2 \beta 3 \gamma 2$ or $\alpha 3 \beta 3 \gamma 2$ demonstrate low affinity.

Absence epilepsy can be accompanied by modifications of $\mathrm{GABA}_{\mathrm{A}}$ and $\mathrm{GABA}_{\mathrm{B}}$ receptors subunit composition. Neonatal treated rats with AY9944 show an increased occurrence of SWDs which correlated significantly with a decreased protein expression of the GABA $\mathrm{A} \gamma 2$ subunit in RTN and VB nuclei of the thalamus, but not in somatosensory cortex. Conversely, $\alpha 1$ subunit expression decreased in somatosensory cortex in the AY9944 model, but not in the thalamus [206]. The decreased $\mathrm{GABA}_{\mathrm{A}}$ receptor $\gamma 2$ subunits in thalamus and increased in cortex are gender and age specific [207]. These results coincide with data that in human absence epilepsy is more widespread among women. The synaptic physiology and network property of mice lacking $\mathrm{GABA}_{\mathrm{A}}$ receptor $\alpha 3$, a subunit that is uniquely expressed in the thalamus by inhibitory neurons of the RTN, have been investigated. Deletion of this subunit produced a powerful compensatory gain in inhibitory postsynaptic response in the RTN. Although other forms of inhibitory and excitatory synaptic transmission in the circuit were unchanged, evoked thalamic oscillations were strongly dampened in $\alpha 3$ knockout mice. Furthermore, pharmacologically induced TC absence seizures displayed a reduction in length and power in $\alpha 3$ knockout mice. These studies highlight the role of GABAergic inhibitory strength within the RTN in maintenance of thalamic oscillations and demonstrate that inhibitory intraRTN synapses are a critical control point for regulating higher order corticothalamocortical network activity [208]. The combination of immunocytochemistry and high-resolution immunogold electron microscopy was used to study cellular and subcellular localization of $\mathrm{GABA}_{\mathrm{A}}$ receptors $\alpha 1, \alpha 3$, and $\beta 2 / \beta 3$ subunits in ventral posterior nucleus (VP) and RTN of WAG/Rij and control Wistar rats. In control rats, $\alpha 1$ subunits were prominent at inhibitory synapses in VP and much less prominent in RTN; in contrast, the $\alpha 3$ subunit was highly evident at inhibitory synapses in RTN. $\beta 2 / \beta 3$ subunits were evenly distributed at inhibitory synapses in both VP and RTN. Immunogold particles representing all subunits were concentrated at postsynaptic densities with no extra synaptic localization. Calculated mean number of particles for $\alpha 1$ subunit per postsynaptic density in nonepileptic VP was $6.1 \pm 3.7$, for $\alpha 3$ subunit in RTN, it was $6.6 \pm 3.4$, and for $\beta 2 / \beta 3$ subunits in VP and RTN, the numbers were $3.7 \pm 1.3$ and $3.5 \pm 1.2$, respectively. In WAG/Rij rats, there was a specific loss of $\alpha 3$ subunit immunoreactivity at 
inhibitory synapses in RTN, without reduction in $\alpha 3$ subunit mRNA or significant change in immunostaining for other markers of RTN cell identity such as GABA or parvalbumin. $\alpha 3$ immunostaining in cortex was unchanged [47]. These combined results obtained in mice and rats allow us to assume that different combinations of subunit compositions of $\mathrm{GABA}_{\mathrm{A}}$ receptor in the RTN may contribute to or are the reason for decreased strength of GABAergic inhibition. The functional consequence is that when the RTN is stimulated by the cortex, the thalamic resonance might be larger and SWDs might last longer. Importantly, the changes in subunit composition were already present in presymptomatic rats, suggesting that the changes in the RTN are not caused by the seizures but that they are a property of WAG/Rij rats.

The possibility that absence seizures cause alterations in $\mathrm{GABA}_{\mathrm{A}}$ receptor $(\alpha 1, \alpha 4, \beta 2$, and $\gamma 2)$ subunit gene expression in thalamic relay nuclei was also explored, in this case in an acute absence seizure model, the GHB model [209]. A marked increase in $\alpha 1 \mathrm{mRNA}$ and a corresponding decrease in $\alpha 4 \mathrm{mRNA}$ in thalamic relay nuclei $2-4 \mathrm{~h}$ after the onset of GHB-induced absence seizures (when the seizures were terminating) were detected. These changes were selective to these $\alpha$ isoforms as neither $\beta 2$ nor $\gamma 2$ mRNA changed following seizures and occurred only in thalamic relay nuclei but not in hippocampus. The alterations in $\alpha 1$ and $\alpha 4$ mRNA persisted until about $12 \mathrm{~h}$, and by $24 \mathrm{~h}$ after the seizureonset the mRNA levels normalized. Blocking GHB-seizures produced no change in the levels of $\alpha 1$ and $\alpha 4$ mRNA in thalamic relay nuclei, suggesting that seizures themselves were responsible for mRNA alterations.

The expression of mRNA of $\mathrm{GABA}_{\mathrm{B}}$ receptor subunit was studied in WAG/Rij [210] and GAERS [211]. By using RealTime PCR, the researchers from the Avoli group have found that mRNA levels for most $\mathrm{GABA}_{\mathrm{B} 1}$ subunits are diminished in epileptic WAG/Rij neocortex as compared with agematched nonepileptic controls, whereas $\mathrm{GABA}_{\mathrm{B} 2}$ mRNA is unchanged. Next, it was investigated the cellular distribution of $\mathrm{GABA}_{\mathrm{B} 1}$ and $\mathrm{GABA}_{\mathrm{B} 2}$ subunits by confocal microscopy and it was discovered that $G_{A B A}$ subunits fail to localize in the distal dendrites of WAG/Rij neocortical pyramidal cells [210]. The authors propose that these alterations may contribute to neocortical hyperexcitability and thus to SWD generation in absence epilepsy.

$\mathrm{GABA}_{\mathrm{B}}$ receptor expression in the somatosensory cortex, $\mathrm{VB}$, and RTN in GAERS was also investigated [211]. In situ hybridization results showed a significant increase in mRNA for $G_{A B A}$ in the somatosensory cortex and a decrease in the ventrobasal thalamic nucleus but not in the RTN. By contrast, the immunocytochemical data revealed an increased expression of both $G_{A B A}$ and $G_{B B A}$ receptor subunits in all regions examined, somatosensory cortex, ventrobasal thalamic nucleus and RTN. The main finding was an upregulation of $\mathrm{GABA}_{\mathrm{B}}$ receptor protein in the corticothalamic circuit in GAERS compared to controls. The results, as obtained in GAERS [211] and WAG/Rij [210] rats seem rather opposite to each other, the hyperexcitability in WAG/Rij rats strain and a wide spread upregulation of $\mathrm{GABA}_{\mathrm{B}}$ receptors. We have proposed (see Sections 3 and 4), that both of these processes cause the same reaction, increase of SWD. Perhaps the two opposing processes provide the same response in different strain of animals.

Mutations in inhibitory $\mathrm{GABA}_{\mathrm{A}}$ receptor subunit genes (GABRA1, GABRB3, GABRG2, and GABRD) of human have been associated with genetic epilepsy syndromes including childhood absence epilepsy, juvenile myoclonic epilepsy, pure febrile seizures, generalized epilepsy with febrile seizures plus, and Dravet syndrome (DS)/severe myoclonic epilepsy in infancy. These mutations are found in both translated and untranslated gene regions and have been shown to affect the $\mathrm{GABA}_{\mathrm{A}}$ receptors by altering receptor function and/or by impairing receptor biogenesis by multiple mechanisms including reducing subunit mRNA transcription or stability, impairing subunit folding, stability, or oligomerization and by inhibiting receptor trafficking [48, 49, 212-222]. Besides, it is supposed that the chloride channel gene CLCN2 may be a susceptibility locus in a subset of cases of childhood absence epilepsy [223].

To understand the effect of these mutations, surface targeting of $\mathrm{GABA}_{\mathrm{A}}$ receptors was analyzed by subunit-specific immunofluorescent labeling of living cells. An involvement of the $\gamma 2$-Arg-43 domain in the control of receptor assembly was revealed. This may have some consequences to the effect of the heterozygous $\gamma 2(\mathrm{R} 43 \mathrm{Q})$ mutation leading to childhood absence epilepsy and febrile seizure [224].

Stargazer (stg) mutant mice fail to express stargazin (transmembrane AMPA receptor regulatory protein $\gamma 2$ (TARP $\gamma 2)$ ) and consequently experience absence seizure-like TCSWDs that pervade the hippocampal formation via the dentate gyrus. As in other seizure models, the dentate granule cells of stg develop elaborate reentrant axon collaterals and transiently overexpress brain-derived neurotrophic factor. It was investigated whether GABAergic parameters were affected by the stg mutation in this brain region. $\mathrm{GABA}_{\mathrm{A}}$ receptor $\alpha 4$ and $\beta 3$ subunits were consistently upregulated, $\mathrm{GABA}_{\mathrm{A}}$ receptor delta expression appeared to be variably reduced, whereas $\mathrm{GABA}_{\mathrm{A}}$ receptor $\alpha 1, \beta 2$, and $\gamma 2$ subunits and the $\mathrm{GABA}_{\mathrm{A}}$ receptor synaptic anchoring protein gephyrin were essentially unaffected. It was established that the $\alpha 4 \beta \gamma 2$ subunit-containing, flunitrazepam-insensitive subtype of $\mathrm{GABA}_{\mathrm{A}}$ receptors, not normally a significant $\mathrm{GABA}_{\mathrm{A}}$ receptor in dentate gyrus neurons, was strongly upregulated in stg gyrus neurons, apparently arising at the expense of extra synaptic $\alpha 4 \beta \delta$-containing receptors. This change was associated with a reduction in neurosteroidsensitive $\mathrm{GABA}_{\mathrm{A}}$ receptor-mediated tonic current. This switch in $\mathrm{GABA}_{\mathrm{A}}$ receptor subtypes was not reciprocated in the tottering mouse model of absence epilepsy implicating a unique, intrinsic adaptation of GABAergic networks in stg. Contrary to previous reports that suggested that TARP $\gamma 2$ is expressed in the dentate, it was found that TARP $\gamma 2$ was neither detected in stg nor in control dentate gyrus. It was reported that TARP $\gamma 8$ is the principal TARP isoform found in the dentate gyrus and that its expression is compromised by the stg mutation. These effects on GABAergic parameters and TARP $\gamma 8$ expression are likely to arise as a consequence of failed expression of TARP $\gamma 2$ elsewhere in the brain, resulting in hyperexcitable inputs to the dentate [225]. 
The expression of one $\mathrm{GABA}_{\mathrm{A}}$ receptor gene, GABABR1, is distinguished by the expression of multiple splice variants that encode different isoforms of the receptor. Two novel GABABR1 variants, GABABR1h (R1h) and GABABR1i (R1i), which appear to arise from alternative splicing of the GABABR1 gene, were identified. The expression of R1h and Rli is differentially regulated in brain and peripheral tissues, but expression is not altered in the brain of GAERS. Both the R1h and R1i variants exhibit a novel 80-bp insert downstream of exon 4 that is flanked by consensus splice sites, and both encode C-terminal-truncated proteins. The new insight into the family of GABABR1 variants gained from this study identifies exon 4 as a preferred locus, or as a hot spot for regulated splicing in the GABABR1 gene. This finding correlates with the microexonic nature of exon 4 (21 bp). Bioinformatic analysis of micro-exon 4 and its flanking pre-mRNA sequences has revealed multiple, potentially competitive, exonic splicing enhancers that provide a mechanistic basis for the preponderance of alternative splicing events at this locus. Conservation of GABABR1 microexon 4 across species suggests a conserved functional role, facilitating either $\mathrm{N}$-terminal protein production or posttranscriptional gene regulation through regulated splicing coupled to transcript decay [226].

Mutations in the genes encoding the subunits of the low-threshold T-type $\mathrm{Ca}^{2+}$ channel $\left(I_{\mathrm{Ca}, \mathrm{T}}\right)$ in patients [44$46,227-231$ ] and also in GAERS but not in WAG/Rij rats, are probably associated with a dysfunction of pacemaker $I_{\mathrm{h}}$ channels in cortex and thalamus. First, it has been shown that the $I_{\mathrm{f}}$ pacemaker channel in the atrial sinus node functions in pair with the $\left(I_{\mathrm{Ca}, \mathrm{T}}\right)$ channel $[232,233]$. The $I_{\mathrm{f}}$ pacemaker channel in the sinus node opens at $-80 \mathrm{mV}$, and the low-threshold $\left(I_{\mathrm{Ca}, \mathrm{T}}\right)$ channel is activated at $-90 \mathrm{mV}$ and fully inactivated at $+40 \mathrm{mV}$. Blockage of the $\left(I_{\mathrm{Ca}, \mathrm{T}}\right)$ channels by low concentrations of $\mathrm{NiCl}_{2}$ diminishes the spontaneous activity of the $I_{\mathrm{f}}$ channel but does not affect the $\left(I_{\mathrm{Ca}, \mathrm{T}}\right)$ channel (the L-type $\mathrm{Ca}^{2+}$ channel). Participation of the low-threshold $\left(I_{\mathrm{Ca}, \mathrm{T}}\right)$ channel in the regulation of SWDs has been shown in both WAG/Rij rats [234] and GAERS rats [75]. There are two centers of bursting neurons which are activated by hyperpolarization: the RTN [19-22] as the source for spindle oscillations and the other is localized in the somatosensory cortex, the site of origin of SWDs $[6,9,13,14]$. The somatosensory cortex is reciprocally connected with the VPM, VPL, and Posterior nucleus of the thalamus, both the ascending and descending pathways from VPM and VPL give collaterals to the RTN, which inhibits thalamic neurons. Interestingly, exactly the thalamus [67] and pyramidal neurons of cortical layers II, IV, and V of the somatosensory cortex $[73,74,81]$ contain hyperpolarization-activated pacemaker $I_{\mathrm{h}}$ channels. The presence of hyperpolarization-activated pacemaker $I_{\mathrm{h}}$ channels in the RTN makes them an interesting object in the discussion and analysis of normal and pathological behavioral and neurophysiologic processes and mechanisms.

Thus, one of the reasons of the occurrence absence epilepsy is the mutation of several genes coding of $\mathrm{GABA}_{\mathrm{A}}$ receptors which causes abnormal functioning of the GABAergic system. This abnormal functioning of the GABAergic system and mutations of $\left(I_{\mathrm{Ca}, \mathrm{T}}\right)$ channel, which functions in a tandem with $I_{\mathrm{h}}$ channel, can lead to the occurrence of spontaneous SWDs in an EEG.

\section{Excitatory Glutamatergic System}

It had been shown some time ago that the well-known noncompetitive NMDA antagonist $\mathrm{MK}-801$ reduced the number and mean duration of SWD; the drug caused also large behavioural abnormalities such as head waving and agitation jeopardizing the interpretation whether the SWDs were primarily or secondarily (via behavior) affected by this NMDA antagonist [235]. Intracerebroventricular (i.c.v.) injection of NMDA induced a dose dependently increase in the number of SWDs. The competitive NMDA antagonist 2-amino-7-phosphonoheptanoic acid (APH) caused a dosedependent reduction in the number and mean duration of SWDs. The effect of NMDA was blocked completely by APH [236]. Finally, the anticonvulsant remacemide, a noncompetitive, low-affinity NMDA receptor antagonist and its major metabolite FPL 12495 after oral administration suppressed the number of SWDs in WAG/Rij rats [237]. Interestingly, the mean duration of the few SWDs that persisted, was prolonged. These results obtained after i.c.v. injections demonstrated unambiguously that the NMDA receptor is involved in the control of SWDs. The involvement of other glutamate receptors such as AMPA and kainate receptors was also studied by i.c.v. injections of AMPA, GDEE (glutamate diethyl ester, a non-NMDA receptor antagonists), kainic acid, and kynurenic acid in WAG/Rij rats [238]. EEG registrations showed that AMPA dose dependently increased absences while GDEE caused a dose-dependent decrease. All effects of GDEE could be blocked by an inactive AMPA dosage. Kainic acid had no effects on nonconvulsive seizures. Kynurenic acid decreased dose dependently the incidence of SWDs; this effect of kynurenic acid could be blocked by a nonconvulsive dosage of kainic acid. Next the interaction between NMDA and non-NMDA receptors was studied [239]. Compounds acting on NMDA (NMDA, APH) and non-NMDA (AMPA, GDEE, kainic acid, kynurenic acid) receptors were coinjected i.c.v. It appeared that the epilepsy increase, induced by the non-NMDA receptor agonist AMPA, and in a less obvious way, by kainic acid, could be blocked by the NMDA receptor antagonist APH. The effects of NMDA were completely blocked by the non-NMDA receptor antagonists GDEE and kynurenic acid. Kain, the kainate agonist, had no effect on the number of SWDs, but the antagonist kynurenic acid decreased the discharges. CNQX, another non-NMDA antagonist, also reduces the number of SWDs [240].

The glutamate release inhibitor and anticonvulsant lamotrigine thought to inhibit the excitatory neurotransmitter release was indicated for nonconvulsive seizures [241]. Only in a high dose lamotrigine reduced SWD in WAG/Rij rats, but in that dose side-effect such as abnormal locomotion, were also seen [242]. Interestingly, a recent double blind EEG multicentered controlled study confirmed the poor absence 
suppressive effects of lamotrigine in childhood absence epilepsy [243].

In other series of experiments, two noncompetitive AMPA receptor antagonists, CFM-2 and THIQ-10c demonstrated to antagonize generalized tonic-clonic seizures in different animal models [100], were evaluated in WAG/Rij rats. Animals were focally microinjected into specific brain areas of the corticothalamic circuit and EEGs were recorded. The focal microinjection of the two AMPA antagonists into thalamic nuclei (ventralis posteromedialis, RTN, ventralis posterolateralis) and forelimb region was, generally, not able to modify the occurrence of SWDs. However, both compounds were able to reduce the number and duration of SWDs dose dependently when microinjected into the perioral region of the primary somatosensory cortex. These findings suggest that AMPA plays a role in absence epilepsy and that it depends on the involvement of specific neuronal areas. In the next series of experiments the authors demonstrated that noncompetitive AMPA receptor antagonists alone might not be useful in the treatment of absence epilepsy because of their low therapeutic index [244]. A similar low therapeutic index was earlier also found with the AMPA antagonist 7,8-methylenedioxy-1-(4-aminophenyl)-4-methyl-3-acetyl-4,5-dihydro-2,3-benzodiazepine (LY 300164) [135]. Nevertheless, the results from Citraro et al. showed that the center in the perioral region of the primary somatosensory cortex takes the lead or has a more considerable position in generation SWDs and that the local strengthening of $\mathrm{GABA}_{\mathrm{A}}$ receptor activity in RTN strengthens SWDs [99].

In some studies, the effects of glutamatergic receptors ligands cannot be explained by a simple interaction at the receptor. To illustrate, the effects of ketamine, a noncompetitive antagonist at the NMDA receptor, were studied on the EEG and in the open field in the WAG/Rij rat strain [245]. Ketamine was systemically administered in a dose range from 3 to $30 \mathrm{mg} / \mathrm{kg}$. Biphasic effects of ketamine were observed in the EEG. The first phase was a dose dependent suppression of SWDs, followed by a second phase characterized by the facilitation of SWDs. This increase was expressed first as an increased number of SWDs, and later on as a significant prolongation of individual discharges and decrease in frequency of SWDs. An obvious amplitude modulation of the discharges was also found. Ketamine also produced a dose-related initial behavioral excitation, a decrease of muscle tone in hind quarters, followed by front quarters and head, and an absence of locomotor activity. However, the time course of the behavioral changes was not in parallel with the complex EEG effects. It can be concluded that ketamine has more effects on the EEG than previously assumed which cannot be explained by a simple blockade of the NMDA receptor. It is proposed that the obtained specific dynamics of SWDs' frequency may be caused by changes in the activity of the corticothalamocortical pacemakers that are generating SWDs. The following study was conducted to investigate the effects of two noncompetitive AMPA receptor antagonists, GYKI 52466 and GYKI 53405 (the racemate of talampanel, the latter drug is a potent and selective AMPA-receptor antagonist) on the generation of
SWD parallel with the vigilance and behavioral changes in WAG/Rij rats [246]. Intraperitoneal administration of GYKI 52466 (1-[4-aminophenyl]-4-methyl-7,8-methylenedioxy$5 \mathrm{H}-2,3$-benzodiazepine), the prototypic compound of the 2,3-benzodiazepine family acting as an ionotropic glutamate receptor antagonist, and which unlike the conventional 4,5benzodiazepines, does not act on $\mathrm{GABA}_{\mathrm{A}}$ receptors, caused a fast dose-dependent increase in the number and total duration of SWD. These changes were accompanied by dosedependent increase in duration of light slow wave sleep and passive awake, vigilance states associated with the presence of SWD. In addition a short, transient behavioral activation occurred that was followed by strong ataxia and immobility, decrease of active wakefulness and increase in deep slow wave sleep. GYKI 53405 (7-acetyl-5-(4-aminophenyl)-8-methyl8,9-dihydro-7H-1,3-dioxolo[4,5-b][2,3]benzodiazepine),

the racemate of talampanel, $16 \mathrm{mg} / \mathrm{kg}$, i.p. failed to affect any measure of SWD and vigilance. When used as a pretreatment, GYKI $52466(10 \mathrm{mg} / \mathrm{kg})$ slightly attenuated the SWD-promoting effects of the $5-\mathrm{HT}_{1 \mathrm{~A}}$ receptor agonist 8-OH-DPAT, and it decreased the cumulative duration and mean duration of the paroxysms.

Interest of researchers has turned into metabotropic glutamate receptors (mGluR's) since their effects are more subtle and allow for a more refined intervention than would be the case with the ionotropic glutamate receptors. MGluRs are positioned at synapses of the corticothalamocortical network crucial for the occurrence of SWDs. mGluRs form a family of eight subtypes subdivided into three groups on the basis of amino acid sequence, pharmacologic profile, and G-protein coupling [247-249]. Group I comprises mGlul and mGlu5 receptors, which are coupled to Gq proteins. Their activation stimulates polyphosphoinositide hydrolysis with ensuing formation of inositol-1,4,5-trisphosphate and diacylglycerol. The receptors of this group also regulate the activity of different types of $\mathrm{Ca}^{2+}$ and $\mathrm{K}^{+}$channels [250]. Group II includes mGlu2 and mGlu3 receptors and they are coupled to Gi/Go proteins. They negatively modulate the activity of adenyl cyclase and voltage-sensitive $\mathrm{Ca}^{2+}$ channels (VSCCs). Group III comprises mGlu4, mGlu6, mGlu7, and mGlu8 receptors, which are also coupled to Gi/Go proteins. The individual receptor subtypes have a modulatory role on excitatory and inhibitory synaptic transmission in the corticothalamocortical circuitry. Until now, receptors from all three groups have been studied in WAG/Rij rats.

Group I mGluRs are preferentially localized in the peripheral portion of the postsynaptic density of both TCand corticothalamic cells, where they generate excitatory responses and regulate mechanisms of synaptic plasticity. Group II and III mGluRs are found preferentially (albeit not exclusively) in presynaptic terminals, where they negatively regulate neurotransmitter release [251].

Group I. mGlula receptor expression is reduced in the VB nucleus of the thalamus and pharmacologic potentiation of mGlul receptors with the selective PAM, SYN119 (corresponding to Ro0711401), reduces the incidence of absence seizures, whereas treatment with the mGlul receptor NAM (JNJ16259685) exacerbates SWDs [248, 249]. 
The expression of mGlu5 receptors was increased in the somatosensory cortex and decreased in the VB. Interestingly, these changes preceded the onset of the epileptic phenotype. SWDs in symptomatic WAG/Rij rats were not influenced by pharmacological blockade of mGlu5 receptors with MTEP, but were significantly decreased by $\mathrm{mGlu} 5$ receptor potentiation with the novel enhancer, VU0360172-6 without affecting motor behaviour. The effect of VU0360172-6 was prevented by cotreatment with MTEP [252]. It seems that PAMs affecting Group I mGluRs might be interesting new targets against absence epilepsy.

The outcomes do contrast with data obtained in the lethargic $(\mathrm{lh} / \mathrm{hl})$ mice model, where mGlul receptor blockade with the orthosteric antagonists, AIDA or LY367385, reduces the incidence of SWDs [253]. Therefore, it appears that the role of mGlul receptors in the regulation of pathologic SWDs is species/model dependent and may also depend on the genetic determinants of absence epilepsy.

Group II. Symptomatic WAG/Rij rats showed an increased expression of $\mathrm{mGlu} 2 / 3$ receptors in the ventrolateral regions of the somatosensory cortex, ventrobasal thalamic nuclei, and hippocampus, but not in the RTN and in the corpus striatum, as assessed by immunohistochemistry and Western blotting [254]. In contrast, mGlu $2 / 3$ receptor signalling was reduced in slices prepared from the somatosensory cortex of these symptomatic rats, as assessed by the ability of the agonist, LY379268, to inhibit forskolin-stimulated cAMP formation. It therefore seems that mGlu2/3 receptors are involved in the generation of SWDs and that an upregulation of these receptors in the somatosensory cortex might be involved in the pathogenesis of absence epilepsy.

Group III. Studies towards the role of receptors of this category have been limited because of lack of specific agonists. They are, however, interesting for absence epilepsy considering that activation of these receptors reduces GABAergic inhibitory responses within the thalamus, possibly via a presynaptic mechanism [255-257]. In addition, they have a profound effect in reducing the corticothalamic input onto thalamic relay cells [258]. Interestingly, and accordingly, an increased incidence of SWDs has been found in WAG/Rij rats when treated with the selective mGlu4 receptor enhancer, N-phenyl-7-(hydroxyimino)cyclopropa[b]chromen-la-carboxamide (PHCCC) [259]. In humans, the mGlu4 receptor gene is localized at a susceptibility locus for juvenile myoclonic epilepsy [260, 261], which is characterized by absence seizures in addition to myoclonus and tonic-clonic seizures. Another group-III mGlu receptor, the mGlu7 receptor, is also associated with the development of absence seizures. Mutant mice in which mGlu7 receptors failed to interact with PICK1 (protein interacting with C kinase 1) develop absence seizures [262, 263], as do mice injected with a peptide that disrupts the interaction between mGlu7 receptors and PICK1 [262]. The precise mechanism whereby an interaction between mGlu7 receptors and PICK1 restrains SWDs in the corticothalamic network remains to be determined.
Thus, despite of the somewhat atypical features of the action of some substances on SWDs, it is possible to conclude that the role of the glutamatergic system in absence epilepsy corresponds to its role in idiopathic convulsive epilepsy. Seizures typical for both nonconvulsive and convulsive epilepsy could be due to the strengthened functioning of the glutamatergic system, which might be considered as hyperexcitability $[157,264]$. The results suggest that the three types of ionotropic excitatory glutamate receptors enhance SWDs and this alleviating influence can be explained as follows. The spike in the SWD appears as a rebound spike, in fact it is the low threshold $\mathrm{Ca}^{2+}$ spike (Figure 1(b)). It appears after the hyperpolarization phase when the gating mechanism of an $I_{\mathrm{h}}$ channel is activated. Then the spike or the depolarization returns again to the hyperpolarization phase, and the process is repeated. The effects of all three types of excitatory glutamate receptors consist in the enhancement of the depolarization phase, that is, in increasing the amplitude of the spike. A larger spike increases the amplitude of the hyperpolarization, which in turn increases the subsequent spike [265]. This process appears as enhanced SWDs in the EEG. Besides, it is known from classical neurophysiology [266] that intensification of depolarization enlarges the frequency of action potentials, which are indeed crowned on the $\mathrm{Ca}^{2+}$ spike.

\section{Dopaminergic System of the Brain}

5.1. Structure and Function of Mesencephalon DA Systems. It is well known [267-269] that midbrain DA neurons are comprised of three groups of cells: A8, A9, and A10. The A10 DA neurons are located in the ventral tegmental area (VTA), whereas the more lateral DA cells of the substantia nigra pars compacta (SNpc) belong to the A9 cell group; the A8 neurons take a more caudal position in the retrorubral field (RRF) of the midbrain (Figure 7). The terminals of these neuron groups form the nigrostriatal and mesolimbic (or mesocorticolimbic) DAergic systems. A9 neurons group originating from $\mathrm{SNpc}$ predominantly forms the nigrostriatal system. The terminals of these cells innervate the caudate nucleus and neostriatum. The terminals of A10 VTA neurons innervate the mesolimbic system: hypothalamus, nucleus accumbens (Nab, the nucleus of the ventral striatum), olfactory tubercle, central and basal nucleus of amygdala, habenula, septum, hippocampus, prefrontal, cingulate, and entorhinal cortex. The mesocortical DAergic system is predominantly formed by $\mathrm{A} 10$ and partly by $\mathrm{A} 8$ neurons. The area of innervations by this system is the prefrontal, anterior cingulate, entorhinal, and piriform cortex and deep layer of the frontal cortex. The DA terminals innervate also the visual and motor cortex.

There are 5 types of metabotropic DA receptors associated with $G$ proteins $[270,271] \mathrm{D}_{1}, \mathrm{D}_{2}, \mathrm{D}_{3}, \mathrm{D}_{4}$, and $\mathrm{D}_{5}$. They belong to two basic families of receptors: the $\mathrm{D}_{1}$-like receptors including $\mathrm{D}_{1}$ and $\mathrm{D}_{5}$ DA receptors, the $\mathrm{D}_{2}$-like receptors including $\mathrm{D}_{2}, \mathrm{D}_{3}$, and $\mathrm{D}_{4} \mathrm{DA}$ receptors. The $\mathrm{D}_{1}$-like receptors are associated with $G_{S}$ proteins; they increase cyclic nucleotides (cAMP) synthesis and produce upregulation of DA-induced intracellular events such as phosphorilation 


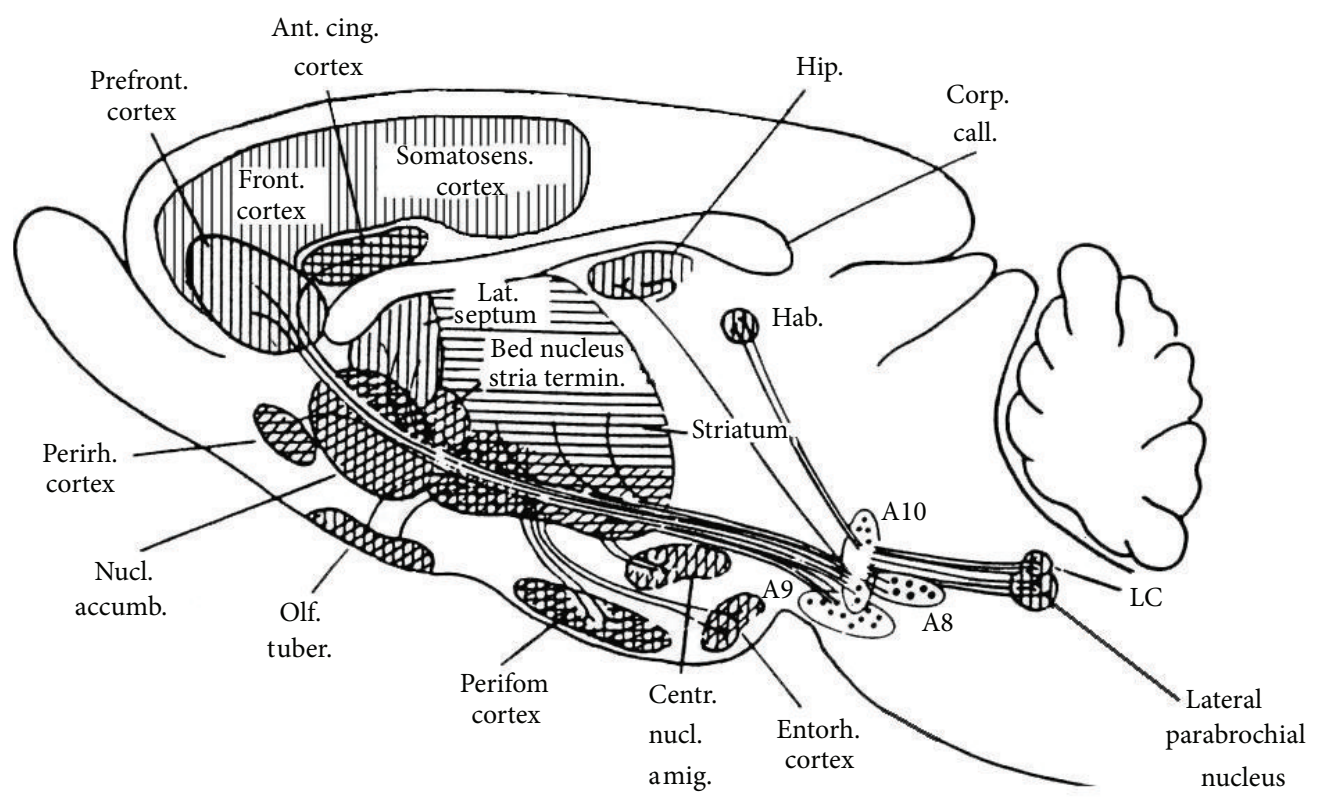

A 10

A9

A8

FIGURE 7: Schematic presentation of the efferent projections of the A8, A9, and A10 dopamine cell groups. The projection fields of the A10 neurons are designated by vertical hatching, those of the A9 cells by horizontal hatching, and the targets of the A8 DA neurons by diagonal hatching. Hatching is not intended to indicate the density of the various projections (scheme modified from [267]).

leading to an alteration in cellular activity and changes in the gene expression within the responding cells. The $\mathrm{D}_{2}$-like receptors are associated with $G_{i}$ proteins; they decrease cyclic nucleotides (cAMP) synthesis and produce downregulation of DA-induced intracellular reactions of dephosphorylation $[272,273]$. Most of the $\mathrm{D}_{2}$-like presynaptic receptors are autoreceptors, an exception is the $\mathrm{D}_{2}$-like somatodendritic DA receptors [272-274]. These autoreceptors are located on DA terminals and downregulation occurs due to inhibition of DA synthesis and depolarization-induced release of DA from terminals [275-278].

As specified above, the nigrostriatal DA system supervises the activity of GABA and glutamatergic synapses of the dorsal striatum (nucleus caudatus and putamen), which in turn activate TC networks and regulate motor behavior in animals and humans $[279,280]$. Corticostriatal transmission is essential in the regulation of voluntary movement, in addition to behavioural control. Long-term potentiation (LTP) and long-term depression (LTD), the two main forms of synaptic plasticity, are both represented at corticostriatal synapses and strongly depend on the activation of DA receptors [273]. The dorsal striatum is extremely homogeneous in comparison with other cerebral areas. About 95\% of dorsal striatal neurons have the same morphology and are medium spiny neurons, their function is to integrate all incoming signals $[272,279,281]$. The medium spiny dorsal striatal neurons receive excitatory glutamatergic synaptic information through AMPA, kainite, and NMDA receptors practically from all areas of the neocortex $[272,279]$. The medium spiny neurons are GABAergic; they use GABA as synaptic transmitter. Consequently, postsynaptic inhibitory reactions are carried out through postsynaptic $\mathrm{GABA}_{\mathrm{A}}$ receptors. Postsynaptic $\mathrm{GABA}_{\mathrm{A}}$ receptors are located on dendrites and the soma of the striatal medium spiny neurons, and also on neurons of the globus pallidus, substantia nigra pars reticulate, and thalamus [279]. The medium spiny neurons of nucleus caudatus and putamen are morphologically identical, but differ neurochemically. One population contains GABA, dynorphin, and substance $\mathrm{P}$ and primarily expresses $\mathrm{D}_{1}$ receptors. These neurons send axons to GPi and to SNpr (Figure 8) and form a direct pathway which inhibit GPi and SNpr and are responsible for a reduction of an inhibitory influence on TC inputs, thereby activating TC input neurons. The second population contains GABA and enkephalin and primarily expresses $\mathrm{D}_{2}$ receptors. These neurons projects to GPe and form a indirect pathway which inhibits TC input (Figure 8). It is important to note that GABAergic terminals form an indirect pathway that project to neurons of the RTN [282]. That is, neurons of the RTN are controlled by $\mathrm{D}_{2}$ receptors through GABAergic projections from the ventral striatum.

In detail, an induction of intracellular signals DA by receptors and control of GABAergic and glutamatergic synaptic activity of medium spiny neurons of dorsal striatum 


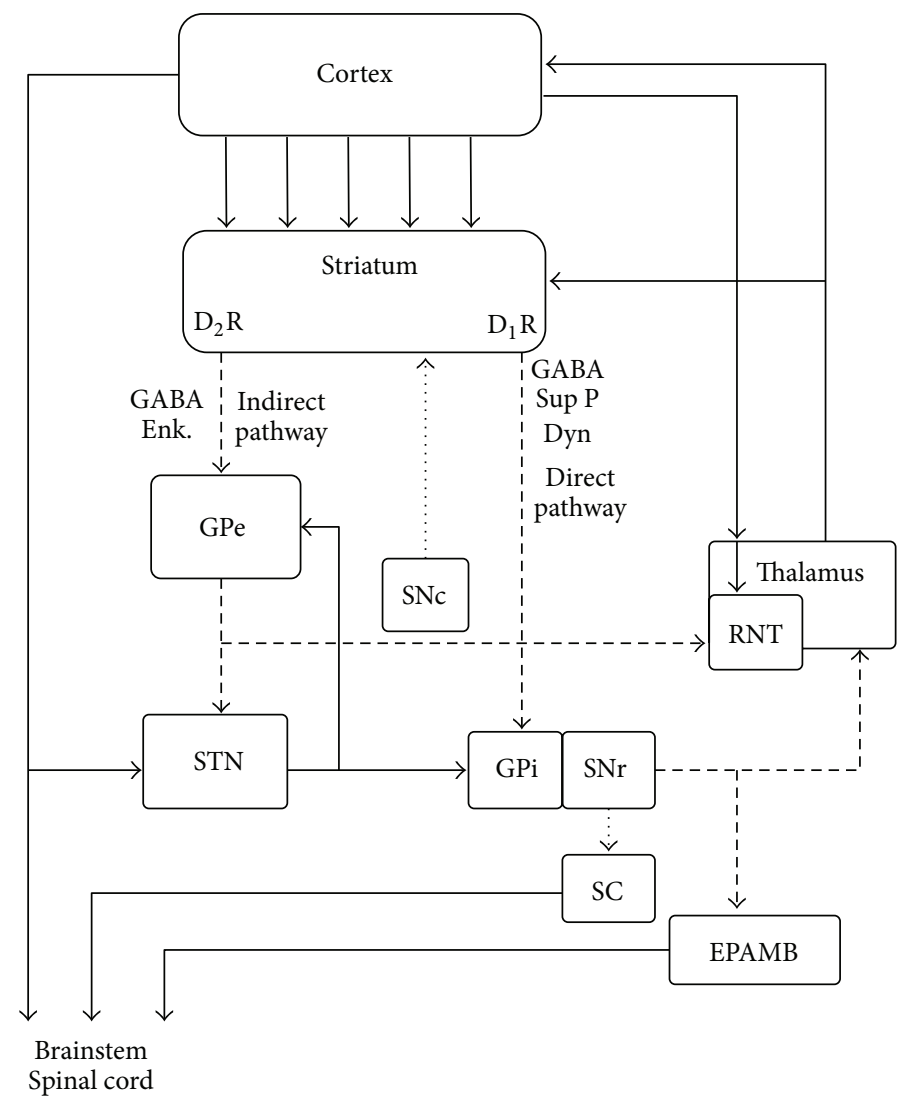

FIGURE 8: Communications of dorsal striatum. Continuous lines: glutamatergic communications (activating). Large dashed lines: GABAergic communications (inhibiting). Fine dotted line: dopaminergic communications. GPe: globus pallidus external. SNpc: substantia nigra pars compacta. STN: subthalamic nucleus. GPi: globus pallidus internal. SNpr: substantia nigra pars reticulata. RNT: reticular nucleus of thalamus. SC: superior colliculus. EPAMB: extrapyramidal area of a middle brain. Enk: enkephalin. Sub P: substance P: Dyn-dynorphin (scheme modified from [282]).

has been described [272]. The DARPP-32/PP-1 (dopamine and cyclic adenosine $3^{\prime}, 5^{\prime}$-monophosphate-regulated phosphoprotein, $32 \mathrm{kDa}$ /phosphoprotein-1) pathway integrates information from a variety of neurotransmitters and produces a coordinated response involving numerous downstream physiological effectors. DARPP-32 phosphorilation at Thr-34 by PKA is regulated by the actions of various neurotransmitters, principally DA acting at $D_{1}$ receptors, but also adenosine acting at $\mathrm{A}_{2 \mathrm{~A}}$ receptors and VIP acting at VIP receptors. PKG is activated in response to NO, also phosphorylates Thr-34 of DARPP-32. In medium spiny neurons that coexpress $\mathrm{D}_{1}$ and $\mathrm{D}_{2}$ classes of DA receptors, activation of $\mathrm{D}_{2}$ receptors acts to decrease cAMP levels. In medium spiny neurons that coexpress adenosine $A_{2 A}$ receptors and $\mathrm{D}_{2}$ receptors, activation of $\mathrm{D}_{2}$ receptors also acts to decrease cAMP levels. Opiates acting at either $\mu$ or $\delta$ receptors decrease cAMP levels in cells stimulated with $\mathrm{D}_{1}$ agonists or adenosine $\mathrm{A}_{2 \mathrm{~A}}$ agonists, respectively. DARPP32 phosphorylated at Thr-34 is dephosphorylated by PP-2B, a $\mathrm{Ca}^{2+} /$ calmodulin-dependent protein phosphatase. PP-2B activity is activated by a number of different neurotransmitter receptors, principally following $\mathrm{Ca}^{2+}$ influx mediated by glutamate acting at NMDA receptors. Glutamate acting at
AMPA receptors also stimulates DARPP-32 dephosphorilation by PP-2B, by an indirect mechanism that involves depolarization of the neuron and influx of $\mathrm{Ca}^{2+}$. Activation of $\mathrm{D}_{2}$ receptors also leads to an increase in $\mathrm{Ca}^{2+}$ levels, via an unidentified mechanism, and increased activity of PP2B. In contrast, GABA acting at $\mathrm{GABA}_{\mathrm{A}}$ receptors stimulates DARPP-32 phosphorilation by hyperpolarization of the neuron, decreased influx of $\mathrm{Ca}^{2+}$, and inactivation of PP2B. Neurotensin acts to increase DARPP-32 phosphorilation by increasing the release of DA. CCK decreases DARPP-32 phosphorilation by increasing glutamatergic neurotransmission. The psychomotor stimulants cocaine and amphetamine increase DARPP-32 phosphorilation by increasing DA neurotransmission. All antipsychotic drugs achieve some of their clinical effects via antagonism of the $\mathrm{D}_{2}$ class of DA, an action leading to an increase in the state of phosphorilation of DARPP-32. Phospho-DARPP-32, by inhibiting the activity of PP-1, acts in a synergistic manner with different protein kinases to increase the level of phosphorilation of various downstream effector proteins. The resulting increase in phosphorilation is associated with increased activity of NMDA and AMPA glutamate receptors, L-, N-, and P-type $\mathrm{Ca}^{2+}$ channels, and early gene CREB and with decreased 
activity of $\mathrm{GABA}_{\mathrm{A}}$ receptors, $\mathrm{Na}^{+}$channels, and the $\mathrm{Na}^{+} / \mathrm{K}^{+}$ATPase. It is important to note from [272] scheme that antagonists of the $\mathrm{D}_{2}$ class of $\mathrm{DA}$ receptors increase $\mathrm{GABA}_{\mathrm{A}}$ receptors activity, and agonists of the $\mathrm{D}_{2}$ class of DA receptors decrease $\mathrm{GABA}_{\mathrm{A}}$ receptors activity. Thus, intracellular integrating transduction signal modifies all parameters of neuronal activity. Modification of GABA and glutamate ionotropic receptors activity will lead to updating of synaptic neuronal inputs and outputs, defining participation of neuron in functioning of a neural network. Modification of voltagedependent ionic channels activity modifies properties of the electrogenic neural membrane. Integrating transduction signal possesses the ability to modify not only the activity of ionotropic, but also of metabotropic receptors of neurons localized on membranes and supervising transduction signal. Such updating of all parameters of neurons, synaptic, electric, and chemical, switches neurons to another functionally active state or on other levels of functional activity. Depending on the brain structure and of the modulatory system inducing modification of transduction signal, a particular neuronal state can be formed which can switch into another functional state. For example, activation of the mesocorticolimbic DA system of ventral tegmental area (Figure 7, A10) lateral hypothalamus [283-285], nAcb [286, 287], prefrontal cortex [288-291], and anterior cingulate cortex [292, 293], induces an emotional positive state (pleasure and happiness [294297]), a state referring to its own prolongation and/or intensification (intra-cranial-self-stimulation $[283,285,286,288$, $290,298]$, self-administration of drugs [290, 292, 299], selfcontrol of drug administration, or place-preference paradigm [299-301]). Switching of neuron activity in other functional state, through intracellular integration with the help of transduction signal and modification of ionotropic and metabotropic receptors and potential sensitive ionic channels activity, it is possible to explain the role of the opioid [285, 298], GABAergic [284, 287], acetylcholinergic [289], serotoninergic [286, 287], and other systems in the control of the mesocorticolimbic DAergic reinforcement system. We define reinforcement as an emotional positive state arising as a consequence of a reward and of an avoidance or escape of an aversive stimulus, it induces purposeful motivated behavior.

As it has been shown above, one of the important structures of the mesocorticolimbic DA system is the nAcb, which is also called the ventral striatum [279]. The nAcb consists of two groups of cells which differ anatomically: the shell and core. Both parts of the ventral striatum participate in emotionally positive reactions and in reinforcement. The degree of participation of these two parts in reinforcement (see above) depends on features of the experimental model [302]. It is supposed that the core of the nAcb together with the dorsal striatum participates in the realization and control of purposeful behavior. The nigrostriatal DA system participates in regulation of motor behavior by regulation of TC neural networks (it is described in more details above). The shell receives innervations from A10 DA cellular groups (Figure 7), it is associated with the limbic system [268]. The nAcb core receives glutamatergic inputs from prefrontal cortices (another important structure of reinforcement reaction), thalamus, hippocampus, amygdala, and habenula.
Direct and indirect projections from the core of the $\mathrm{nAcb}$ to the SNpr and VP in rats are described [303, 304]. Both structures receive projections from the dorsal striatum. Thus, the DA system of the ventral striatum (mesocorticolimbic) cooperates with that of the dorsal striatum (nigrostriatal) at the level of SNpr and VP which regulate TC networks through the GABAergic system. It is necessary to add that this interaction is supervised by the prefrontal cortex. It is the structural basis for the realization of purposeful motivated motor behavior, in particular when a choice for the correct response can be made in order to get reinforced. Behavioral experiments suggest that learning is driven by changes in the expectations about future salient events such as rewards and punishments. Physiological work has recently complemented these studies by identifying DA neurons in the primate whose fluctuating output signals changes or errors in the predictions of future salient and rewarding events [305-307].

\subsection{Features of WAG/Rij Rats Strain Related to the Function} of the DA System. It is known that SWDs are controlled by the brain's dopaminergic (DAergic) system. Antagonists of $\mathrm{D}_{2}$ DA receptors increase and agonists decrease of SWDs $[32,304,308-310]$.

The WAG/Rij rats can be regarded as a valid genetic animal model of absence epilepsy with co morbidity of depression [50-52]. Behavioral studies indicate that WAG/Rij rats exhibit depression-like symptoms: decreased explorative activity in the open field test, increased immobility in the forced swimming test, and decreased sucrose consumption and preference (anhedonia). In addition, WAG/Rij rats adopt passive strategies in stressful situations, express some cognitive disturbances (reduced long-term memory), helplessness, and submissiveness, inability to make choices, and overcome obstacles, which are typical for depressed patients. Elevated anxiety is not a characteristic (specific) feature of WAG/Rij rats; it is a characteristic for only a substrain of WAG/Rij rats susceptible to audiogenic seizures [51]. Interestingly, WAG/Rij rats display a hyperresponse to amphetamine similar to anhedonic depressed patients. WAG/Rij rats are sensitive only to chronic, but not acute, antidepressant treatments, suggesting that WAG/Rij rats fulfill a criterion of predictive validity for a putative animal model of depression. However, more and different antidepressant drugs still await evaluation. Depression-like behavioral symptoms in this model are evident at baseline conditions, not exclusively after exposure to stress. Experiments with foot-shock stress do not point towards higher stress sensitivity at both behavioral and hormonal levels. However, freezing behavior (coping deficits) and blunted response of $5 \mathrm{HT}$ in the frontal cortex to uncontrollable sound stress, increased c-fos expression in the terminal regions of the mesocorticolimbic brain systems and larger DA response of the mesolimbic system to forced swim stress suggests that WAG/Rij rats are vulnerable to some, but not to all types of stressors. In all, it seems that the depressivelike behavior in WAG/Rij rats has a DA-dependent character [311]. These results allow the assumption that the WAG/Rij strain possesses a deficiency of the brain's DA system activity. 
A low threshold for catalepsy, among others induced by sound stress, was repeatedly found in WAG/Rij compared to Wistar rats [308, 312]. WAG/Rij rats showed also both a larger novelty and amphetamine induced increase in total distance moved than ACI rats in a brightly lit open field [310]. This novelty/amphetamine-induced ambulation score was interpreted as an index of the reactivity of the DA system in the mesolimbic system [313-315]. Index of the reactivity is in addition bound, as well as a catalepsy threshold, to a threshold of sensitivity of a ligand-receptor interaction. It means that the dissociation constant $\left(K_{\mathrm{d}}\right)$ of WAG/Rij rats DA receptors is lower than in nonepileptic rats [316]. Unfortunately, there are no data measuring the dissociation constant of DA receptors.

It is possible to assume that control of SWDs by $\mathrm{D}_{2}$-like DA receptors is carried out through an indirect GABAergic pathway from the dorsal striatum which terminates in the RTN through pathways passing through the GP (Figure 8), one of the sources of rhythmic oscillations. Antagonists of $\mathrm{D}_{2}$-like DA receptors enlarge activity of $\mathrm{GABA}_{\mathrm{A}}$ receptor and increase SWD activity, and agonists reduce $G_{A B A}$ receptor activity and reduce SWDs (see Section 3.1.1). $\mathrm{D}_{2}$ like DA receptors in dorsal striatum induces phosphorilation of $\mathrm{GABA}_{\mathrm{A}}$ receptor and reduce its activity [272]. It has been shown that $\mathrm{D}_{2}$-like $\mathrm{DA}$ receptors selectively block N-type $\mathrm{Ca}^{2+}$ channels to reduce GABA release onto rat striatal cholinergic interneurons [317]. $\mathrm{DA} \mathrm{D}_{2}$ receptormediated presynaptic inhibition of striatopallidal $\mathrm{GABA}_{\mathrm{A}}$ IPSCs in vitro [318]. There were significant increases in $\left[{ }^{3} \mathrm{H}\right]$ nemonapride binding to $\mathrm{D}_{2}$-like receptors at different time points due to treatment with haloperidol, chlorpromazine, and olanzapine in rat striatum. By contrast, treatment with clozapine and olanzapine caused a time-dependent decrease in $\left[{ }^{3} \mathrm{H}\right]$ muscimol binding to the $\mathrm{GABA}_{\mathrm{A}}$ receptor of striatum [319]. Dopamine $\mathrm{D}_{4}$ receptor induced postsynaptic inhibition of GABAergic currents in mouse GP neurons [320]. An increase of GABAergic neurotransmission in the striatum of mice lacking DA $\mathrm{D}_{2}$ receptors was found [321]. The inhibitory effects of the $\mathrm{DA} \mathrm{D}_{2}$ receptor agonist quinpirole on $\mathrm{GABA}_{\mathrm{A}}$-mediated spontaneous inhibitory postsynaptic currents correlate with the total number of $D_{2}$ receptor sites in the striatum [322]. L-DOPA acting as $\mathrm{D}_{2}$-like agonist inhibits GABA release in the rat globus pallidus and induces turning behavior in rats with unilateral lesions of the DA innervation [323]. Quinelorane, a dopamine $\mathrm{D}_{3} / \mathrm{D}_{2}$ receptor agonist, reduces prepulse inhibition of startle and GABA efflux in the VP [324]. GABA release from pallidal terminals in the STN nucleus and in the RTN is inhibited by activation of $\mathrm{D}_{4}$ receptors [325]. Dopamine inhibits GABA transmission from the GP to the RTN via presynaptic $\mathrm{D}_{4}$ receptors $[326$, 327].

Thus, antagonists of $\mathrm{D}_{2}$-like DA receptors strengthen GABA transmission into striatum, GP and RTN and raise SWDs by promoting burst activity in the RTN, and agonists operate in an opposite direction. Based on the electrophysiological and lesion studies in WAG/Rij rats it is proposed that there is no direct source of SWD activity in the RTN, however, bursting neurons in the RTN are a necessary condition for maintenance and spreading of SWD [13, 20,99].

5.2.1. The Processes of Defensive Learning and Memory Controlled by DA System. An infringement of WAG/Rij rat's behavior was shown [51, 52, 328-331]. A decrease of memory reproduction, spontaneous catalepsy, low threshold of haloperidol-induced catalepsy, disturbances in maternal behavior, and symptoms of depression-like behavior were found in WAG/Rij rats. All these data can be explained by a DA deficit on the WAG/Rij rat's brain. The goal of the investigation $[332,333]$ was to study the possibility of WAG/Rij rat's behavior correction by pharmacological activation of DAergic system by disulfiram and L-3,4dihydroxyphenylalanine (L-DOPA, the precursor of DA synthesis). Higher doses of disulfiram $(100-300 \mathrm{mg} / \mathrm{kg}$ ) block the efficiency of dopamine- $\beta$-hydroxyls, the enzyme involved in the synthesis of noradrenalin (NA) from DA. A lower dose of $25 \mathrm{mg} / \mathrm{kg}$ of disulfiram increases the DA content in the brain without change of NA and transforms animals with an emotional negative reaction to animals with an emotional positive reaction in the emotional resonance behavioral reaction test [334].

Rats were tested in a passive light avoidance and in a classical two-way active avoidance task and the effects of this dose of disulfiram on memory were investigated. The index of memory trace storage $\left(I_{\mathrm{MT}}\right)$ was calculated as

$$
I_{\mathrm{MT}}=\frac{A_{2}-A_{1}}{A_{1}} \times 100 \%,
$$

where $A_{1}$ is the number of avoidance's in learning session on day $1, A_{2}$ is the number of avoidance's in the session on day 2 (both 50 trials).

There were three series of experiments. First series: disulfiram was administered to Wistar and WAG/Rij rats of the 1st group 4 hours before the 1st day learning session. Second series: L-DOPA (also $25 \mathrm{mg} / \mathrm{kg}$ i.p.) was administered to Wistar and WAG/Rij rats of the 2nd group 4 hours before the 1st learning session. In the 3rd series of experiment disulfiram was administered immediately after 1st learning session in Wistar and WAG/Rij rats. Control Wistar and WAG/Rij rats received the same volume of saline.

Control WAG/Rij rats showed an amnesic reaction compared to control Wistar rats at day 2 of the passive avoidance conditioning procedure (Figures 9(a) and 9(b); in 2.65 and 3.89 times in (a) and (b), resp.). The administration of disulfiram before as well as after passive avoidance conditioning improved memory as measured the next day both in Wistar and WAG/Rij rats, although the extent of increase was higher in WAG/Rij than in Wistar rats. The reproduction of memory, as established in the passive avoidance test, was increased 1.34 and 1.41 times in Wistar rats and 4.21 and 4.89 times in WAG/Rij rats accordingly. Administration of disulfiram before learning did not change the latency to enter the dark compartment in the first day nor induced a difference between the strains later.

The administration of disulfiram 4 hours before establishment of active avoidance conditioning changed the learning 


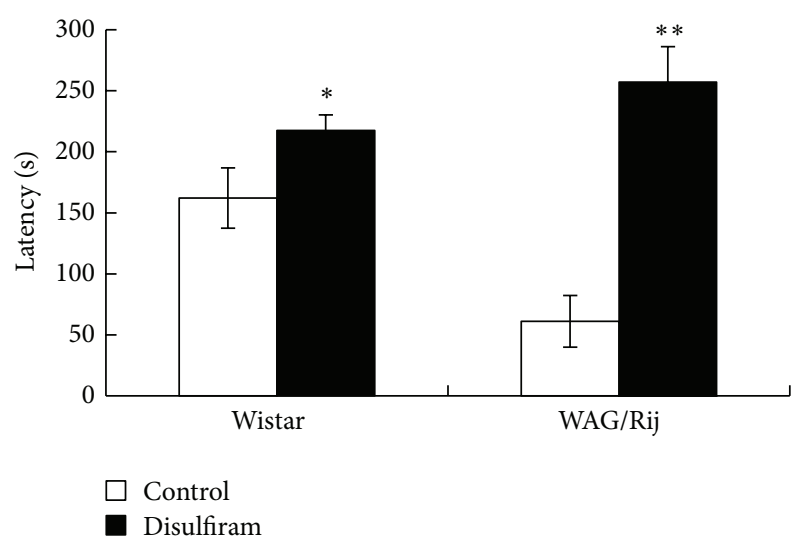

(a)

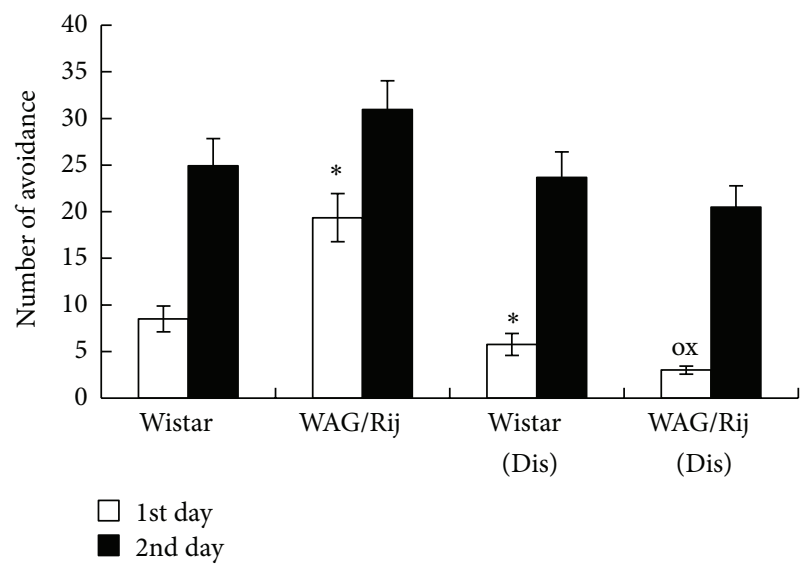

(c)

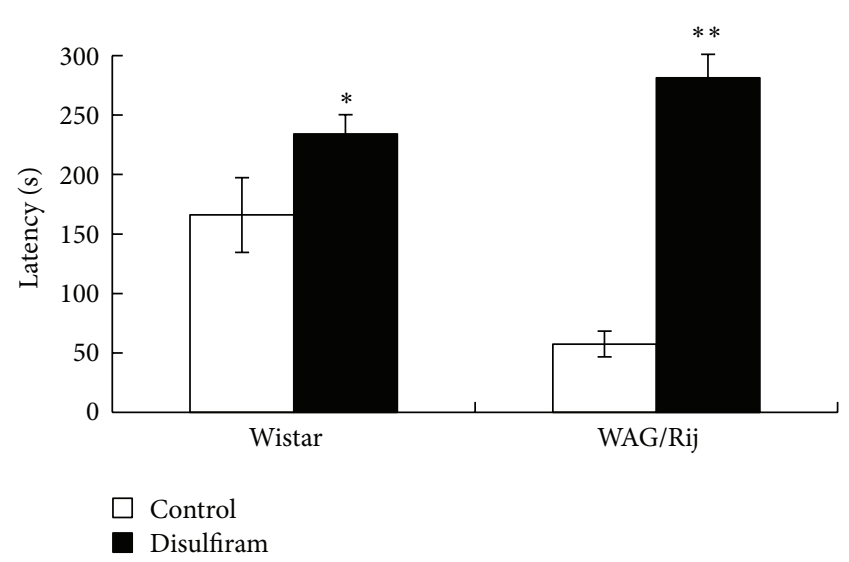

(b)

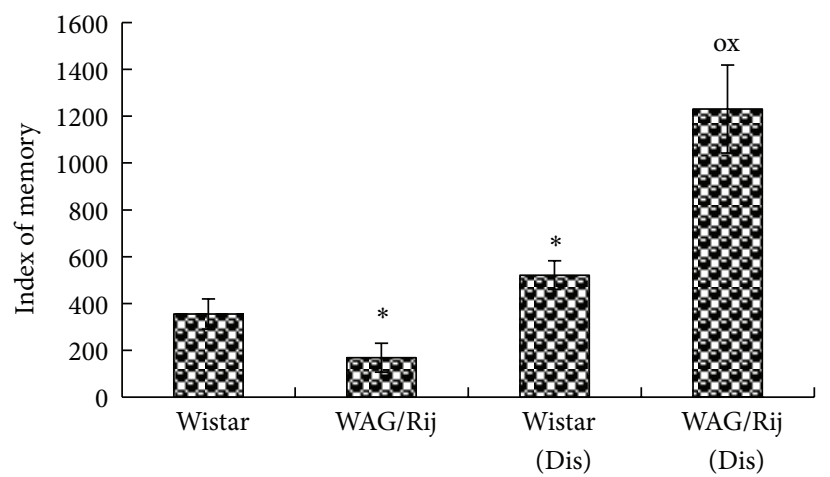

(d)

FIGURE 9: The action of disulfiram in the reproduction of passive and active avoidance reflex on the next day by Wistar and WAG/Rij rats strains. (a) is disulfiram ( $25 \mathrm{mg} / \mathrm{kg}$ ) administration 4 hours before learning of passive avoidance. (b) is disulfiram ( $25 \mathrm{mg} / \mathrm{kg}) \mathrm{administration}$ immediately after learning of passive avoidance. ${ }^{\mathrm{x}} P<0.05$ versus to Wistar, ${ }^{*} P<0.05$ versus to control, ${ }^{* *} P<0.01$ versus to control. (c) is number of avoidances. (d) is index of memory trace storage. ${ }^{*} P<0.05$ versus to Wistar control, ${ }^{\mathrm{x}} P<0.05$ versus to WAG/Rij control, ${ }^{\circ} P<0.05$ versus to Wistar (Dis).

processes in the first day (Figure 9(c)). Control WAG/Rij rats realized 2.23 times more avoidance responses than control Wistar rats in the first day of learning (Figure 9(c)). Disulfiram administration (DIS) before learning decreased the number of avoidance responses in the first day: in Wistar rats 1.47 times and in WAG/Rij rats 6.45 times (Figure 9(c)). An amnesic effect in control WAG/Rij versus control Wistar rats was found in the second day of learning: the memory index of WAG/Rij rats was 2.11 times lower than in Wistar rats (Figure 9(d)). The administration of disulfiram increased memory index of Wistar rats 1.44 times and in WAG/Rij rats 7.33 times (Figure $9(\mathrm{~d})$ ).

The other inductor of DA system activation, L-DOPA, was used for comparison. Synergic effects of disulfiram and L-DOPA administered 4 hours before learning were found (Figure 10). The administration of L-DOPA 4 hours before learning decreased the number of avoidances in the first day of learning in Wistar rats 1.76 times and in WAG/Rij rats 7.65 times (Figure 10(a)). Herewith, the index of memory trace storage was increased in Wistar rats 1.82 times and in WAG/Rij rats 7.70 times (Figure 8(b)).

A higher number of active avoidance responses in the first day of learning and an amnesic effect in the second day of learning in WAG/Rij versus Wistar rats (Figures 9(c), 10(a), and 10(c)) was reproduced three times in our experiments. Administration of disulfiram immediately after active avoidance conditioning in the first day significantly increased the number of avoidance responses in the second day; the reaction of WAG/Rij rats was more intense than in Wistar rats (Figure 10(c)). In the memory trace storage the relation Wistar (Dis) to Wistar is 1.8 and relation WAG/Rij (Dis) to WAG/Rij is 2.48 (Figure 10(d)).

The amnesic effect in WAG/Rij versus Wistar rats in the passive avoidance reflex was found earlier $[328,335]$. The amnesic effect can be explained by WAG/Rij rat's epileptic activity, the low efficiency of DA system and as a consequence, a reduced sensitivity for reward (see above). The improvement in the passive avoidance, (the dark was longer 


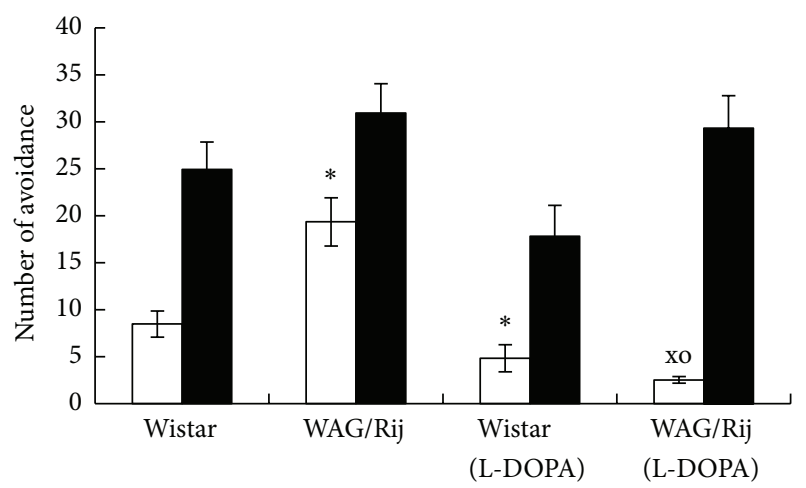

(a)

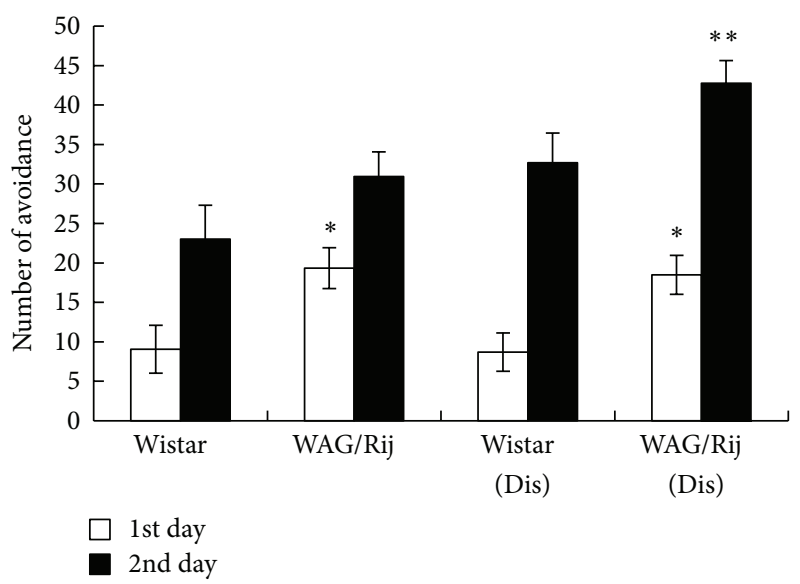

(c)

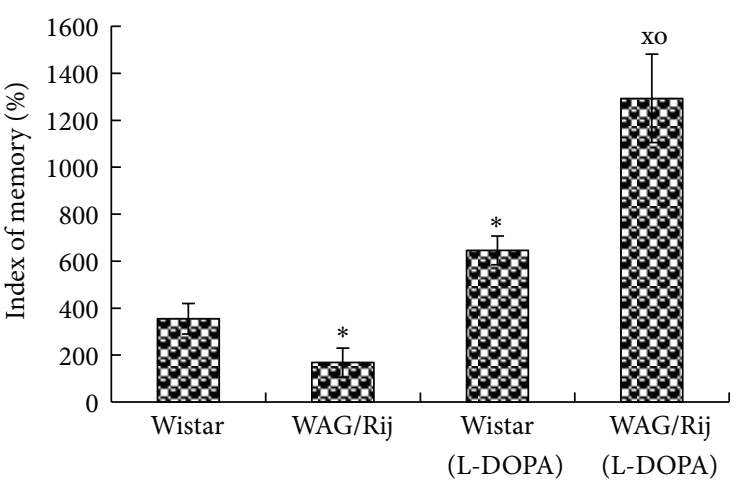

(b)

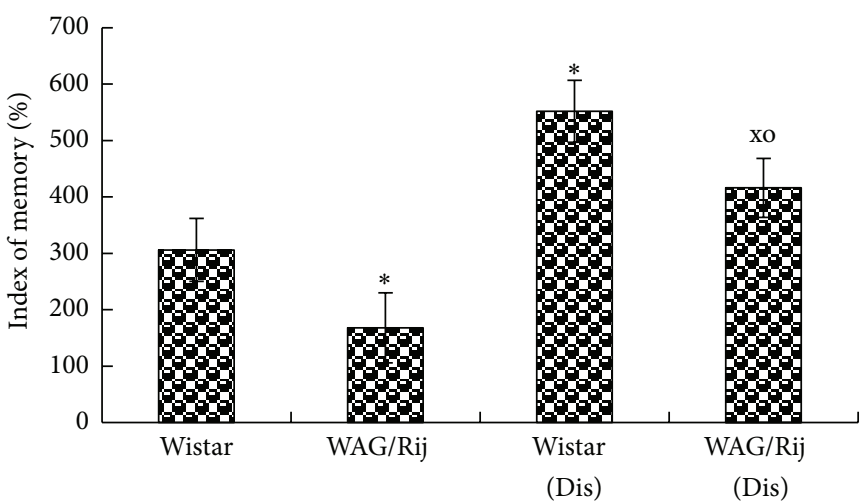

(d)

FIGURE 10: The action of administration of L-DOPA $(25 \mathrm{mg} / \mathrm{kg})$ and disulfiram (Dis) $(25 \mathrm{mg} / \mathrm{kg}$ ) on two days active avoidance conditioning sessions for Wistar and WAG/Rij rats. (a) and (b) are L-DOPA administration 4 hours before learning of active avoidance, ${ }^{*} P<0.05$ versus Wistar control, ${ }^{\mathrm{x}} \mathrm{P}<0.05$ versus WAG/Rij control, ${ }^{\circ} \mathrm{P}<0.05$ versus Wistar (L-DOPA). (c) and (d) of disulfiram administered immediately after the first day learning of active avoidance, ${ }^{*} P<0.05$ versus Wistar, ${ }^{* *} P<0.05$ versus WAG/Rij and to Wistar DIS ${ }^{\mathrm{x}} P<0.05$ versus WAG/Rij control, ${ }^{\circ} \mathrm{P}<0.05$ versus Wistar (Dis).

avoided) in both WAG/Rij and Wistar rats after disulfiram administration (Figure 7) can be explained by the same processes, which is an agreement with the changes in the emotional resonance behavioral reaction test [328]. It can be supposed that a low dose of disulfiram before as well as after learning increases the DA content in the brain, increase the sensitivity for reward, and, as a consequence, the consolidation process, the latter as expressed by a better performance in the passive avoidance test the next day. It is proposed here that the larger effects of disulfiram in WAG/Rij rats reflect their deficit in the DA system. Besides, the increase of DA system efficiency decreases in WAG/Rij rat's amount of epileptic activity $[32,304,308,309]$. Activation of the DA system can be considered as an anti-amnesic effect.

As it was specified above, the mesocorticolimbic DAergic system is a reinforcement system, not a reward system. We believe that there is a basic difference between reinforcement and reward. Usually, as reward food, sweets and so on are used. For some people one kind of food can be reward, and for other people the same food can be aversive. Hence, the relation to what is considered as reward is developed in the history of an individual's life. Usually reward, food and sweets are given through the mouth. As in the somatosensory and motor projections to dorsal striatum remains somatotopy inherent to the cortex $[279,280]$ it is natural that the reward involves nigrostriatal DA system [307, 336-340]. It is necessary to notice that a subset of striatal neurons (10\%) is tonically active with discharge rates of 2 to $10 \mathrm{~Hz}$. These neurons are distributed throughout the striatum and their discharge bears no specific relation to movement. These tonically active neurons (TANs) fire in relation to certain sensory stimuli that are associated with reward. For example, a TAN will fire in relation to a clicking sound if the click precedes a fruit juice reward but will not fire to the click alone or to the reward alone $[279,341]$. It has been suggested that these neurons signal aspects of tasks that are related to learning and reinforcement. TANs are not activated by electrical stimulation of the GP and thus are probably not 
projection neurons. It is thought that TANs are cholinergic large aspiny interneurons that innervate the medium spiny neurons (see earlier discussions), which would place them in a position to modify the sensitivity of the medium spiny neurons to cortical input in relation to specific behavioral contexts [279].

We think that reinforcing properties of reward cause emotionally positive states which induce emotionally positive reactions, such as pleasure [342]. The purest kind of implication of the emotionally positive reaction refers to the prolongation of the emotionally positive state is the reaction of selfstimulation. Self-stimulation reaction can be observed only at stimulation of the mesocorticolimbic DA systems [291, 343349], but not by stimulation of nigrostriatal DA systems. But prolongation of emotionally positive state is motivation, hence mesocorticolimbic DA system executes also function of motivation $[348,350]$. Thus, the mesocorticolimbic DA system organizes behavior via modulation of emotional and motivation states. In this case, it is conceivable that tonically activated neurons of dorsal striatum play a complementary role, due to their small numbers. It is possible that these neurons are involved in the interaction processes of reinforcement and reward. We consider that in our investigation the avoidance of electrical current causes an emotionally positive state and reinforces an avoidance reaction. The augmentation of DA concentration in the brain by disulfiram or L-DOPA strengthens the reaction to a reinforcer. Against the prospect of a deficiency of DA and hyper reactivity of DA systems, the investigated substances provoke much more intensive effect in WAG/Rij than in Wistar rats.

The brain's opioid system also controls SWDs. Different agonists of kappa and antagonists of mu opioid receptors decrease SWDs, and mu receptors agonists increase SWDs [351-353]. It was also shown that a specific peptide of the proenkephalin system was increased in the striatum, the frontal cortex, and the mesencephalon [354, 355], structures directly or indirectly controlling inhibitory processes in corticothalamocortical neuronal networks [21, 279, 280]. Also from in situ hybridization studies, it appeared that the level of the proenkephalin mRNA was enhanced in the striatum of WAG/Rij rats [356].

The opioid system controls the threshold of pain sensitivity and actualizes the motivation of escape and avoidance of pain $[299,357,358]$. A high number of avoidance responses were found earlier in WAG/Rij rats on the first day of active avoidance conditioning (Figures 9 and 10) $[328,335]$. We explain this reaction by the low efficiency of opioid system in WAG/Rij strain [351-356] and as a consequence a low pain threshold and a high level of escape and avoidance motivation. It has been shown [359-361] that activation of the DAergic system evokes analgesic reaction including activation of the opioid system [362-366]. It is important that in the analgesic reaction of DAergic system the $\mathrm{nAcb}$ is included $[359,360]$ and also that the interaction of DAergic and opioid systems takes place in the striatum [272, 364], a structure controlling SWDs. It is supposed that disulfiram or L-DOPA administration before learning increases the content of DA in the brain and via an enhancement of the opioid system activity increases the pain threshold and decreases pain avoidance motivation. At the same time DAinduced reinforcement (modification of mesocorticolimbic DA system) is increased, as well as memory consolidation and memory reproduction on the next day (Figures 9 and 10). It has been shown (Kuznetsova, not published data) that L-DOPA $(25 \mathrm{mg} / \mathrm{kg})$ administration decreases SWDs activity in WAG/Rij rats and that the same has been found for the DA agonists apomorphine and cocaine [32, 367].

Disulfiram administration immediately after learning increased DA-induced reinforcement (see above), increased the process of memory consolidation, and increased active avoidance memory reproduction on the next day (Figure 10). It is possible that the larger effect in WAG/Rij rats is a reflection of the DA and opioid systems efficiency deficit in this strain of rats.

In all, a deficit of DA system in WAG/Rij rats and an increase in the sensitivity to a DA agent as the response on the deficit is proposed to be the causative factor for the behavioural differences in Wistar and WAG/Rij rats.

A stable memory trace was found in the passive avoidance task in Wistar rats; however, WAG/Rijs performed less well. Disulfiram administration before and after learning increased memory reproduction in this task in both strains of rats. The enhancement of memory reproduction was more intense for WAG/Rij than for Wistar rats. WAG/Rij rats realized more correct avoidances than Wistar rats in the first day of active avoidance learning. But in the next day of learning a memory deficit was found in WAG/Rij rats. Low dose of disulfiram and L-DOPA administration before learning decreased learning in the first day, but increased active avoidance memory reproduction in the next day in both strains. This decrease of learning and enhancement of memory was more intense in WAG/Rij than in Wistar rats. It was suggested that a deficit of DA system in WAG/Rij rats is the biological correlate of these behavioural deficits and that an enhanced sensitivity to DAergic agents is the consequence of this deficit.

\subsubsection{Measurement of DA Systems Activity in WAG/Rij Rats} Strain. Some parameters of DA activity in WAG/Rij rats were studied in order to establish whether there was a deficiency. DA synthesis and its degradation have been investigated in $70-80$ th of the last century in detail. It is well known that DA is synthesized in DA terminals from tyrosine. The limitation enzyme tyrosine-hydroxylase synthesizes L-DOPA (L-3,4dihydroxyphenylanine) from tyrosine. The second enzyme, DOPA-decarboxylase, synthesizes DA from L-DOPA. DA is taken up by vesicles of varicosity and stored there [368, 369]. During depolarization, DA is released into the intercellular space and interacts with DA receptors. At this state a higher concentration of released DA, receptors activity and DA efficiency are observed. Further DA is retaken up in terminals and glia cells by assistance of DA-transporter. $\mathrm{DA}$ is inactivated by monoamine oxidase enzyme (MAO) and through a number of enzymatic transformations turns onto metabolite DOPAC (3,4-dihydroxyphenylacetic acid) measured experimentally. By the help of another enzyme of inactivationcatechol-O-methyltransferase (COMT) DA passes through another enzymatic transformations and turns 
into the metabolite HVA (homovanillic acid) also measured experimentally. The inhibition of the DA-transporter, MAO, and COMT activity reduces an inactivation of DA, reduces the concentration of DOPAC and HVA, raises the duration of DA interaction with receptors, and enhances the efficiency of the DA system [370-374].

The goal of our first experiment [375] was to investigate DA and its metabolites, DOPAC and HVA concentration in the following brain structures of Wistar and WAG/Rij rats: frontal cortex, parietal cortex, medulla, striatum, thalamus, and cerebellum. Concentrations of DA and its metabolites have been defined by method of High Performance Liquid Chromatography (HPLC). There was no difference in DA concentration in WAG/Rij compared to Wistar rats. However, the concentrations of metabolites and the HVA/DA ratio were substantially different in some structures between WAG/Rij and Wistar rats. DOPAC concentration was reduced in striatum and HVA concentration in thalamus in WAG/Rij rats. As noted above, one source of oscillations is located in thalamus [19-22]. The dorsal striatum is innervated by nigrostriatal DA system controlling activity of TC networks and modulates the occurrence of SWDs [21, 55, 279]. Reduction of the concentration of metabolites in thalamus and striatum is related to enhanced DA activity in these structures. The strengthening of DA activity may occur as compensation for DA deficiency at behavioural level.

The deficiency of DA activity is likely to be linked with changes of DA receptors. In order to test such probability, we compared $[376,377] \mathrm{D}_{1}$ and $\mathrm{D}_{2} / \mathrm{D}_{3} \mathrm{DA}$ receptors binding sites with autoradiography in brain areas of WAG/Rij while ACI rats were used as controls; the latter strain is nearly free of SWDs [79].

Analyses of the optical densities of the autoradiograms showed a significant reduction of $\left[{ }^{3} \mathrm{H}\right] \mathrm{SCH} 23390$ binding sites ( $D_{1}$ DA receptors) of WAG/Rij rats compared to ACI rats in the shell of nAcb and in the head of caudate nucleus. In other structures no significant changes were observed. The results are presented in Table 1.

The results of $\left[{ }^{3} \mathrm{H}\right]$ spiperone binding for $\mathrm{D}_{2} / \mathrm{D}_{3}$ DA receptors are given in Table 2. An increase of these binding sites was seen in WAG/Rij compared to ACI rats in motor, somatosensory, and parietal cortex. The number of binding sites was substantially lower than in the same structures of ACI rat; in the head of caudate nucleus and in the hippocampal CA3 area, a higher number was found in WAG/ Rij rats. No significant differences in these measures were found in other structures.

Our results, a decrease of $D_{1} D A$ receptors number in nAcb shell and in the head of caudate nucleus (Table 1), might be related to a reduction of an upregulating effect of DAergic transmission induced by phosphorilation. The increase in the number of $\mathrm{D}_{2} / \mathrm{D}_{3}$ DA receptors in motor, somatosensory, and parietal cortex was due to an amplification of downregulating effect of DAergic transmission, induced by dephosphorilation. The reduction of $\mathrm{D}_{2} / \mathrm{D}_{3}$ DA receptors number in the head caudate nucleus and in the $\mathrm{CA} 3$ area of hippocampus (Table 2) corresponds to reduction of downregulating effect
TABLE 2: Density of $\left[{ }^{3} \mathrm{H}\right]$ spiperone binding sites in different brain areas of $A C I$ and WAG/Rij rats $\left(D_{2} / D_{3}\right.$ receptors $)$.

\begin{tabular}{lccc}
\hline Brain regions & ACI rats & WAG/Rij rats & $P<0.05$ \\
\hline Motor cortex & $7.23 \pm 0.52$ & $9.8 \pm 0.61$ & 0.018 \\
Somatosensory cortex & $5.18 \pm 0.32$ & $8.19 \pm 0.72$ & 0.0052 \\
Parietal cortex & $6.41 \pm 0.40$ & $8.40 \pm 0.78$ & 0.0064 \\
Nucleus accumbens (core) & $16.15 \pm 0.70$ & $14.94 \pm 1.25$ & \\
Nucleus accumbens (shell) & $22.79 \pm 0.54$ & $21.79 \pm 1.22$ & \\
Caudate nucleus (head) & $25.89 \pm 1.13$ & $21.64 \pm 0.47$ & 0.0088 \\
Caudate nucleus (ventral) & $32.77 \pm 1.09$ & $36.33 \pm 1.72$ & \\
Caudate-putamen & $30.15 \pm 2.77$ & $27.87 \pm 2.46$ & \\
CA3 area of hippocampus & $2.80 \pm 0.15$ & $1.85 \pm 0.30$ & 0.024 \\
\hline
\end{tabular}

of DAergic transmission, inducing the processes of dephosphorilation and enhancement of $\mathrm{GABA}_{\mathrm{A}}$ receptors activity. The $\mathrm{D}_{1}$ DA receptors are somatodendritic receptors; they have not been found on DA terminals [378]. At the same time, $\mathrm{D}_{2} / \mathrm{D}_{3}$ DA receptors are both placed on soma and dendrites of target cells, and on DA terminals [272, 274-278]. As shown above, the autoreceptors modify DA release affecting a synthesis measured by DA concentration in tissue samples. In our previous study [375], we did not reveal significant differences in DA concentration in various brain structures of WAG/Rij compared to nonepileptic rats. It is possible that changes of $\mathrm{D}_{2} / \mathrm{D}_{3}$ DA receptors number revealed in this work were mainly related with somatodendritic receptors.

The low number of somatodendric $\mathrm{D}_{2}$-like DA receptors in the caudate nucleus induces endogenous processes of dephosphorilation and enhancement of $\mathrm{GABA}_{\mathrm{A}}$ receptors activity in striatum, GP, and RTN (Figure 8) and is an endogenous cause for the increase of SWD activity in the corticothalamocortical network. The high number of somatodendric $\mathrm{D}_{2}$-like DA receptors in somatosensory cortex induce the endogenous processes of phosphorilation and decrease of $\mathrm{GABA}_{\mathrm{A}}$ receptors activity in somatosensory cortex, forming an endogenous cause for decreasing SWDs in the cortical focus, which supervises an oscillatory drive in the RTN [20]. Possibly, it assumes compensatory reaction from outside somatosensory cortex in relation to caudate nucleus. That is why in WAG/Rij a compensated deficiency of $\mathrm{D}_{2}$-like DA receptors is observed. But $\mathrm{D}_{2}$-like DA receptors antagonists' administration both in cortex and caudate nucleus enhances processes of dephosphorilation and $\mathrm{GABA}_{\mathrm{A}}$ receptors activity amplify, enlarging activity of SWDs.

A deficiency of mesolimbic (nAcb shell) DAergic activity at the level of somatodendritic $\mathrm{D}_{1}$-like DA receptors in WAG/Rij versus to ACI rats was found. At the same time a deficiency of nigrostriatal DAergic system in the head of caudate nucleus was caused by a reduction of $D_{1}$-like and $\mathrm{D}_{2}$-like DA receptors number. The deficiency of nigrostriatal DAergic system by reduction of $\mathrm{D}_{2}$-like DA receptors is at the bottom of an additional rising activity of SWDs. As $\mathrm{D}_{1}$-like DA receptors supervise a direct pathway from striatum which terminates on non epileptic nucleus of thalamus (Figure 8), to us, there is no reason to assume that the deficiency $D_{1}$-like 
DA receptors has an impact on the occurrence of activity of SWDs.

The deficiency of mesocorticolimbic DA systems corresponds to behavioral features of WAG/Rij rats. During active and passive avoidance a deficit of reinforcement in WAG/Rij rats has been revealed [332, 333] which was eliminated by administration of the DA precursor, or a low dose of disulfiram (Figures 9 and 10), inhibitor of dopamine- $\beta$ hydroxylase, by increase of DA concentration in brain [334]. Besides, it was shown that WAG/Rij rats have a higher level of depression than control Wistar rats without absence epilepsy $[50-52,379]$. Depression of WAG/Rij rats has a DAergic nature [311] and can be explained by a deficiency of the DA mesolimbic system. Behavioural changes and activity of the mesolimbic DAergic systems in WAG/Rij rats are influenced by activation of $D_{1}$ DA receptors in the shell of the $n A c b$ $[380,381]$ and prefrontal cortex $[382,383]$, the main sources of positive reinforcement. $\mathrm{D}_{2}$-like DA receptors are also involved in reinforcement [380, 381, 384, 385]. A link between modification of behavior and alternative splicing of $\mathrm{D}_{3} \mathrm{DA}$ receptor has been shown [386, 387]. The nAcb core [388] and neostriatum [381] are not involved in reinforcement. It is likely that $\mathrm{D}_{1}$ - and $\mathrm{D}_{2}$-like $\mathrm{DA}$ receptors in the nAcb may have more general influence on reinforced behavior [381].

The nigrostriatal DA system mediates behavioral reactions through the control of TC neuronal networks. The nAcb shell receives DAergic cellular innervations from the VTA; this part of the $\mathrm{nAcb}$ is connected with limbic system [268, 279]. The nAcb core receives glutamatergic inputs from the prefrontal cortex and thalamus, as well as from hippocampus and amygdala. There are direct and indirect projections from nAcb core to SNpr and VP in rats [304]. The projections from ventral striatum also pass to these structures. Thus, interaction of mesocorticolimbic and striatonigral DA systems at level of SNpr and VP controls thalamocortical networks through GABAergic system, behavioral reactions, and absence epileptic activity [21,304].

Despite a compensated deficit of DA system of WAG/Rij rats DA agonists and antagonists increase and decrease SWDs, respectively [32]. Similar results were obtained in the GAERS rats [389]. Intra-accumbal injections of DA agonists and antagonists produced increase and decrease of SWDs respectively [304]. Herewith the significant changes in the $\mathrm{nAcb}$ (upregulation of mRNA $\mathrm{D}_{3} \mathrm{DA}$ receptor) were revealed, although the levels of mRNA coding transporters or enzyme of DA synthesis did not differ from controls [390]. The changes of DAergic system in nAcb core in GAERS rats were slightly different than those received in WAG/Rij rats at present work. But the general orientation of the regulation of SWDs by DAergic in GAERS and WAG/Rij rats was the same. Therefore it is possible to admit that the mechanisms of DAergic regulation are also similar. It can be that upregulation of mRNA $\mathrm{D}_{3} \mathrm{DA}$ receptor in the nAcb also is a process of compensation.

Thus a deficiency in DA systems in WAG/Rij rats is described and is mediated by $\mathrm{D}_{1}$ - and $\mathrm{D}_{2}$-like DA receptors. Reduction of $\mathrm{D}_{1}$-like $\mathrm{DA}$ receptors number in the shell of the nAcb and in nucleus caudatus, reduction of $\mathrm{D}_{2}$ like DA receptors number in nucleus caudatus and increase of $\mathrm{D}_{2}$-like DA receptors number in motor, somatosensory, and parietal cortex. Reduction of $\mathrm{D}_{2}$-like $\mathrm{DA}$ receptors number in nucleus caudatus enhances the activity of $\mathrm{GABA}_{\mathrm{A}}$ receptors in striatum, GP, and RTN, causing a rise in SWDactivity in corticothalamocortical networks. High number of somatodendric $\mathrm{D}_{2}$-like DA receptors in somatosensory cortex inducing the endogenous processes of phosphorilation and decrease of $\mathrm{GABA}_{\mathrm{A}}$ receptors activity in somatosensory cortex, causing endogenous decrease of SWDs in cortical focus, which supervises an oscillatory source in the RTN. We assume that it reflects compensated deficiency of $\mathrm{D}_{2}$-like DA receptors of WAG/Rij rats. Despite process of compensation antagonists of $\mathrm{D}_{2}$-like $\mathrm{DA}$ receptors can raise activity $\mathrm{GABA}_{\mathrm{A}}$ receptors both in a somatosensory cortex and in the RTN, raising SWDs. Deficiency of WAG/Rij rats mesolimbic DA systems, caused by reduction $D_{1}$-like $D A$ receptors in the shell of the nAcb causes depression-like behavior of animals, weakens formation of emotional positive state, worsens processes of reinforcement, and counteracts learning and memory processes. Pharmacological intensification of DA systems takes out negative reaction of deficiency of mesolimbic DA system.

\subsubsection{Possible Mechanisms of Infringement of DA System} Function in Absence Epilepsy. The question arises, if absence epilepsy is related to disturbances or mutations of $\mathrm{GABA}_{\mathrm{A}}$ receptor and low-threshold T-type $\mathrm{Ca}^{2+}$ channel, then what is the role of DA receptors in it. Why is there a functional deficiency of these receptors? We suggest two mechanisms of infringement of the function of the DA system during absence epilepsy.

(1) $\mathrm{GABA}_{\mathrm{A}}$ receptors mediate trophic effectson embryonic brainstem monoamine neurons. GABA is present in the mammalian brain during early stages of development, where it may act as a trophic signal for developing neurons. In the embryonic rat, GABA axons project through the brainstem when 5-HT, DA, and NA neurons are being generated [391-394]. This raises the possibility that GABA exert trophic influences on developing monoamine neurons, if they express appropriate receptors. In adult rat brain, these neurons do express functional $\mathrm{GABA}_{\mathrm{A}}$ receptors [395-397]. The initial disruption of $\mathrm{GABA}_{\mathrm{A}}$ receptor disrupts trophic influences on developing monoamine neurons and induces pathological changes in monoaminergic systems in adult animals.

(2) Intraneuronal integration triggered by a transduction signal. We believe that infringement of the function of the DA system by intraneuronal integration triggered by transduction signal occurs in the brain, especially in structures in which there are no DA neurons, but DA terminals, such as cortex, striatum, GP, thalamus, nucleus nAcb, and so on.

5.2.4. Intraneuronal Integration Triggered by Transduction Signal. Earlier it has been shown [165] that the development of pentylenetetrazole (PTZ) kindling (4-month-old 
animals) is accompanied by $20 \%$ reduction of the density $\left(B_{\max }\right)$ of $\mathrm{GABA}_{\mathrm{A}}$ receptor benzodiazepine (BDZ) sites. In 10 -month animals, kindling reduced densities of the $\mathrm{BDZ}$ site of $\mathrm{GABA}_{\mathrm{A}}$ receptor by $50 \%$. Acute administration of a subconvulsive dose of PTZ in the rats at 10 months of age that were kindled at 4 month induces convulsive seizures and densities of $\mathrm{GABA}_{\mathrm{A}}$ receptor $\mathrm{BDZ}$ site $\left(B_{\max }\right)$ to $20 \%$ of control rats. The results suggest that the density of the $\mathrm{BDZ}$ site at the $\mathrm{GABA}_{\mathrm{A}}$ receptors is reproduced at a level of receptor molecule density independent of their current status and age. The increased density of $\mathrm{BDZ}$ site of $\mathrm{GABA}_{\mathrm{A}}$ receptors in kindled versus control rats can be interpreted as an enhancement of GABAergic inhibition, while it is thought that seizures are based on the process of neuronal hyperactivation accompanied by a reduction in the $\mathrm{BDZ}$ site density both in kindling-induced and single-dose PTZinduced seizures [165]. Therefore, it is likely that at 10 months, when seizures are retrieved by aTZ challenge and the level of GABAergic inhibition is restored, the level of glutamate receptors may also be restored, assuming that they were modified and consolidated in the process of kindling 6 months ago. The level of glutamate receptors may only be restored if neuronal GABA and glutamate receptors interact within a single integrated system interconnected through an intracellular transduction signal.

The interaction and integration of neuronal GABA and glutamate receptors have been shown in several studies. A reduction in GABAergic functions in PTZ-induced kindling is blocked by MK-801, an antagonist of NMDA receptors [162]. NMDA receptors are also involved in the process of kindling induced by FG 7142, an inverse agonist of the $\mathrm{BDZ}$ receptor [398]. Kindling produced by high-frequency hippocampal stimulation induces an enhancement of NMDA receptors [399] as well as modification of $\mathrm{GABA}_{\mathrm{A}}$ receptors [400]. Also, the NMDA-induced LTP is found to be controlled by the intercellular metabolic systems of the $\mathrm{GABA}_{\mathrm{A}}$ receptor complex, being inhibited by agonists acting at the BDZ site [401, 402] and facilitated by its antagonists [403, 404]. Conversely, the NMDA antagonist CPP can modulate the long-term modification (tolerance) of $\mathrm{BDZ}$ receptors [405]. Positive allosteric activation of $\mathrm{GABA}_{\mathrm{A}}$ receptors bidirectionally modulates hippocampal glutamate plasticity and behavior [406]. Finally, BDZ withdrawal anxiety is associated with potentiation of AMPA receptor currents in hippocampal CA1 pyramidal neurons attributable to increased synaptic incorporation of GluAl-containing AMPA receptors [407].

The $\mathrm{BDZ}$ site is one of the metabolic sites of the $\mathrm{GABA}_{\mathrm{A}}$ supramolecular receptor complex [408-412] which is subject to long-term modifications $[165,400,413]$. The next of the $\mathrm{GABA}_{\mathrm{A}}$ receptor metabolic site is the neuroactive steroids site [116, 414]. LTP and LTD, like any long-term processes, are maintained by modifications of gene expression [399, 400, 415-418]. BDZ site, acting via the second messengers system and protein kinase $\mathrm{C}$, can induce slow metabolic reactions in the cell and modify gene expression in various structures of rat brain $[105,408,410,419]$. $\mathrm{GABA}_{\mathrm{A}}$ receptors are known to be regulated by phosphorilation mediated by protein kinase C and G [272, 273, 420-422]. Substrate for phosphorilation and dephosphorilation of $\mathrm{GABA}_{\mathrm{A}}$ receptor is the intracellular loop between the 3rd and 4th domain [204, 423, 424].

As indicated above, changes in cellular phosphorilation levels by protein kinases can modify glutamatergic receptors [162, 398, 399, 401-405], augmenting their responses to endogenous excitatory amino acids. The prospective scheme of this intracellular interaction is presented in Figure 11. The metabolic regulation of glutamatergic synapses (Figure 11) is described as a regulation of AMPA receptors by NMDA receptors. Control of AMPA receptor by NMDA receptor is described by plasticity in glutamatergic synapses of hippocampus, striatum, and cortex [273, 425]. We added a feedback loop for the regulation of AMPA receptors by NMDA receptors as it is repeatedly described in studies of the synthesis and trafficking of AMPA receptors subunit to the plasmatic membrane [426-428]. The regulation of AMPA receptors and autoregulation of NMDA receptors in the hippocampus, striatum and cortex have been studied experimentally $[427,429,430]$. The autoregulation of $\mathrm{GABA}_{\mathrm{A}}$ receptors is also well described in investigations of synthesis and trafficking of $\mathrm{GABA}_{\mathrm{A}}$ receptors subunit to the plasmatic membrane [204, 431-433].

Thus, one can assume that plasticity is a result of cooperative activity of GABA and glutamatergic receptors integrated into interrelated system. Integration includes also the automodification of the activity or receptors. Furthermore, a new level of activity, produced by secondary intranuclear signals, modifies the gene expression and consolidates the newly developed activity of receptors.

Functional interactions of the striatal glutamate and DA receptors in learning and memory [279, 305, 306, 434, 435], and postsynaptic integration of glutamatergic and DA signals in the striatum based on interactions of intracellular second messengers [272, 273, 279, 436-438] have been reported. The $\mathrm{D}_{4}$ receptor activation increases cofilin activity, causing a decrease in the myosin-based transport of $\mathrm{GABA}_{\mathrm{A}}$ receptors clusters to the surface in the prefrontal cortex [439]. It has been shown [440] that the induction of LTD by low frequency stimulation in hippocampal $\mathrm{CA}_{1}$ neurons is under the influence of both NMDA and GABA receptors; both $\mathrm{D}_{1}$ and $\mathrm{D}_{2}$ receptors are involved in the modulation of LTD (activation of $\mathrm{D}_{1}$ receptors enhances LTD, activation of $\mathrm{D}_{2}$ receptors inhibits it) and the induction of LTD is blocked by picrotoxin, this effect is superseded by $D_{1}$ receptors agonist SKF-38393. Our results [441] also point to synergistic interactions of $\mathrm{GABA}_{\mathrm{A}}$ and DA receptors in memory retrieval.

The intracellular integration by transduction signal of glutamate, $\mathrm{GABA}_{\mathrm{A}}$ and DA receptors is schematically shown in Figure 11. DA receptors can undergo automodification by the metabolic feedback loop and then modify the activity of glutamate and $\mathrm{GABA}_{\mathrm{A}}$ receptors by intracellular phosphorilation $[272,273]$. Via the same reactions of intracellular phosphorilation, glutamate and $\mathrm{GABA}_{\mathrm{A}}$ receptors can control the efficiency of DA receptors. At the second stage, the modifications established at the first stage are consolidated through the modification of expression of the respective genes. The ability of DA receptors to undergo automodifications has been demonstrated both at the level of radioligand binding and at the level of gene expression in 


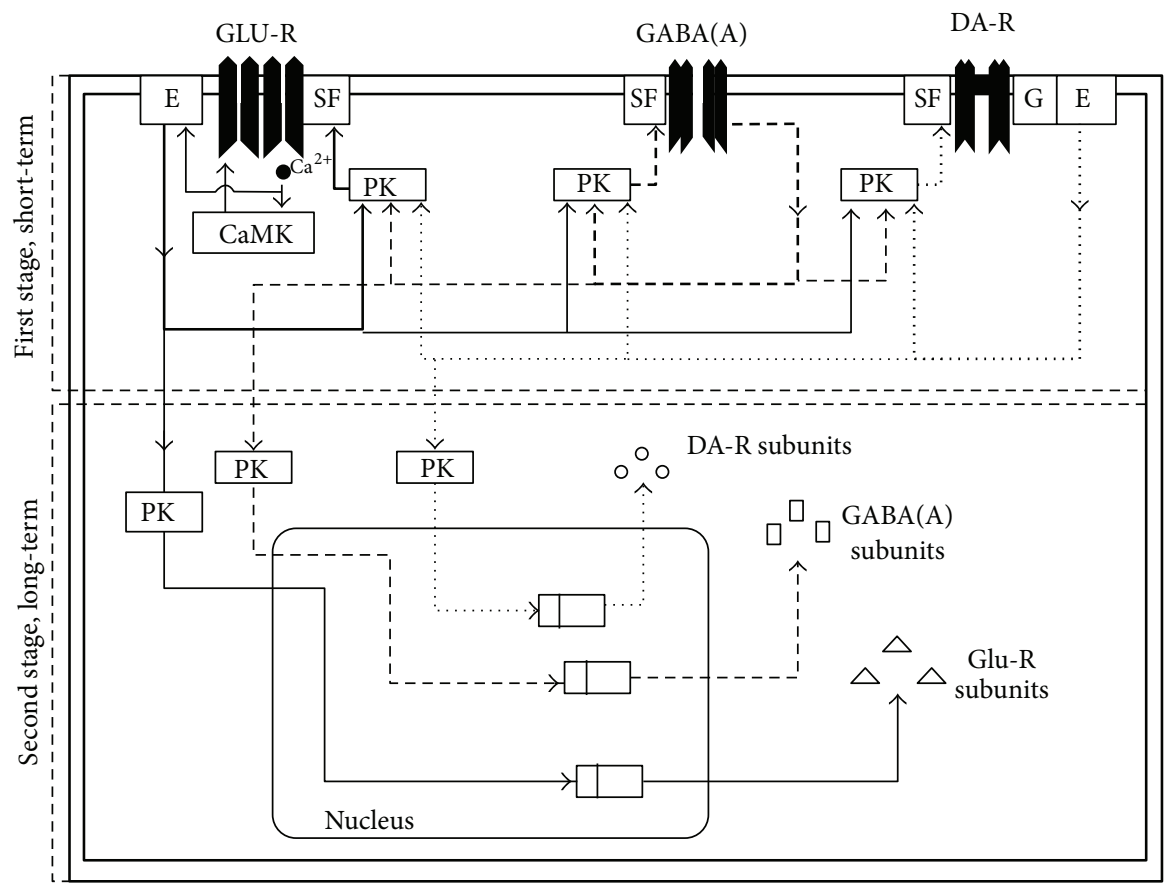

FIGURE 11: A tentative model of intraneuronal integration triggered by transduction signal. GLU-R: glutamatergic receptors; GABA(A), $\mathrm{GABA}_{\mathrm{A}}$ receptor; DA-R: dopamine receptor; E: second messenger synthesizing enzyme; SF: phosphorilation substrate; G: G-protein, PK: different type of protein kinases; CaMK: calcium/calmodulin-dependent protein kinase. Metabolic reactions mediated by glutamatergic receptors are shown as solid lines. Metabolic reactions mediated by $\mathrm{GABA}_{\mathrm{A}}$ receptor are shown as dashed lines. Metabolic reactions mediated by dopamine receptors are shown as dotted lines. Intracellular metabolic feedback loops (autoregulation) are shown as the respective thick lines. For other details, see text.

various brain structures and various experimental procedures [319, 442-447].

We suggest that diminished activity of DA receptors and DA system deficit occur due to disruption of intracellular integration triggered by a transduction signal (Figure 11). In the first place the initial disruption of $\mathrm{GABA}_{\mathrm{A}}$ receptor activity disrupts the transduction signal from this receptor. Disruption of transduction signal shapes the modification of other receptors and their activity. In the second place the disrupted activity of receptors is consolidated and stored by expression of genes. It should be noted that we did not see changes of DA concentrations in the structures that we investigated, but we could see changes in receptor activity and consequences of receptors activity. So, a process of intracellular integration may disrupt activity of other neurotransmitter and neuromodulatory systems, for instance the activity of the opioid system that is disrupted in WAG/Rij rats [351-356].

If the first possible mechanism of infringement of the function of the DA system, mediation of trophic factor by $\mathrm{GABA}_{\mathrm{A}}$ receptors, operates during a limited time period corresponding to the period of embryonic development, the second mechanism, intraneuronal integration triggered by transduction signal, operates during the whole life and, possibly, collects as a snow clot.

\section{Conclusions}

The hyperpolarization-activated and cAMP-modulated HCN channels contribute to direct rhythmic activation in the brain. Four isoforms of this channel are known: HCN1-HCN4. $\mathrm{HCN}$ channels resemble voltage-dependent $\mathrm{K}^{+}$channels; they are tetrameric and consist of monomeric subunits, each containing six transmembrane domains (S1-S6) with a Ploop that forms a pore between the S5 and S6 domains. Different HCN subunits may be connected and form a heteromultimeric complex, thus significantly increasing the diversity of $I_{\mathrm{h}}$ channels. The HCN1 channel has a minimal response to cAMP binding $(+4 \mathrm{mV})$ with a cAMP-binding domain, whereas the HCN2 channel has a clear response $(+17 \mathrm{mV})$. The coexpression of HCN1 and HCN2 with heteromultimeric channel formation leads to $I_{\mathrm{h}}$ currents, which tend to possess functional properties intermediate between HCN1 and HCN2 homomeric channels. Experimental data suggest that the $I_{\mathrm{h}}$ channel and the low-threshold T-type $\mathrm{Ca}^{2+}$ channel $\left(I_{\mathrm{Ca}, \mathrm{T}}\right)$ work in tandem. Hyperpolarization opens the $I_{\mathrm{h}}$ channel and a cationic current depolarizes the membrane to the threshold and induces a spike. Hyperpolarization also opens the $\left(I_{\mathrm{Ca}, \mathrm{T}}\right)$ channel. The $\mathrm{Ca}^{2+}$ ions that enter the cell induce $\mathrm{Ca}^{2+}$-dependent cAMP synthesis and cAMP dramatically increases channel activity through binding to 
the CNBD locus of HCN subunits. The HCN1 subunit reacts weakly to $\mathrm{CAMP}$ binding; therefore, the decrease in the proportion of HCN1 subunits in the channel increases pacemaker activity and an increase in the proportion of HCN1 subunits in the channel decreases pacemaker activity. Analysis of the experimental data shows that one of the basic mechanisms for the long-term regulation of $I_{\mathrm{h}}$ pacemaker activity is the modification of the number of HCN1 subunits in the pacemaker channel. It has been assumed that the source of SWDs is the $I_{\mathrm{h}}$ pacemaker channel that is localized at pyramidal cells in the perioral region of the somatosensory cortex (in WAG/Rij rats), more specifically layers III-VI. This part of the cortex is fully integrated in a corticothalamocortical circuit, which intactness is obligatory for the full expression of the bilateral generalized SWDs. The RTN is part of this circuitry, it has also pacemaker properties, and it generates sleep spindles.

The density of a subtype of HCN channels (HCN1) in the apical dendrites of the subgranular layers in this onset zone determines the somatodendritic excitability and a decrease of these dendritic HCN1 channels neurons increases the occurrence of absences. Also in the thalamus HCN channels are involved in burst firing typical for delta activity. Burst firing of TC-cells is, however, rare during SWDs; it occurs in only $7 \%$ of the TC cells although it cannot be excluded that this a necessary condition for SWD occurrence. Burst firing is caused by tandem hyperpolarization of $I_{\mathrm{h}}$ and $\left(I_{\mathrm{Ca}, \mathrm{T}}\right)$ channels.

Pharmacological observations supported this point of view since activation of GABAergic system through $\mathrm{GABA}_{\mathrm{A}}$, $\mathrm{GABA}_{\mathrm{B}}$ receptors and inhibition of GABA inactivation in the synaptic cleft all leads to unequivocal result, intensification of SWD activity. However, the measurements of the efficiency of GABAergic system lead to diverse results. There might be three reasons for this. First, different models of absence epilepsy such as GAERS and WAG/Rij rats, various types of mice with spontaneous mutations, and knock-out lines have been used. It is possible that in these different models, various mechanisms of GABAergic system deficiency are present. The second reason of occurrence of the variety of results is the so-called process of uncertainty of the central nervous system. The analysis of several works has shown that an increase or decrease of the general activity of the transmission system in different animals can be achieved in different ways and depends on specific features of these animals. The third reason of occurrence of diverse results can be processes of indemnification. Strengthening of conductivity of chlorine through $\mathrm{GABA}_{\mathrm{A}}$ receptors as found in WAG/Rij rats can be considered as a compensation for the failure of inhibition of GABAergic systems.

One of the reasons for the occurrence of absence epilepsy is the mutation of several genes coding for $\mathrm{GABA}_{\mathrm{A}}$ receptors which cause abnormal functioning of GABAergic system. Such abnormal functioning of the GABAergic system and mutations of $\left(I_{\mathrm{Ca}, \mathrm{T}}\right)$ channel, which functions in tandem with $I_{\mathrm{h}}$ channel, can contribute to the occurrence of SWDs in the EEG.

However, SWDs during absence epilepsy may also be enhanced by the activation of the glutamate ionotropic and metabotropic excitatory system. Agonists of three type's ionotropic excitatory glutamate receptors AMPA, kainate and NMDA enhance SWDs; antagonists of these receptors reduce SWDs. It is known from classical neurophysiology that intensification of depolarization enlarges the frequency of action potential discharges. The metabotropic glutamatergic receptors also control SWDs, strengthening or controlling them, dependent on their location within the corticothalamocortical network. Various changes in number of receptors were identified within the network. Indeed some mGluR's enhance SWDs, while mGlul and mGlu5 receptor agonists and especially the positive allosteric modulators of Group I receptors might be good candidates to control absence seizures.

Deficiencies in DA systems in WAG/Rij rats were revealed. They are mediated by $\mathrm{D}_{1}$ - and $\mathrm{D}_{2}$-like DA receptors. Reduction of the number of $\mathrm{D}_{1}$-like $\mathrm{DA}$ receptors in the shell of the nucleus nAcb and in the nucleus caudatus, and a reduction of $\mathrm{D}_{2}$-like DA receptors number in nucleus caudatus and increase of $\mathrm{D}_{2}$-like $\mathrm{DA}$ receptors number in motor, somatosensory, and parietal cortex. Reduction of $\mathrm{D}_{2}$ like DA receptors number in nucleus caudatus causes an enhancement of $\mathrm{GABA}_{\mathrm{A}}$ receptor activity in the striatum, GP, and RTN; they are responsible for sleep spindle generation and other rhythmic activity in TC networks. High number of somatodendric $\mathrm{D}_{2}$-like DA receptors in somatosensory cortex inducing the endogenous processes of phosphorilation and decrease of $\mathrm{GABA}_{\mathrm{A}}$ receptors activity in somatosensory cortex, causing endogenous decreasing of SWD activity in the cortical focus, which might trigger and entrain thalamic rhythmic firing and oscillations in the form of SWDs. We assume that the enhanced $\mathrm{D}_{2}$-like $\mathrm{DA}$ receptors reflect a compensated deficiency. Despite process of compensation, antagonists of $\mathrm{D}_{2}$-like $\mathrm{DA}$ receptors can raise activity $\mathrm{GABA}_{\mathrm{A}}$ receptors both in a somatosensory cortex and in the RTN, raising SWDs. Deficiency of WAG/Rij rats mesolimbic DA systems, caused by reduction $\mathrm{D}_{1}$-like $\mathrm{DA}$ receptors in the shell of the nucleus nAcb, causes depression-like behavior in animals, weakens the formation of emotional positive state, worsens processes of reinforcement and counteracts learning and memory processes. A pharmacological increase of the DA system removes the negative consequences of the deficiency of mesolimbic DA system.

The question arises, if absence epilepsy is due to disturbances or mutations of $\mathrm{GABA}_{\mathrm{A}}$ receptors and low-threshold T-type $\mathrm{Ca}^{2+}$ channel what is the role of DA receptors in it. Why is there a functional deficiency of these receptors? We propose two mechanisms of infringement of the function of the DA system during absence epilepsy.

(1) Intraneuronal integration is triggered by a transduction signal. We believe that the infringement of the function of the DA system by intraneuronal integration triggered by transduction signal is carried out in the brain, especially in structures in which there are no DA neurons, but DA terminals are present such as cortex, striatum, GP, thalamus, and nucleus nAcb.

We suggest that diminished activity of DA receptors and DA system deficits occur due to disruption of intracellular 
integration triggered by a transduction signal. The initial disruption of $\mathrm{GABA}_{\mathrm{A}}$ receptor activity disrupts the transduction signal of this receptor in the first stage. Disruption of the transduction signal changes and modifies other receptors and their activity. On the second stage the disrupted activity of receptors is consolidated and stored by the expression of genes. It should be noted that we did not see changes of DA concentrations in structures investigated, but we could see the changes of receptors activity. So, a process of intracellular integration may disrupt activity of other neurotransmitter and neuromodulatory systems, for instance the activity of the opioid system is disrupted in WAG/Rij rats.

(2) $\mathrm{GABA}_{\mathrm{A}}$ receptors mediate trophic effectson embryonic brainstem monoamine neurons. GABA is present in the mammalian brain during early stages of development, where it may act as a trophic signal for developing neurons. In the embryonic rat, GABA axons project through the brainstem when 5-HT, DA, and NA neurons are being generated. This raises the possibility that GABA could exert trophic influences on developing monoamine neurons, if they express the appropriate receptors. In adult rat brain, these neurons do express functional $\mathrm{GABA}_{\mathrm{A}}$ receptors. The initial disruption of $\mathrm{GABA}_{\mathrm{A}}$ receptor disrupts the trophic influences on developing monoamine neurons and induces pathological changes in monoaminergic systems of adult animals.

The first possible mechanism, intraneuronal integration triggered by transduction signal, operates during the whole life and, possibly, collects as a snow clod. The second mechanism, the infringement of the DA system's function on absence epilepsy and the mediation of trophic factor by $\mathrm{GABA}_{\mathrm{A}}$ receptors, operates during a limited period of time corresponding to the period of embryonic development.

\section{Abbreviations}

ACI rats: Agouti Copenhague Irish rats

AMPA: 2-Amino-3-[3-hydroxy-5methylisoxazol-4-yl] propionic acid

APH: 2-Amino-7-phosphonoheptanoic acid

BDZ: Benzodiazepine

cAMP: Cyclic adenosine mono phosphate

AY-9944: Cholesterol synthesis inhibitor Ayerst-9944

CCK: Cholecystokinin

CBZ: Carbamazepine

CD: Cyclodextrin

CFM-2: 1-[4-Aminophenyl]-3,5-dihydro-7,8dimethoxy-4H-2,3-benzodiazepin-4-one

CNBD: Cyclic nucleotide-binding domain

CNQX: 6-Cyano-7-nitroquinoxaline-2,3-dione

COMP: Catechol-O-methyltransferase

CREB: cAMP-responsive element binding protein

$\mathrm{CS}^{+}: \quad$ Cesium
Cys: Cysteine

DARPP-32/PP-1: Dopamine and cyclic adenosine $3^{\prime}, 5^{\prime}$-monophosphate-regulated phosphoprotein, $32 \mathrm{kDa}$ /phosphoprotein-1

DOPAC: 3,4-Dihydroxyphenylacetic acid

DS:

EEG:

GABA:

GABRA1: Autosomal dominant

Electroencephalogram

Gamma-aminobutyric acid

GABRB3: The gene encoding the beta 3 subunit of the $\mathrm{GABA}_{\mathrm{A}}$ receptor

GABRG2: The gene encoding the gamma 2 subunit of the $\mathrm{GABA}_{\mathrm{A}}$ receptor

GABRD: The gene encoding the sigma subunit of the $\mathrm{GABA}_{\mathrm{A}}$ receptor

GAD:

GAERS:

Glutamic acid decarboxylase

GAT-1:

GAT-2:

GDEE:

GHBA:

GHB:

GHBL:

GIRK:

GPe:

GPi:

GYG:

Genetic absence epilepsy rats from

Strasburg

Glutamic acid transporter-1

Glutamic acid transporter-2

Glutamate diethyl ester

Gamma-hydroxybutyric acid

Gamma-hydroxybutyrate

Gamma-hydroxybutyrolactone

$G$ protein-gated inwardly rectifying $\mathrm{K}^{+}$

Globus pallidus external

Globus pallidus internal

GYKI 52466: 1-[4-Aminophenyl]-4-methyl-7,8methylenedioxy-5H-2,3-benzodiazepine

GYKI 53405: 7-Acetyl-5-[4-aminophenyl]-8-methyl8,9-dihydro-7H-1,3-dioxolo $[4,5-b][2,3]$ benzodiazepine

GVG:

$\mathrm{HCN}$ :

HPLC:

5-HT:

HVA:

Ih/Ih:

IPSP:

L-DOPA:

LGNd:

LTP:

LTD:

MAO:

mIPSC:

nAcb:

NA:

NCSE:

NMDA:

NO:

PCR:

PKA:
Gamma-vinyl GABA

Hyperpolarization-activated and cyclic nucleotide-gated

High performance liquid

chromatography

5-Hydroxytryptamine [serotonin]

Homovanillic acid

Mutant mice

Inhibitory post synaptic potential

L-dihydroxyphenylalanine

Dorsal part of the lateral geniculate nucleus

Long-term potentiation

Long-term depression

Monoamine oxidase

Miniature inhibitory post synaptic

current

Nucleus accumbens

Noradrenalin

Nonconvulsive status epilepticus

$\mathrm{N}$-methyl-D-aspartate

Nitric oxide

Polymerase chain reaction

Protein kinase A 


$\begin{array}{ll}\text { PP-1: } & \text { Phosphoprotein-1 } \\ \text { PP-2B: } & \text { Phosphoprotein-2B } \\ \text { PTx: } & \text { Pertussis toxin } \\ \text { PTZ: } & \text { Pentylenetetrazole } \\ \text { RRF: } & \text { Retrorubral field } \\ \text { RTN: } & \text { Reticular thalamic nucleus } \\ \text { SNpc: } & \text { Substantia nigra pars compacta } \\ \text { stg: } & \text { Stargazer } \\ \text { STN: } & \text { Subthalamic nucleus } \\ \text { SWDs: } & \text { Spike-wave discharges } \\ \text { TBPS: } & \text { T-butylbicyclophosphorothionate } \\ \text { THIQ-10c: } & \text { N-acetyl-1-[4-chlorophenyl]-6,7- } \\ & \text { dimethoxy-1,2,3,4- } \\ & \text { tetrahydroisoquinoline } \\ \text { THIP: } & \text { 4,5,6,7-Tetrahydroisooxazolo(5,4-c) } \\ & \text { pyridin-3-ol } \\ \text { Thr-34: } & \text { Threonine in the position 34 } \\ \text { VB: } & \text { Ventrobasal thalamus } \\ \text { VIP: } & \text { Vasoactive intestinal peptide } \\ \text { VP: } & \text { Ventral posterior nucleus } \\ \text { WAG/Rij: } & \text { Wistar Albino Glaxo, originating from } \\ & \text { Rijswijk } \\ \text { ZD 7288: } & \text { Non-selective } I_{\mathrm{h}} \text { channel blocker. }\end{array}$

\section{Acknowledgment}

The authors want to acknowledge the value of discussions with Dr. Maarten Kole and the contribution of MSc Nicole Tillmanns.

\section{References}

[1] A. M. L. Coenen, E. H. M. Blezer, and E. L. J. M. van Luijtelaar, "Effects of the GABA-uptake inhibitor tiagabine on electroencephalogram, spike-wave discharges and behaviour of rats," Epilepsy Research, vol. 21, no. 2, pp. 89-94, 1995.

[2] D. A. Hosford and Y. Wang, "Utility of the lethargic (lh/lh) mouse model of absence seizures in predicting the effects of lamotrigine, vigabatrin, tiagabine, gabapentin, and topiramate against human absence seizures," Epilepsia, vol. 38, no. 4, pp. 408-414, 1997.

[3] M. Z. Gören and F. Onat, "Ethosuximide: from bench to bedside," CNS Drug Reviews, vol. 13, no. 2, pp. 224-239, 2007.

[4] M. Inoue, J. Duysens, J. M. H. Vossen, and A. M. L. Coenen, "Thalamic multiple-unit activity underlying spike-wave discharges in anesthetized rats," Brain Research, vol. 612, no. 1-2, pp. 35-40, 1993.

[5] T. Seidenbecher, R. Staak, and H. C. Pape, "Relations between cortical and thalamic cellular activities during absence seizures in rats," European Journal of Neuroscience, vol. 10, no. 3, pp. 11031112,1998

[6] H. K. M. Meeren, J. P. M. Pijn, E. L. J. M. van Luijtelaar, A. M. L. Coenen, and F. H. L. da Silva, "Cortical focus drives widespread corticothalamic networks during spontaneous absence seizures in rats," Journal of Neuroscience, vol. 22, no. 4, pp. 1480-1495, 2002.

[7] H. Meeren, G. van Luijtelaar, F. L. da Silva, and A. Coenen, "Evolving concepts on the pathophysiology of absence seizures: the cortical focus theory," Archives of Neurology, vol. 62, no. 3, pp. 371-376, 2005.
[8] A. A. Gurbanova, R. Aker, K. Berkman, F. Y. Onat, C. M. van Rijn, and G. van Luijtelaar, "Effect of systemic and intracortical administration of phenytoin in two genetic models of absence epilepsy," The British Journal of Pharmacology, vol. 148, no. 8, pp. 1076-1082, 2006.

[9] G. van Luijtelaar and E. Sitnikova, "Global and focal aspects of absence epilepsy: the contribution of genetic models," Neuroscience and Biobehavioral Reviews, vol. 30, no. 7, pp. 983-1003, 2006.

[10] G. van Luijtelaar, E. Sitnikova, and A. Lüttjohann, "On the origin and suddenness of absences in genetic absence models," Clinical EEG and Neuroscience, vol. 42, no. 2, pp. 83-97, 2011.

[11] A. Lüttjohann, S. Zhang, R. de Peijper, and G. van Luijtelaar, "Electrical stimulation of the epileptic focus in absence epileptic WAG/Rij rats: assessment of local and network excitability," Neuroscience, vol. 188, pp. 125-134, 2011.

[12] A. Lüttjohann and G. van Luijtelaar, "The dynamics of corticothalamo-cortical interactions at the transition from pre-ictal to ictal LFPs in absence epilepsy," Neurobiology of Disease, vol. 47, no. 1, pp. 49-60, 2012.

[13] D. Pinault, "Cellular interactions in the rat somatosensory thalamocortical system during normal epileptic 5-9 Hz oscillations," Journal of Physiology, vol. 552, part 3, pp. 881-905, 2003.

[14] P. O. Polack, I. Guillemain, E. Hu, C. Deransart, A. Depaulis, and S. Charpier, "Deep layer somatosensory cortical neurons initiate spike-and-wave discharges in a genetic model of absence seizures," Journal of Neuroscience, vol. 27, no. 24, pp. 6590-6599, 2007.

[15] L. Danober, C. Deransart, A. Depaulis, M. Vergnes, and C. Marescaux, "Pathophysiological mechanisms of genetic absence epilepsy in the rat," Progress in Neurobiology, vol. 55, no. 1, pp. 27-57, 1998.

[16] A. Depaulis and G. van Luijtelaar, "Genetic models of absence epilepsy in the rat," in Models of Seizures and Epilepsy, A. Pitkanen, P. A. Schwartzskroin, and S. L. Moshe, Eds., pp. 233248, Elsevier/Academic Press, San Diego, Calif, USA, 2006.

[17] J. P. Manning, D. A. Richards, N. Leresche, V. Crunelli, and N. G. Bowery, "Cortical-area specific block of genetically determined absence seizures by ethosuximide," Neuroscience, vol. 123, no. 1, pp. 5-9, 2004.

[18] S. D. Chen, K. H. Yeh, Y. H. Huang, and F. Z. Shaw, "Effect of intracranial administration of ethosuximide in rats with spontaneous or pentylenetetrazol-induced spike-wave discharges," Epilepsia, vol. 52, no. 7, pp. 1311-1318, 2011.

[19] M. Steriade and R. R. Llinas, "The functional states of the thalamus and the associated neuronal interplay," Physiological Reviews, vol. 68, no. 3, pp. 649-742, 1988.

[20] H. K. M. Meeren, J. G. Veening, T. A. E. Möderscheim, A. M. L. Coenen, and G. van Luijtelaar, "Thalamic lesions in a genetic rat model of absence epilepsy: dissociation between spike-wave discharges and sleep spindles," Experimental Neurology, vol. 217, no. 1, pp. 25-37, 2009.

[21] G. Buzsaki, A. Smith, S. Berger, L. J. Fisher, and F. H. Gage, "Petit mal epilepsy and parkinsonian tremor: hypothesis of a common pacemaker," Neuroscience, vol. 36, no. 1, pp. 1-14, 1990.

[22] R. Staak and H. C. Pape, "Contribution of $G_{A B A}$ and $G_{A B A}$ receptors to thalamic neuronal activity during spontaneous absence seizures in rats," Journal of Neuroscience, vol. 21, no. 4, pp. 1378-1384, 2001.

[23] P. O. Polack, S. Mahon, M. Chavez, and S. Charpier, "Inactivation of the somatosensory cortex prevents paroxysmal 
oscillations in cortical and related thalamic neurons in a genetic model of absence epilepsy," Cerebral Cortex, vol. 19, no. 9, pp. 2078-2091, 2009.

[24] M. D. Holmes, M. Brown, and D. M. Tucker, "Are "generalized" seizures truly generalized? Evidence of localized mesial frontal and frontopolar discharges in absence," Epilepsia, vol. 45, no. 12, pp. 1568-1579, 2004.

[25] D. M. Tucker, M. Brown, P. Luu, and M. D. Holmes, "Discharges in ventromedial frontal cortex during absence spells," Epilepsy and Behavior, vol. 11, no. 4, pp. 546-557, 2007.

[26] F. Amor, S. Baillet, V. Navarro, C. Adam, J. Martinerie, and M. le van Quyen, "Cortical local and long-range synchronization interplay in human absence seizure initiation," NeuroImage, vol. 45, no. 3, pp. 950-962, 2009.

[27] I. Westmijse, P. Ossenblok, B. Gunning, and G. van Luijtelaar, "Onset and propagation of spike and slow wave discharges in human absence epilepsy: a MEG study," Epilepsia, vol. 50, no. 12, pp. 2538-2548, 2009.

[28] D. Gupta, P. Ossenblok, and G. van Luijtelaar, "Space-time network connectivity and cortical activations preceding spike wave discharges in human absence epilepsy: a MEG study," Medical and Biological Engineering and Computing, vol. 49, no. 5, pp. 555-565, 2011.

[29] P. Ossenblok, P. van de Houdt, A. Lüttjohann, and G. van Luijtelaar, "Network analysis of generalized epileptic discharges 5th workshop on Seizure prediction," accepted, 2013.

[30] A. S. Bazyan and O. L. Segal, "Hyperpolarization-activated $I_{\mathrm{h}}$ pacemaker channel in the mammalian brain," Neurochemical Journal, vol. 4, no. 4, pp. 241-251, 2010.

[31] E. L. J. M. van Luijtelaar and A. M. L. Coenen, "Two types of electrocortical paroxysms in an inbred strain of rats," Neuroscience Letters, vol. 70, no. 3, pp. 393-397, 1986.

[32] I. S. Midzianovskaia, G. D. Kuznetsova, A. M. L. Coenen, A. M. Spiridonov, and E. L. J. M. van Luijtelaar, "Electrophysiological and pharmacological characteristics of two types of spike-wave discharges in WAG/Rij rats," Brain Research, vol. 911, no. 1, pp. 62-70, 2001.

[33] V. Crunelli and N. Leresche, "Childhood absence epilepsy: genes, channels, neurons and networks," Nature Reviews Neuroscience, vol. 3, no. 5, pp. 371-382, 2002.

[34] A. M. L. Coenen and E. L. J. M. van Luijtelaar, "Genetic animal models for absence epilepsy: a review of the WAG/Rij strain of rats," Behavior Genetics, vol. 33, no. 6, pp. 635-655, 2003.

[35] D. L. Burgess, "Transgenic and gene replacement models of epilepsy: targeting ion channel and pathways in mice," in Models of Seizures and Epilepsy, A. Pitkanen, P. A. Schwartzkroin, and S. L. Moshe, Eds., pp. 199-222, Elsevier Academic Press, San Diego, Calif, USA, 2006.

[36] J. L. Noebels, "Spontaneous epileptic mutations in the mouse," in Models of Seizures and Epilepsy, A. Pitkanen, P. A. Schwartzkroin, and S. L. Moshe, Eds., pp. 223-232, Elsevier/Academic Press, San Diego, Calif, USA, 2006.

[37] V. Santucci, M. Fournier, and P. Keane, "EEG effects of IV infusion of pentylenetetrazol in rats: a model for screening and classifying antiepileptic compounds," Psychopharmacology, vol. 87, no. 3, pp. 337-343, 1985.

[38] M. A. Cortez, C. McKerlie, and O. C. Snead III, "A model of atypical absence seizures: EEG, pharmacology, and developmental characterization," Neurology, vol. 56, no. 3, pp. 341-349, 2001.
[39] M. A. Cortez and O. C. Snead III, "Pharmacological models of generalized absence seizures in rodents," in Models of Seizures and Epilepsy, M. Pitkanen, P. Schwartzkroin, and S. Moshé, Eds., pp. 111-126, Elsevier/Academic Press, San Diego, Calif, USA, 2006.

[40] I. Serbanescu, M. A. Cortez, C. McKerlie, and O. C. Snead III, "Refractory atypical absence seizures in rat: a two hit model," Epilepsy Research, vol. 62, no. 1, pp. 53-63, 2004.

[41] F. Y. Onat, G. van Luijtelaar, A. Nehlig, and O. Carter Snead III, "The involvement of limbic structures in typical and atypical Absence Epilepsy," Epilepsy Research, vol. 103, no. 2-3, pp. 111123, 2013.

[42] G. van Luijtelaar and A. M. Coenen, "Genetic models of absence epilepsy," in Encyclopedia of Basic Epilepsy Research, P. Schwartzkroin, Ed., vol. 1, pp. 1-8, Academic Press, Oxford, UK, 2009.

[43] T. Broicher, T. Kanyshkova, P. Meuth, H. C. Pape, and T. Budde, "Correlation of T-channel coding gene expression, IT, and the low threshold $\mathrm{Ca}^{2+}$ spike in the thalamus of a rat model of absence epilepsy," Molecular and Cellular Neuroscience, vol. 39, no. 3, pp. 384-399, 2008.

[44] Y. Chen, J. Lu, H. Pan et al., "Association between genetic variation of CACNA1H and childhood absence epilepsy," Annals of Neurology, vol. 54, no. 2, pp. 239-243, 2003.

[45] I. Vitko, I. Bidaud, J. M. Arias, A. Mezghrani, P. Lory, and E. Perez-Reyes, "The I-II loop controls plasma membrane expression and gating of Ca v3.2 T-type $\mathrm{Ca}^{2+}$ channels: a paradigm for childhood absence epilepsy mutations," Journal of Neuroscience, vol. 27, no. 2, pp. 322-330, 2007.

[46] I. I. Arias-Olguín, I. Vitko, M. Fortuna et al., "Characterization of the gating brake in the I-II loop of Cav3.2 T-type $\mathrm{Ca}^{2+}$ channels," The Journal of Biological Chemistry, vol. 283, no. 13, pp. 8136-8144, 2008.

[47] X. B. Liu, J. Coble, G. van Luijtelaar, and E. G. Jones, "Reticular nucleus-specific changes in $\alpha 3$ subunit protein at GABA synapses in genetically epilepsy-prone rats," Proceedings of the National Academy of Sciences of the United States of America, vol. 104, no. 30, pp. 12512-12517, 2007.

[48] D. N. Bowser, D. A. Wagner, C. Czajkowski et al., "Altered kinetics and benzodiazepine sensitivity of a GABAA receptor subunit mutation [ $\gamma 2(\mathrm{R} 43 \mathrm{Q})]$ found in human epilepsy," Proceedings of the National Academy of Sciences of the United States of America, vol. 99, no. 23, pp. 15170-15175, 2002.

[49] J. Kang and R. L. Macdonald, "The GABA $\mathrm{A}_{\mathrm{A}}$ receptor $\gamma 2$ subunit R43Q mutation linked to childhood absence epilepsy and febrile seizures causes retention of $\alpha 1 \beta 2 \alpha 2 S$ receptors in the endoplasmic reticulum," Journal of Neuroscience, vol. 24, no. 40, pp. 8672-8677, 2004.

[50] K. Y. Sarkisova, I. S. Midzianovskaia, and M. A. Kulikov, "Depressive-like behavioral alterations and c-fos expression in the dopaminergic brain regions in WAG/Rij rats with genetic absence epilepsy," Behavioural Brain Research, vol. 144, no. 1-2, pp. 211-226, 2003.

[51] K. Sarkisova and G. van Luijtelaar, "The WAG/Rij strain: a genetic animal model of absence epilepsy with comorbidity of depressiony," Progress in Neuro-Psychopharmacology and Biological Psychiatry, vol. 35, no. 4, pp. 854-876, 2011.

[52] G. van Luijtelaar, "The prevention of behavioral consequences of idiopathic generalized epilepsy: evidence from rodent models," Neuroscience Letters, vol. 497, no. 3, pp. 177-184, 2011. 
[53] H. Jahnsen and R. Llinás, "Ionic basis for the electroresponsiveness and oscillatory properties of guinea-pig thalamic neurons in vitro," Journal of Physiology, vol. 349, pp. 227247, 1984.

[54] D. A. McCormick and T. Bal, "Sleep and arousal: thalamocortical mechanisms," Annual Review of Neuroscience, vol. 20, pp. 185-215, 1997.

[55] A. S. Bazyan, "Two types of epilepsy models and processes of cognition: pentylenetetrazole kindling and absence epilepsy of WAG/Rij rats strain," in Underlying Mechanisms of Epilepsy, F. S. Kaneez, Ed., pp. 283-302, InTech, Rijeka, Croatia, 2011.

[56] R. Gauss, R. Seifert, and U. B. Kaupp, "Molecular identification of a hyperpolarization-activated channel in sea urchin sperm," Nature, vol. 393, no. 6685, pp. 583-587, 1998.

[57] A. Ludwig, X. Zong, M. Jeglitsch, F. Hofmann, and M. Biel, "A family of hyperpolarization-activated mammalian cation channels," Nature, vol. 393, no. 6685, pp. 587-591, 1998.

[58] B. Santoro, D. T. Liu, H. Yao et al., "Identification of a gene encoding a hyperpolarization-activated pacemaker channel of brain," Cell, vol. 93, no. 5, pp. 717-729, 1998.

[59] J. Chen, J. S. Mitcheson, M. Lin, and M. C. Sanguinetti, "Functional roles of charged residues in the putative voltage sensor of the HCN2 pacemaker channel," The Journal of Biological Chemistry, vol. 275, no. 46, pp. 36465-36471, 2000.

[60] T. Xue and R. A. Li, "An external determinant in the S5-P linker of the pacemaker (HCN) channel identified by sulfhydryl modification," The Journal of Biological Chemistry, vol. 277, no. 48, pp. 46233-46242, 2002.

[61] N. Decher, J. Chen, and M. C. Sanguinetti, "Voltage-dependent gating of hyperpolarization-activated, cyclic nucleotide-gated pacemaker channels: molecular coupling between the S4-S5 and C-linkers," The Journal of Biological Chemistry, vol. 279, no. 14, pp. 13859-13865, 2004.

[62] T. Xue, E. Marbán, and R. A. Li, "Dominant-negative suppression of HCN1- and HCN2-encoded pacemaker currents by an engineered HCN1 construct: insights into structure-function relationships and multimerization," Circulation Research, vol. 90, no. 12, pp. 1267-1273, 2002.

[63] S. Chen, J. Wang, and S. A. Siegelbaum, "Properties of hyperpolarization-activated pacemaker current defined by coassembly of HCN1 and HCN2 subunits and basal modulation by cyclic nucleotide," Journal of General Physiology, vol. 117, no. 5, pp. 491-504, 2001.

[64] C. Ulens and J. Tytgat, "Functional heteromerization of HCN1 and HCN2 pacemaker channels," The Journal of Biological Chemistry, vol. 276, no. 9, pp. 6069-6072, 2001.

[65] J. P. Bénitah, G. F. Tomaselli, and E. Marbán, "Adjacent porelining residues within sodium channels identified by paired cysteine mutagenesis," Proceedings of the National Academy of Sciences of the United States of America, vol. 93, no. 14, pp. 73927396, 1996.

[66] R. G. Tsushima, R. A. Li, and P. H. Backx, "P-loop flexibility in $\mathrm{Na}^{+}$channel pores revealed by single- and double-cysteine replacements," Journal of General Physiology, vol. 110, no. 1, pp. 59-72, 1997.

[67] D. E. Clapham, "Not so funny anymore: pacing channels are cloned," Neuron, vol. 21, no. 1, pp. 5-7, 1998.

[68] J. Wang, S. Chen, and S. A. Siegelbaum, "Regulation of hyperpolarization-activated $\mathrm{HCN}$ channel gating and cAMP modulation due to interactions of $\mathrm{COOH}$ terminus and core transmembrane regions," Journal of General Physiology, vol. 118, no. 3, pp. 237-250, 2001.
[69] J. Chen, J. S. Mitcheson, M. Tristani-Firouzi, M. Lin, and M. C. Sanguinetti, "The S4-S5 linker couples voltage sensing and activation of pacemaker channels," Proceedings of the National Academy of Sciences of the United States of America, vol. 98, no. 20, pp. 11277-11282, 2001.

[70] N. P. Poolos, "The Yin and Yang of the H-channel and its role in epilepsy," Epilepsy Currents, vol. 4, no. 1, pp. 3-6, 2004.

[71] E. Sitnikova and G. van Luijtelaar, "Electroencephalographic characterization of spike-wave discharges in cortex and thalamus in WAG/Rij rats," Epilepsia, vol. 48, no. 12, pp. 2296-2311, 2007.

[72] A. Ludwig, T. Budde, J. Stieber et al., "Absence epilepsy and sinus dysrhythmia in mice lacking the pacemaker channel HCN2," EMBO Journal, vol. 22, no. 2, pp. 216-224, 2003.

[73] U. Strauss, M. H. P. Kole, A. U. Bräuer et al., "An impaired neocortical Ih is associated with enhanced excitability and absence epilepsy," European Journal of Neuroscience, vol. 19, no. 11, pp. 3048-3058, 2004.

[74] U. Schridde, U. Strauss, A. U. Bräuer, and G. van Luijtelaar, "Environmental manipulations early in development alter seizure activity, Ih and HCN1 protein expression later in life," European Journal of Neuroscience, vol. 23, no. 12, pp. 3346-3358, 2006.

[75] M. Kuisle, N. Wanaverbecg, A. L. Brewster et al., "Functional stabilization of weakened thalamic pacemaker channel regulation in rat absence epilepsy," Journal of Physiology, vol. 575, no. 1, pp. 83-100, 2006.

[76] M. H. P. Kole, A. U. Bräuer, and G. J. Stuart, "Inherited cortical HCN1 channel loss amplifies dendritic calcium electrogenesis and burst firing in a rat absence epilepsy model," Journal of Physiology, vol. 578, part 2, pp. 507-525, 2007.

[77] B. Santoro, S. G. N. Grant, D. Bartsch, and E. R. Kandel, "Interactive cloning with the $\mathrm{SH} 3$ domain of N-src identifies a new brain specific ion channel protein, with homology to Eag and cyclic nucleotide-gated channels," Proceedings of the National Academy of Sciences of the United States of America, vol. 94, no. 26, pp. 14815-14820, 1997.

[78] B. Santoro, S. Chen, A. Lüthi et al., "Molecular and functional heterogeneity of hyperpolarization-activated pacemaker channels in the mouse CNS," Journal of Neuroscience, vol. 20, no. 14, pp. 5264-5275, 2000.

[79] M. Inoue, B. W. M. M. Peeters, E. L. J. M. van Luijtelaar, J. M. H. Vossen, and A. M. L. Coenen, "Spontaneous occurrence of spike-wave discharges in five inbred strains of rats," Physiology and Behavior, vol. 48, no. 1, pp. 199-201, 1990.

[80] U. Schridde and G. van Luijtelaar, "The influence of strain and housing on two types of spike-wave discharges in rats," Genes, Brain and Behavior, vol. 3, no. 1, pp. 1-7, 2004.

[81] U. Schridde and G. van Luijtelaar, "The role of the environment on the development of spike-wave discharges in two strains of rats," Physiology and Behavior, vol. 84, no. 3, pp. 379-386, 2005.

[82] H. Blumenfeld, J. P. Klein, U. Schridde et al., "Early treatment suppresses the development of spike-wave epilepsy in a rat model," Epilepsia, vol. 49, no. 3, pp. 400-409, 2008.

[83] T. Bal and D. A. McCormick, "Mechanisms of oscillatory activity in guinea-pig nucleus reticularis thalami in vitro: a mammalian pacemaker," Journal of Physiology, vol. 468, pp. 669-691, 1993.

[84] H. Jahnsen and R. Llinás, "Electrophysiological properties of guinea-pig thalamic neurones: an in vitro study, Journal of Physiology, vol. 349, pp. 205-226, 1984. 
[85] D. A. McCormick and H. C. Pape, "Properties of a hyperpolarization-activated cation current and its role in rhythmic oscillation in thalamic relay neurones," Journal of Physiology, vol. 431, pp. 291-318, 1990.

[86] M. Steriade, D. A. McCormick, and T. J. Sejnowski, “Thalamocortical oscillations in the sleeping and aroused brain," Science, vol. 262, no. 5134, pp. 679-685, 1993.

[87] D. Pinault, N. Leresche, S. Charpier et al., "Intracellular recordings in thalamic neurones during spontaneous spike and wave discharges in rats with absence epilepsy," Journal of Physiology, vol. 509, no. 2, pp. 449-456, 1998.

[88] S. Charpier, N. Leresche, J. M. Deniau, S. Mahon, S. W. Hughes, and V. Crunelli, "On the putative contribution of $\mathrm{GABA}_{B}$ receptors to the electrical events occurring during spontaneous spike and wave discharges," Neuropharmacology, vol. 38, no. 11, pp. 1699-1706, 1999.

[89] A. Lüthi, T. Bal, and D. A. McCormick, "Periodicity of thalamic spindle waves is abolished by ZD7288, a blocker of $I_{\mathrm{h}}$," Journal of Neurophysiology, vol. 79, no. 6, pp. 3284-3289, 1998.

[90] I. Soltesz, S. Lightowler, N. Leresche, D. Jassik-Gerschenfeld, and C. E. V. P. Crunelli, "Two inward currents and the transformation of low-frequency oscillations of rat and cat thalamocortical cells," Journal of Physiology, vol. 441, pp. 175197, 1991.

[91] M. von Krosigk, T. Bal, and D. A. McCormick, "Cellular mechanisms of a synchronized oscillation in the thalamus," Science, vol. 261, no. 5119, pp. 361-364, 1993.

[92] T. Bal and D. A. McCormick, "What stops synchronized thalamocortical oscillations?” Neuron, vol. 17, no. 2, pp. 297308, 1996.

[93] A. Lüthi and D. A. McCormick, "H-current: properties of a neuronal and network pacemaker," Neuron, vol. 21, no. 1, pp. 912, 1998.

[94] A. Lüthi and D. A. McCormick, " $\mathrm{Ca}^{2+}$-mediated up-regulation of Ih in the thalamus. How cell-intrinsic ionic currents may shape network activity," Annals of the New York Academy of Sciences, vol. 868, pp. 765-769, 1999.

[95] K. H. Lee and D. A. McCormick, "Abolition of spindle oscillations by serotonin and norepinephrine in the ferret lateral geniculate and perigeniculate nuclei in vitro," Neuron, vol. 17, no. 2, pp. 309-321, 1996.

[96] S. W. Hughes, D. W. Cope, and V. Crunelli, "Dynamic clamp study of $\mathrm{I}(\mathrm{h})$ modulation of burst firing and $\delta$ oscillations in thalamocortical neurons in vitro," Neuroscience, vol. 87 , no. 3 , pp. 541-550, 1998.

[97] B. W. Yue and J. R. Huguenard, "The role of H-current in regulating strength and frequency of thalamic network oscillations," Thalamus and Related Systems, vol. 1, no. 2, pp. 95-103, 2001.

[98] T. Budde, L. Caputi, T. Kanyshkova et al., "Impaired regulation of thalamic pacemaker channels through an imbalance of subunit expression in absence epilepsy," Journal of Neuroscience, vol. 25, no. 43, pp. 9871-9882, 2005.

[99] R. Citraro, E. Russo, E. D. Di Paola et al., "Effects of some neurosteroids injected into some brain areas of WAG/Rij rats, an animal model of generalized absence epilepsy," Neuropharmacology, vol. 50, no. 8, pp. 1059-1071, 2006.

[100] R. Citraro, E. Russo, S. Gratteri et al., "Effects of noncompetitive AMPA receptor antagonists injected into some brain areas of WAG/Rij rats, an animal model of generalized absence epilepsy," Neuropharmacology, vol. 51, no. 6, pp. 10581067, 2006.
[101] S. R. Williams and G. J. Stuart, "Mechanisms and consequences of action potential burst firing in rat neocortical pyramidal neurons," Journal of Physiology, vol. 521, no. 2, pp. 467-482, 1999.

[102] C. Lüscher, L. Y. Jan, M. Stoffel, R. C. Malenka, and R. A. Nicoll, "G protein-coupled inwardly rectifying $\mathrm{K}^{+}$channels (GIRKs) mediate postsynaptic but not presynaptic transmitter actions in hippocampal neurons," Neuron, vol. 19, no. 3, pp. 687-695, 1997.

[103] J. W. Sohn, D. Lee, H. Cho et al., "Receptor-specific inhibition of $\mathrm{GABA}_{\mathrm{A}}$-activated $\mathrm{K}^{+}$currents by muscarinic and metabotropic glutamate receptors in immature rat hippocampus," Journal of Physiology, vol. 580, no. 2, pp. 411-422, 2007.

[104] F. Ciruela, V. Fernández-Dueñas, K. Sahlholm et al., "Evidence for oligomerization between GABAB receptors and GIRK channels containing the GIRK1 and GIRK3 subunits," European Journal of Neuroscience, vol. 32, no. 8, pp. 1265-1277, 2010.

[105] R. L. Macdonald and R. W. Olsen, "GABA A receptor channels," Annual Review of Neuroscience, vol. 17, pp. 569-602, 1994.

[106] E. Costa, "From GABAA receptor diversity emerges a unified vision of GABAergic inhibition," Annual Review of Pharmacology and Toxicology, vol. 38, pp. 321-350, 1998.

[107] A. K. Mehta and M. K. Ticku, "An update on $\mathrm{GABA}_{\mathrm{A}}$ receptors," Brain Research Reviews, vol. 29, no. 2-3, pp. 196-217, 1999.

[108] A. M. L. Coenen and E. L. J. M. van Luijtelaar, "Effects of diazepam and two $\beta$-carbolines on epileptic activity and on EEG and behavior in rats with absence seizures," Pharmacology Biochemistry and Behavior, vol. 32, no. 1, pp. 27-35, 1989.

[109] E. L. J. M. van Luijtelaar, D. N. Stephens, and A. M. L. Coenen, "Comparison of abecarnil and diazepam on hypnotic activity in rats," in Sleep '90, J. Horne, Ed., pp. 152-154, Pontenagel Press, Bochum, Germany, 1990.

[110] A. M. L. Coenen, D. N. Stephens, and E. L. J. M. van Luijtelaar, "Effects of the $\beta$-carboline abecarnil on epileptic activity, EEG, sleep and behavior of rats," Pharmacology Biochemistry and Behavior, vol. 42, no. 3, pp. 401-405, 1992.

[111] A. M. L. Coenen, W. H. I. M. Drinkenburg, M. Inoue, and E. L. J. M. van Luijtelaar, "Genetic models of absence epilepsy, with emphasis on the WAG/Rij strain of rats," Epilepsy Research, vol. 12, no. 2, pp. 75-86, 1992.

[112] M. Vergnes, A. Boehrer, X. He et al., "Differential sensitivity to inverse agonists of $\mathrm{GABA}_{\mathrm{A}}$ /benzodiazepine receptors in rats with genetic absence-epilepsy," Epilepsy Research, vol. 47, no. 1-2, pp. 43-53, 2001.

[113] H. Depoortere, D. Françon, E. L. J. M. van Luijtelaar, W. H. I. M. Drinkenburg, and A. M. L. Coenen, "Differential effects of midazolam and zolpidem on sleep-wake states and epileptic activity in WAG/Rij rats," Pharmacology Biochemistry and Behavior, vol. 51, no. 4, pp. 571-576, 1995.

[114] B. W. M. M. Peeters, C. M. van Rijn, D. J. Nutt, M. N. G. Titulaer, J. M. H. Vossen, and A. M. L. Coenen, "Diazepam and Ro 15-1788 increase absence epilepsy in WAG/Rij rats chronically exposed to diazepam," European Journal of Pharmacology, vol. 178, no. 1, pp. 111-114, 1990.

[115] C. Marescaux, G. Micheletti, M. Vergnes, L. Rumbach, and J. M. Warter, "Diazepam antagonizes GABAmimetics in rats with spontaneous petit mal-like epilepsy," European Journal of Pharmacology, vol. 113, no. 1, pp. 19-24, 1985.

[116] R. Rupprecht and F. Holsboer, "Neuroactive steroids: mechanisms of action and neuropsychopharmacological perspectives," Trends in Neurosciences, vol. 22, no. 9, pp. 410-416, 1999.

[117] R. A. Grünewald, V. Aliberti, and C. P. Panayiotopoulos, "Exacerbation of typical absence seizures by progesterone," Seizure, vol. 1, no. 2, pp. 137-138, 1992. 
[118] T. Bäckström, B. Zetterlund, S. Blom, and M. Romano, "Effects of intravenous progesterone infusions on the epileptic discharge frequency in women with partial epilepsy," Acta Neurologica Scandinavica, vol. 69, no. 4, pp. 240-248, 1984.

[119] O. C. Snead III, "Ganaxolone, a selective, high-affinity steroid modulator of the $\gamma$-aminobutyric acid-A receptor, exacerbates seizures in animal models of absence," Annals of Neurology, vol. 44, no. 4, pp. 688-691, 1998.

[120] B. Budziszewska, G. van Luijtelaar, A. M. L. Coenen, M. Leśkiewicz, and W. Lasoń, "Effects of neurosteroids on spikewave discharges in the genetic epileptic WAG/Rij rat," Epilepsy Research, vol. 33, no. 1, pp. 23-29, 1999.

[121] G. van Luijtelaar, B. Budziszewska, L. Jaworska-Feil, J. Ellis, A. Coenen, and W. Lasoń, "The ovarian hormones and absence epilepsy: a long-term EEG study and pharmacological effects in a genetic absence epilepsy model," Epilepsy Research, vol. 46, no. 3, pp. 225-239, 2001.

[122] G. van Luijtelaar, B. Budziszewska, M. Tetich, and W. Lason, "Finasteride inhibits the progesterone-induced spike-wave discharges in a genetic model of absence epilepsy," Pharmacology Biochemistry and Behavior, vol. 75, no. 4, pp. 889-894, 2003.

[123] V. Persad, C. G. T. Wong, M. A. Cortez, Y. T. Wang, and O. C. Snead, "Hormonal regulation of atypical absence seizures," Annals of Neurology, vol. 55, no. 3, pp. 353-361, 2004.

[124] B. W. M. M. Peeters, C. M. Van Rijn, J. M. H. Vossen, and A. M. L. Coenen, "Effects of GABAergic agents on spontaneous nonconvulsive epilepsy, EEG and behaviour, in the WAG/Rij inbred strain of rats," Life Sciences, vol. 45, no. 13, pp. 1171-1176, 1989.

[125] M. Vergnes, C. Marescaux, G. Micheletti, A. Depaulis, L. Rumbach, and J. M. Warter, "Enhancement of spike and wave discharges by gabamimetic drugs in rats with spontaneous petit-mal-like epilepsy," Neuroscience Letters, vol. 44, no. 1, pp. 91-94, 1984.

[126] A. Puigcerver, E. L. J. M. van Luijtelaar, W. H. I. M. Drinkenburg, and A. L. M. Coenen, "Effects of the $\mathrm{GABA}_{\mathrm{B}}$ antagonist CGP 35348 on sleep-wake states, behaviour, and spike-wave discharges in old rats," Brain Research Bulletin, vol. 40, no. 3, pp. 157-162, 1996.

[127] D. Getova, N. G. Bowery, and V. Spassov, "Effects of GABA receptor antagonists on learning and memory retention in a rat model of absence epilepsy," European Journal of Pharmacology, vol. 320, no. 1, pp. 9-13, 1997.

[128] D. A. Hosford, S. Clark, Z. Cao et al., "The role of $\mathrm{GABA}_{B}$ receptor activation in absence seizures of lethargic (lh/lh) mice," Science, vol. 257, no. 5068, pp. 398-401, 1992.

[129] D. A. Hosford, F. H. Lin, D. L. Kraemer, Z. Cao, Y. Wang, and J. T. Wilson Jr., "Neural network of structures in which $\mathrm{GABA}_{\mathrm{B}}$ receptors regulate absence seizures in the lethargic (lh/lh) mouse model," Journal of Neuroscience, vol. 15, no. 11, pp. 7367-7376, 1995.

[130] D. A. Hosford, Y. Wang, C. C. Liu, and O. C. Snead, "Characterization of the antiabsence effects of SCH 50911, a GABA receptor antagonist, in the lethargic mouse, $\gamma$-hydroxybutyrate, and pentylenetetrazole models," Journal of Pharmacology and Experimental Therapeutics, vol. 274, no. 3, pp. 1399-1403, 1995.

[131] O. C. Snead, "Antiabsence seizure activity of specific $\mathrm{GABA}_{B}$ and $\gamma$-hydroxybutyric acid receptor antagonists," Pharmacology Biochemistry and Behavior, vol. 53, no. 1, pp. 73-79, 1996.

[132] Z. Liu, M. Vergnes, A. Depaulis, and C. Marescaux, "Involvement of intrathalamic $\mathrm{GABA}_{\mathrm{B}}$ neurotransmission in the control of absence seizures in the rat," Neuroscience, vol. 48, no. 1, pp. 87-93, 1992.
[133] M. Vergnes, A. Boehrer, S. Simler, R. Bernasconi, and C. Marescaux, "Opposite effects of $\mathrm{GABA}_{\mathrm{B}}$ receptor antagonists on absences and convulsive seizures," European Journal of Pharmacology, vol. 332, no. 3, pp. 245-255, 1997.

[134] D. P. Getova and N. G. Bowery, "Effects of high-affinity $\mathrm{GABA}_{\mathrm{B}}$ receptor antagonists on active and passive avoidance responding in rodents with $\gamma$-hydroxybutyrolactone-induced absence syndrome," Psychopharmacology, vol. 157, no. 1, pp. 8995, 2001.

[135] R. M. Kamiński, C. M. van Rijn, W. A. Turski, S. J. Czuczwar, and G. van Luijtelaar, "AMPA and $G_{A B A}$ receptor antagonists and their interaction in rats with a genetic form of absence epilepsy," European Journal of Pharmacology, vol. 430, no. 2-3, pp. 251259, 2001.

[136] K. A. Smith and R. S. Fisher, “The selective GABA B $_{B}$ antagonist CGP-35348 blocks spike-wave bursts in the cholesterol synthesis rat absence epilepsy model," Brain Research, vol. 729, no. 2, pp. 147-150, 1996.

[137] A. Skardoutsou, K. A. Voudris, and E. A. Vagiakou, "Nonconvulsive status epilepticus associated with tiagabine therapy in children," Seizure, vol. 12, no. 8, pp. 599-601, 2003.

[138] S. Knake, H. M. Hamer, U. Schomburg, W. H. Oertel, and F. Rosenow, "Tiagabine-induced absence status in idiopathic generalized epilepsy," Seizure, vol. 8, no. 5, pp. 314-317, 1999.

[139] A. Vinton, A. J. Kornberg, M. Cowley, Z. Matkovic, C. Kilpatrick, and T. J. O’Brien, “Tiagabine-induced generalised non convulsive status epilepticus in patients with lesional focal epilepsy," Journal of Clinical Neuroscience, vol. 12, no. 2, pp. 128133, 2005.

[140] F. Y. Onat, R. G. Aker, A. A. Gurbanova, N. Ateş, and G. van Luijtelaar, "The effect of generalized absence seizures on the progression of kindling in the rat," Epilepsia, vol. 48, no. 5, pp. 150-156, 2007.

[141] E. A. Tolmacheva and G. van Luijtelaar, "Absence seizures are reduced by the enhancement of GABA-ergic inhibition in the hippocampus in WAG/Rij rats," Neuroscience Letters, vol. 416, no. 1, pp. 17-21, 2007.

[142] E. L. J. M. van Luijtelaar, W. H. I. M. Drinkenburg, C. M. van Rijn, and A. M. L. Coenen, "Rat models of genetic absence epilepsy: what do EEG spike-wave discharges tell us about drug effects?" Methods and Findings in Experimental and Clinical Pharmacology, vol. 24, supplement D, pp. 65-70, 2002.

[143] A. P. J. Parker, A. Agathonikou, R. O. Robinson, and C. P. Panayiotopoulos, "Inappropriate use of carbamazepine and vigabatrin in typical absence seizures," Developmental Medicine and Child Neurology, vol. 40, no. 8, pp. 517-519, 1998.

[144] M. T. Yang, W. T. Lee, L. W. Chu, and Y. Z. Shen, "Antiepileptic drugs-induced de novo absence seizures," Brain and Development, vol. 25, no. 1, pp. 51-56, 2003.

[145] P. Thomas, L. Valton, and P. Genton, "Absence and myoclonic status epilepticus precipitated by antiepileptic drugs in idiopathic generalized epilepsy," Brain, vol. 129, no. 5, pp. 1281-1292, 2006.

[146] B. M. Bouwman, P. L. C. van den Broek, G. van Luijtelaar, and C. M. van Rijn, "The effects of vigabatrin on type II spike wave discharges in rats," Neuroscience Letters, vol. 338, no. 3, pp. 177180, 2003.

[147] M. E. Kelly and D. C. McIntyre, "Hippocampal kindling protects several structures from the neuronal damage resulting from kainic acid-induced status epilepticus," Brain Research, vol. 634, no. 2, pp. 245-256, 1994. 
[148] A. Lüttjohann, P. F. Fabene, and G. van Luijtelaar, "A revised Racine's scale for PTZ-induced seizures in rats," Physiology and Behavior, vol. 98, no. 5, pp. 579-586, 2009.

[149] E. Maris, B. M. Bouwman, P. Suffczynski, and C. M. van Rijn, "Starting and stopping mechanisms of absence epileptic seizures are revealed by hazard functions," Journal of Neuroscience Methods, vol. 152, no. 1-2, pp. 107-115, 2006.

[150] Z. Liu, M. Vergnes, A. Depaulis, and C. Marescaux, "Evidence for a critical role of GABAergic transmission within the thalamus in the genesis and control of absence seizures in the rat," Brain Research, vol. 545, no. 1-2, pp. 1-7, 1991.

[151] C. M. van Rijn, E. W. Bree, J. F. R. de Miranda, J. M. H. Vossen, and A. M. L. Coenen, "Binding of RO 5-4864 to brain membranes of rats with and without absence-like phenomena," Journal of Receptor Research, vol. 11, no. 5, pp. 721-725, 1991.

[152] A. R. Knight and N. G. Bowery, "GABA receptors in rats with spontaneous generalized nonconvulsive epilepsy," Journal of Neural Transmission, Supplementa, no. 35, pp. 189-196, 1992.

[153] O. C. Snead III, A. Depaulis, P. K. Banerjee, V. Hechler, and M. Vergnes, "The $\mathrm{GABA}_{\mathrm{A}}$ receptor complex in experimental absence seizures in rat: an autoradiographic study," Neuroscience Letters, vol. 140, no. 1, pp. 9-12, 1992.

[154] F. Lin, Z. Cao, and D. A. Hosford, "Increased number of GABA receptors in the lethargic $(\mathrm{lh} / \mathrm{lh})$ mouse model of absence epilepsy," Brain Research, vol. 608, no. 1, pp. 101-106, 1993.

[155] R. Spreafico, T. Mennini, L. Danober et al., "GABA A receptor impairment in the genetic absence epilepsy rats from Strasbourg (GAERS): an immunocytochemical and receptor binding autoradiographic study," Epilepsy Research, vol. 15, no. 3, pp. 229-238, 1993.

[156] O. C. Snead III and C. C. Liu, "GABA receptor function in the $\gamma$-hydroxybutyrate model of generalized absence seizures," Neuropharmacology, vol. 32, no. 4, pp. 401-409, 1993.

[157] H. J. Luhmann, T. Mittmann, G. van Luijtelaar, and U. Heinemann, "Impairment of intracortical GABAergic inhibition in a rat model of absence epilepsy," Epilepsy Research, vol. 22, no. 1, pp. 43-51, 1995.

[158] N. G. Bowery, K. Parry, A. Boehrer, P. Mathivet, C. Marescaux, and R. Bernasconi, "Pertussis toxin decreases absence seizures and $\mathrm{GABA}_{\mathrm{B}}$ receptor binding in thalamus of a genetically prone rat (GAERS)," Neuropharmacology, vol. 38, no. 11, pp. 1691-1697, 1999.

[159] I. G. Rebrov, M. N. Karpova, A. A. Andreev et al., "Chlorine conductance of the $\mathrm{GABA}_{\mathrm{A}}$ receptor of synaptoneurosomes from the brain cortex of WAG/Rij rats with absence epilepsy and Wistar rats at an early period in the development of nonconvulsive or tonic-clonic kindling," Neurochemical Journal, vol. 1, no. 4, pp. 293-298, 2007.

[160] T. Bessaïh, L. Bourgeais, C. I. Badiu et al., "Nucleus-specific abnormalities of GABAergic synaptic transmission in a genetic model of absence seizures," Journal of Neurophysiology, vol. 96, no. 6, pp. 3074-3081, 2006.

[161] M. G. Corda, M. Orlandi, D. Lecca, G. Carboni, V. Frau, and O. Giorgi, "Pentylenetetrazol-induced kindling in rats: effect of GABA function inhibitors," Pharmacology Biochemistry and Behavior, vol. 40, no. 2, pp. 329-333, 1991.

[162] M. G. Corda, M. Orlandi, D. Lecca, and O. Giorgi, "Decrease in gabaergic function induced by pentylenetetrazol kindling in rats: antagonism by MK-801," Journal of Pharmacology and Experimental Therapeutics, vol. 262, no. 2, pp. 792-800, 1992.
[163] M. N. G. Titulaer, W. Kamphuis, C. W. Pool, J. J. van Heerikhuize, and F. H. L. da Silva, "Kindling induces timedependent and regional specific changes in the $[3 \mathrm{H}]$ muscimol binding in the rat hippocampus: a quantitative autoradiographic study," Neuroscience, vol. 59, no. 4, pp. 817-826, 1994.

[164] M. N. G. Titulaer, W. Kamphuis, and F. H. L. da Silva, "Autoradiographic analysis of [35S]t-butylbicyclophosphorothionate binding in kindled rat hippocampus shows different changes in CA1 area and fascia dentata," Neuroscience, vol. 66, no. 3, pp. 547-554, 1995.

[165] A. S. Bazyan, V. V. Zhulin, M. N. Karpova, N. Y. Klishina, and R. N. Glebov, "Long-term reduction of benzodiazepine receptor density in the rat cerebellum by acute seizures and kindling and its recovery 6 months later by a pentylenetetrazole challenge," Brain Research, vol. 888, no. 2, pp. 212-220, 2001.

[166] M. C. Prevett, A. A. Lammertsma, D. J. Brooks, V. J. Cunningham, D. R. Fish, and J. S. Duncan, "Benzodiazepine-GABA receptor binding during absence seizures," Epilepsia, vol. 36, no. 6, pp. 592-599, 1995.

[167] D. A. Richards, T. Lemos, P. S. Whitton, and N. G. Bowery, "Extracellular GABA in the ventrolateral thalamus of rats exhibiting spontaneous absence epilepsy: a microdialysis study," Journal of Neurochemistry, vol. 65, no. 4, pp. 1674-1680, 1995.

[168] F. H. Li, Y. Wang, S. Lin, Z. Cao, and D. A. Hosford, “GABA receptor-mediated effects in synaptosomes of lethargic $(\mathrm{lh} / \mathrm{lh})$ mice," Journal of Neurochemistry, vol. 65, no. 5, pp. 2087-2095, 1995.

[169] S. J. Caddick and D. A. Hosford, " $\mathrm{GABA}_{\mathrm{B}}$-activated $\mathrm{gK}^{+}$in thalamic neurons in the lethargic $(\mathrm{lh} / \mathrm{lh})$ mouse model of generalized absence seizures," Neuroscience Letters, vol. 205, no. 1, pp. 29-32, 1996.

[170] R. J. Sutch, C. C. Davies, and N. G. Bowery, "GABA release and uptake measured in crude synaptosomes from genetic absence epilepsy rats from strasbourg (GAERS)," Neurochemistry International, vol. 34, no. 5, pp. 415-425, 1999.

[171] S. A. Chepurnov, N. E. Chepurnova, E. A. Tolmacheva, I. A. Kochetkov, E. L. van Luijtelaar, and A. M. Coenen, "Pregnancy in WAG/Rij rats-changes in the levels of progesterone, estradiol and generalized absence epilepsy," Rossiiskii Fiziologicheskii Zhurnal Imeni I. M. Sechenova, vol. 88, no. 6, pp. 741-750, 2002.

[172] E. A. Tolmacheva, S. A. Chepurnov, N. E. Chepurnova, Y. A. Kochetkov, and G. van Luijtelaar, "Absence seizures during pregnancy in WAG/Rij rats," Physiology and Behavior, vol. 81, no. 4, pp. 623-627, 2004.

[173] R. H. Wallace, C. Marini, S. Petrou et al., "Mutant GABA receptor $\gamma 2$-subunit in childhood absence epilepsy and febrile seizures," Nature Genetics, vol. 28, no. 1, pp. 49-52, 2001.

[174] J. Wu, K. Ellsworth, M. Ellsworth, K. M. Schroeder, K. Smith, and R. S. Fisher, "Abnormal benzodiazepine and zinc modulation of $\mathrm{GABA}_{\mathrm{A}}$ receptors in an acquired absence epilepsy model," Brain Research, vol. 1013, no. 2, pp. 230-240, 2004.

[175] M. Miettinen, E. Koivisto, P. Riekkinen, and R. Miettinen, "Coexistence of parvalbumin and GABA in nonpyramidal neurons of the rat entorhinal cortex," Brain Research, vol. 706, no. 1, pp. 113-122, 1996.

[176] M. R. Celio, "Parvalbumin in most $\gamma$-aminobutyric acidcontaining neurons of the rat cerebral cortex," Science, vol. 231, no. 4741, pp. 995-997, 1986.

[177] Y. Kawaguchi and Y. Kubota, "GABAergic cell subtypes and their synaptic connections in rat frontal cortex," Cerebral Cortex, vol. 7, no. 6, pp. 476-486, 1997. 
[178] M. C. van de Bovenkamp-Janssen, A. Korosi, J. G. Veening, W. J. J. M. Scheenen, E. L. J. M. van Luijtelaar, and E. W. Roubos, "Neuronal parvalbumin and absence epilepsy in WAG/Rij rats," in The WAG/Rij Model for Absence Epilepsy: The NijmegenRussian Federation Papers, E. L. J. M. van Luijtelaar, G. D. Kuznetsova, S. A. Chepurnov, and A. M. L. Coenen, Eds., pp. 29-36, Nijmegen University Press, 2003.

[179] A. S. Bazyan, "The determined and uncertain processes in the nervous system," Neurochimia, vol. 23, no. 1, pp. 19-23, 2006.

[180] J. G. Nicholls, A. R. Martin, B. G. Wallace, and P. A. Fuchs, From Neuron to Brain, Sinauer Associates, Sunderland, Mass, USA, 2001.

[181] E. A. Barnard, P. Skolnick, R. W. Olsen et al., "International union of pharmacology. XV. Subtypes of $\gamma$-aminobutyric acid(A) receptors: classification on the basis of subunit structure and receptor function," Pharmacological Reviews, vol. 50, no. 2, pp. 291-313, 1998.

[182] R. W. Olsen and W. Sieghart, "International Union of Pharmacology. LXX. Subtypes of $\gamma$-aminobutyric acidA receptors: classification on the basis of subunit composition, pharmacology, and function. Update," Pharmacological Reviews, vol. 60, no. 3, pp. 243-260, 2008.

[183] E. A. Barnard, M. G. Darlison, and P. Seeburg, "Molecular biology of the GABAA receptor: the receptor/channel superfamily," Trends in Neurosciences, vol. 10, no. 12, pp. 502-509, 1987.

[184] F. A. Stephenson, “The $\mathrm{GABA}_{\mathrm{A}}$ receptors," Biochemical Journal, vol. 310, no. 1, pp. 1-9, 1995.

[185] J. L. Fisher, J. Zhang, and R. L. Macdonald, "The role of $\alpha 1$ and $\alpha 6$ subtype amino-terminal domains in allosteric regulation of $\gamma$ aminobutyric acid(a) receptors," Molecular Pharmacology, vol. 52, no. 4, pp. 714-724, 1997.

[186] S. A. Thompson, S. A. Arden, G. Marshall, P. B. Wingrove, P. J. Whiting, and K. A. Wafford, "Residues in transmembrane domains I and II determine $\gamma$-aminobutyric acid type A(A) receptor subtype-selective antagonism by furosemide," Molecular Pharmacology, vol. 55, no. 6, pp. 993-999, 1999.

[187] P. B. Wingrove, K. A. Wafford, C. Bain, and P. J. Whiting, "The modulatory action of loreclezole at the $\gamma$-aminobutyric acid type A receptor is determined by a single amino acid in the $\beta 2$ and $\beta 3$ subunit," Proceedings of the National Academy of Sciences of the United States of America, vol. 91, no. 10, pp. 4569-4573, 1994.

[188] A. Hunter, "Kava (Piper methysticum) back in circulation," Australian Centre for Complementary Medicine, vol. 25, no. 7, article 529, 2006.

[189] M. B. Herd, D. Belelli, and J. J. Lambert, "Neurosteroid modulation of synaptic and extrasynaptic $\mathrm{GABA}_{\mathrm{A}}$ receptors," Pharmacology and Therapeutics, vol. 116, no. 1, pp. 20-34, 2007.

[190] A. M. Hosie, M. E. Wilkins, H. M. A. da Silva, and T. G. Smart, "Endogenous neurosteroids regulate $\mathrm{GABA}_{\mathrm{A}}$ receptors through two discrete transmembrane sites," Nature, vol. 444, no. 7118, pp. 486-489, 2006.

[191] C. Braestrup, M. Nielsen, and T. Honore, "Binding of [3H]DMCM, a convulsive benzodiazepine ligand, to rat brain membranes: preliminary studies," Journal of Neurochemistry, vol. 41, no. 2, pp. 454-465, 1983.

[192] R. L. Macdonald, R. E. Twyman, T. Ryan-Jastrow, and T. P. Angelotti, "Regulation of GABA $\mathrm{A}_{\mathrm{A}}$ receptor channels by anticonvulsant and convulsant drugs and by phosphorylation," Epilepsy Research, Supplement, vol. 9, pp. 265-277, 1992.
[193] P. Polc, E. P. Bonetti, R. Schaggner, and W. Haefely, "A threestate model of the benzodiazepine receptor explains the interactions between the benzodiazepine antagonist Ro 15-1788, benzodiazepine tranquilizers, $\beta$-carbolines, and phenobarbitone," Naunyn-Schmiedeberg's Archives of Pharmacology, vol. 321, no. 4, pp. 260-264, 1982.

[194] J. P. Changeux and S. J. Edelstein, "Allosteric receptors after 30 years," Neuron, vol. 21, no. 5, pp. 959-980, 1998.

[195] T. P. Bonnert, R. M. Mckernan, S. Farrar et al., " $\theta$, a novel $\gamma$ aminobutyric acid type A receptor subunit," Proceedings of the National Academy of Sciences of the United States of America, vol. 96, no. 17, pp. 9891-9896, 1999.

[196] P. J. Whiting, G. McAllister, D. Vasilatis et al., "Neuronally restricted RNA splicing regulates the expression of a novel $\mathrm{GABA}_{\mathrm{A}}$ receptor subunit conferring atypical functional properties," Journal of Neuroscience, vol. 17, no. 13, pp. 5027-5037, 1997.

[197] P. Kofuji, J. B. Wang, S. J. Moss, R. L. Huganir, and D. R. Burt, "Generation of two forms of the $\gamma$-aminobutyric acid(A) receptor $\gamma 2$-subunit in mice by alternative splicing," Journal of Neurochemistry, vol. 56, no. 2, pp. 713-715, 1991.

[198] P. Whiting, R. M. McKernan, and L. L. Iversen, "Another mechanism for creating diversity in $\gamma$-aminobutyrate type A receptors: RNA splicing directs expression of two forms of $\gamma 2$ subunit, one of which contains a protein kinase C phosphorylation site," Proceedings of the National Academy of Sciences of the United States of America, vol. 87, no. 24, pp. 9966-9970, 1990.

[199] A. N. Bateson, A. Lasham, and M. G. Darlison, " $\gamma$-aminobutyric $\operatorname{acid}(\mathrm{A})$ receptor heterogeneity is increased by alternative splicing of a novel $\beta$-subunit gene transcript," Journal of Neurochemistry, vol. 56, no. 4, pp. 1437-1440, 1991.

[200] R. J. Harvey, M. A. Chinchetru, and M. G. Darlison, "Alternative splicing of a 51-nucleotide exon that encodes a putative protein kinase $\mathrm{C}$ phosphorylation site generates two forms of the chicken $\gamma$-aminobutyric acid(A) receptor $\beta 2$ subunit," Journal of Neurochemistry, vol. 62, no. 1, pp. 10-16, 1994.

[201] E. F. Kirkness and C. M. Fraser, "A strong promoter element is located between alternative exons of a gene encoding the human $\gamma$-aminobutyric acid-type A receptor $\beta 3$ subunit (GABRB3)," The Journal of Biological Chemistry, vol. 268, no. 6, pp. 44204428, 1993.

[202] Y. Kim, H. Glatt, W. Xie, D. Sinnett, and M. Lalande, "Human $\gamma$ aminobutyric acid-type a receptor $\alpha 5$ subunit gene (GABRA5): characterization and structural organization of the 5 ' flanking region," Genomics, vol. 42, no. 3, pp. 378-387, 1997.

[203] E. R. Korpi, T. Kuner, P. Kristo et al., "Small N-terminal deletion by splicing in cerebellar $\alpha 6$ subunit abolishes $\mathrm{GABA}_{\mathrm{A}}$ receptor function," Journal of Neurochemistry, vol. 63, no. 3, pp. 11671170, 1994.

[204] T. C. Jacob, S. J. Moss, and R. Jurd, "GABA receptor trafficking and its role in the dynamic modulation of neuronal inhibition," Nature Reviews Neuroscience, vol. 9, no. 5, pp. 331-343, 2008.

[205] D. Benke and H. Möhler, "UNIT 1.16 benzodiazepine binding

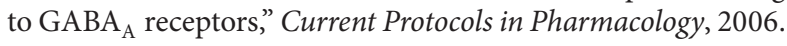

[206] H. Li, A. Kraus, J. Wu, J. R. Huguenard, and R. S. Fisher, "Selective changes in thalamic and cortical $\mathrm{GABA}_{\mathrm{A}}$ receptor subunits in a model of acquired absence epilepsy in the rat," Neuropharmacology, vol. 51, no. 1, pp. 121-128, 2006.

[207] H. Li, J. R. Huguenard, and R. S. Fisher, "Gender and age differences in expression of $\mathrm{GABA}_{\mathrm{A}}$ receptor subunits in rat somatosensory thalamus and cortex in an absence epilepsy model," Neurobiology of Disease, vol. 25, no. 3, pp. 623-630, 2007. 
[208] C. M. Schofield, M. Kleiman-Weiner, U. Rudolph, and J. R. Huguenard, "A gain in $\mathrm{GABA}_{\mathrm{A}}$ receptor synaptic strength in thalamus reduces oscillatory activity and absence seizures," Proceedings of the National Academy of Sciences of the United States of America, vol. 106, no. 18, pp. 7630-7635, 2009.

[209] P. K. Banerjee, N. J. K. Tillakaratne, S. Brailowsky, R. W. Olsen, A. J. Tobin, and O. C. Snead III, "Alterations in GABA receptor $\alpha 1$ and $\alpha 4$ subunit mRNA levels in thalamic relay nuclei following absence-like seizures in rats," Experimental Neurology, vol. 154, no. 1, pp. 213-223, 1998.

[210] D. Merlo, C. Mollinari, Y. Inaba et al., "Reduced $\mathrm{GABA}_{B}$ receptor subunit expression and paired-pulse depression in a genetic model of absence seizures," Neurobiology of Disease, vol. 25, no. 3, pp. 631-641, 2007.

[211] A. P. Princivalle, D. A. Richards, J. S. Duncan, R. Spreafico, and N. G. Bowery, "Modification of GABAB1 and GABAB2 receptor subunits in the somatosensory cerebral cortex and thalamus of rats with absence seizures (GAERS)," Epilepsy Research, vol. 55, no. 1-2, pp. 39-51, 2003.

[212] R. L. Macdonald, J. Q. Kang, and M. J. Gallagher, "Mutations in $\mathrm{GABA}_{\mathrm{A}}$ receptor subunits associated with genetic epilepsies," Journal of Physiology, vol. 588, no. 11, pp. 1861-1869, 2010.

[213] P. Lachance-Touchette, C. Martin, C. Poulin, M. Gravel, L. Carmant, and P. Cossette, "Screening of GABRB3 in FrenchCanadian families with idiopathic generalized epilepsy," Epilepsia, vol. 51, no. 9, pp. 1894-1897, 2010.

[214] M. P. Goldschen-Ohm, D. A. Wagner, S. Petrou, and M. V. Jones, "An epilepsy-related region in the $\mathrm{GABA}_{\mathrm{A}}$ receptor mediates long-distance effects on GABA and benzodiazepine binding sites," Molecular Pharmacology, vol. 77, no. 1, pp. 35-45, 2010.

[215] J. Q. Kang, W. Shen, and R. L. Macdonald, "Two molecular pathways (NMD and ERAD) contribute to a genetic epilepsy associated with the $\mathrm{GABA}_{\mathrm{A}}$ receptor GABRA1 PTC mutation, 975delC, S326fs328X," Journal of Neuroscience, vol. 29, no. 9, pp. 2833-2844, 2009.

[216] M. Tanaka, R. W. Olsen, M. T. Medina et al., "Hyperglycosylation and reduced GABA currents of mutated GABRB3 polypeptide in remitting childhood absence epilepsy," The American Journal of Human Genetics, vol. 82, no. 6, pp. 12491261, 2008.

[217] A. Hempelmann, J. Cobilanschi, A. Heils et al., "Lack of evidence of an allelic association of a functional GABRB3 exon la promoter polymorphism with idiopathic generalized epilepsy," Epilepsy Research, vol. 74, no. 1, pp. 28-32, 2007.

[218] D. Audenaert, E. Schwartz, K. G. Claeys et al., "A novel GABRG2 mutation associated with febrile seizures," Neurology, vol. 67, no. 4, pp. 687-690, 2006.

[219] L. Urak, M. Feucht, N. Fathi, K. Hornik, and K. Fuchs, "A GABRB3 promoter haplotype associated with childhood absence epilepsy impairs transcriptional activity," Human Molecular Genetics, vol. 15, no. 16, pp. 2533-2541, 2006.

[220] S. Maljevic, K. Krampfl, J. Cobilanschi et al., "A mutation in the $\mathrm{GABA}_{\mathrm{A}}$ receptor $\alpha 1$-subunit is associated with absence epilepsy," Annals of Neurology, vol. 59, no. 6, pp. 983-987, 2006.

[221] M. Ito, I. Ohmori, T. Nakahori, M. Ouchida, and Y. Ohtsuka, "Mutation screen of GABRA1, GABRB2 and GABRG2 genes in Japanese patients with absence seizures," Neuroscience Letters, vol. 383, no. 3, pp. 220-224, 2005.

[222] C. Marini, L. A. Harkin, R. H. Wallace, J. C. Mulley, I. E. Scheffer, and S. F. Berkovic, "Childhood absence epilepsy and febrile seizures: a family with a $\mathrm{GABA}_{\mathrm{A}}$ receptor mutation," Brain, vol. 126, part 1, pp. 230-240, 2003.
[223] K. Everett, B. Chioza, J. Aicardi et al., "Linkage and mutational analysis of CLCN2 in childhood absence epilepsy," Epilepsy Research, vol. 75, no. 2-3, pp. 145-153, 2007.

[224] G. Frugier, F. Coussen, M. F. Giraud et al., "A $\gamma 2$ (R43Q) mutation, linked to epilepsy in humans, alters $\mathrm{GABA}_{\mathrm{A}}$ receptor assembly and modifies subunit composition on the cell surface," The Journal of Biological Chemistry, vol. 282, no. 6, pp. 38193828, 2007.

[225] H. L. Payne, P. S. Donoghue, W. M. K. Connelly et al., "Aberrant $\mathrm{GABA}_{\mathrm{A}}$ receptor expression in the dentate gyrus of the epileptic mutant mouse stargazer," Journal of Neuroscience, vol. 26, no. 33, pp. 8600-8608, 2006.

[226] J. Holter, J. Davies, N. Leresche, V. Crunelli, and D. A. Carter, "Identification of two further splice variants of GABABR1 characterizes the conserved micro-exon 4 as a hot spot for regulated splicing in the rat brain," Journal of Molecular Neuroscience, vol. 26, no. 1, pp. 99-108, 2005.

[227] B. Singh, A. Monteil, I. Bidaud et al., "Mutational analysis of CACNA1G in idiopathic generalized epilepsy," Human mutation, vol. 28, no. 5, pp. 524-525, 2007.

[228] H. S. Shin, “T-type $\mathrm{Ca}^{2+}$ channels and absence epilepsy," Cell Calcium, vol. 40, no. 2, pp. 191-196, 2006.

[229] J. B. Peloquin, H. Khosravani, W. Barr et al., "Functional analysis of Cav3.2 T-type calcium channel mutations linked to childhood absence epilepsy," Epilepsia, vol. 47, no. 3, pp. 655658, 2006.

[230] J. J. Lü, Y. H. Zhang, Y. C. Chen et al., "T-type calcium channel gene-CACNA1H is a susceptibility gene to childhood absence epilepsy," Zhonghua Er Ke Za Zhi, vol. 43, no. 2, pp. 133-136, 2005.

[231] H. Khosravani, C. Altier, B. Simms et al., "Gating effects of mutations in the Cav3.2 T-type calcium channel associated with childhood absence epilepsy," The Journal of Biological Chemistry, vol. 279, no. 11, pp. 9681-9684, 2004.

[232] N. Hagiwara, H. Irisawa, and M. Kameyama, "Contribution of two types of calcium currents to the pacemaker potentials of rabbit sino-atrial node cells," Journal of Physiology, vol. 395, pp. 233-253, 1988.

[233] N. Hagiwara, H. Irisawa, H. Kasanuki, and S. Hosoda, "Background current in sino-atrial node cells of the rabbit heart," Journal of Physiology, vol. 448, pp. 53-72, 1992.

[234] E. L. J. M. van Luitelaar and A. M. L. Coenen, The WAG/Rij Model of Absence Epilepsy: Ten Years of Research. A Computation of Papers, Nijmegen University Press, Nijmegan. The Netherlands, 1997.

[235] B. W. M. M. Peeters, C. M. van Rijn, E. L. J. M. van Luijtelaar, and A. M. L. Coenen, "Antiepileptic and behavioural actions of MK-801 in an animal model of spontaneous absence epilepsy," Epilepsy Research, vol. 3, no. 2, pp. 178-181, 1989.

[236] B. W. M. M. Peeters, C. M. Van Rijn, J. M. H. Vossen, and A. M. L. Coenen, "Involvement of NMDA receptors in nonconvulsive epilepsy in WAG/Rij rats," Life Sciences, vol. 47, no. 6, pp. 523-529, 1990.

[237] E. L. J. M. van Luijtelaar and A. M. L. Coenen, "Effects of remacemide and its metabolic FPL 12495 on spike-wave discharges, electroencephalogram and behaviour in rats with absence epilepsy," Neuropharmacology, vol. 34, no. 4, pp. 419425, 1995.

[238] B. W. M. M. Peeters, G. M. J. Ramakers, J. M. H. Vossen, and A. M. L. Coenen, "The WAG/Rij rat model for nonconvulsive absence epilepsy: Involvement of nonNMDA receptors," Brain Research Bulletin, vol. 33, no. 6, pp. 709-713, 1994. 
[239] B. W. M. M. Peeters, G. M. J. Ramakers, B. A. Ellenbroek, J. M. H. Vossen, and A. M. L. Coenen, "Interactions between NMDA and nonNMDA receptors in nonconvulsive epilepsy in the WAG/Rij inbred strain," Brain Research Bulletin, vol. 33, no. 6, pp. 715-718, 1994.

[240] G. M. J. Ramakers, B. W. M. M. Peeters, J. M. H. Vossen, and A. M. L. Coenen, "CNQX, a new non-NMDA receptor antagonist, reduces spike wave discharges in the WAG/Rij rat model of absence epilepsy," Epilepsy Research, vol. 9, no. 2, pp. 127-131, 1991.

[241] J. R. Hughes, "Absence seizures: a review of recent reports with new concepts," Epilepsy and Behavior, vol. 15, no. 4, pp. 404-412, 2009.

[242] C. M. van Rijn, E. W. A. W. Banningh, and A. M. L. Coenen, "Effects of lamotrigine on absence seizures in rats," Polish Journal of Pharmacology, vol. 46, no. 5, pp. 467-470, 1994.

[243] T. A. Glauser, A. Cnaan, S. Shinnar et al., "Ethosuximide, valproic acid, and lamotrigine in childhood absence epilepsy," The New England Journal of Medicine, vol. 362, no. 9, pp. 790799, 2010.

[244] E. Russo, R. Citraro, S. D. Fazio et al., "Enhancement of antiabsence effects of ethosuximide by low doses of a noncompetitive $\alpha$-amino-3-hydroxy-5-methyl-4-isoxazolepropionic acid (AMPA) receptor antagonist in a genetic animal model of absence epilepsy," Epilepsy and Behavior, vol. 13, no. 2, pp. 295299, 2008.

[245] I. S. Midzyanovskaya, D. V. Salonin, D. Y. Bosnyakova, G. D. Kuznetsova, and E. L. J. M. van Luijtelaar, "The multiple effects of ketamine on electroencephalographic activity and behavior in WAG/Rij rats," Pharmacology Biochemistry and Behavior, vol. 79, no. 1, pp. 83-91, 2004.

[246] R. Jakus, M. Graf, R. D. Ando et al., "Effect of two noncompetitive AMPA receptor antagonists GYKI 52466 and GYKI 53405 on vigilance, behavior and spike-wave discharges in a genetic rat model of absence epilepsy," Brain Research, vol. 1008, no. 2, pp. 236-244, 2004.

[247] P. J. Conn and J. P. Pin, "Pharmacology and functions of metabotropic glutamate receptors," Annual Review of Pharmacology and Toxicology, vol. 37, pp. 205-237, 1997.

[248] R. T. Ngomba, I. Santolini, F. Biagioni et al., "Protective role for type-1 metabotropic glutamate receptors against spike and wave discharges in the WAG/Rij rat model of absence epilepsy," Neuropharmacology, vol. 60, no. 7-8, pp. 1281-1291, 2011.

[249] R. T. Ngomba, I. Santolini, T. E. Salt et al., "Metabotropic glutamate receptors in the thalamocortical network: Strategic targets for the treatment of absence epilepsy," Epilepsia, vol. 52, no. 7, pp. 1211-1222, 2011.

[250] E. Hermans and R. A. J. Challiss, "Structural, signalling and regulatory properties of the group I metabotropic glutamate receptors: prototypic family C G-protein-coupled receptors," Biochemical Journal, vol. 359, no. 3, pp. 465-484, 2001.

[251] F. Ferraguti and R. Shigemoto, "Metabotropic glutamate receptors," Cell and Tissue Research, vol. 326, no. 2, pp. 483-504, 2006.

[252] V. D’Amore, I. Santolini, C. M. van Rijn et al., "Potentiation of mGlu5 receptors with the novel enhancer, VU0360172, reduces spontaneous absence seizures in WAG/Rij rats," Neuropharmacology, vol. 66, pp. 330-338, 2013.

[253] A. G. Chapman, P. K. Yip, J. S. Yap et al., "Anticonvulsant actions of LY 367385 ((+)-2-methyl-4-carboxyphenylglycine) and AIDA ((RS)-1-aminoindan-1,5-dicarboxylic acid)," European Journal of Pharmacology, vol. 368, no. 1, pp. 17-24, 1999.
[254] R. T. Ngomba, F. Biagioni, S. Casciato et al., "The preferential mGlu2/3 receptor antagonist, LY341495, reduces the frequency of spike-wave discharges in the WAG/Rij rat model of absence epilepsy," Neuropharmacology, vol. 49, pp. 89-103, 2005.

[255] T. E. Salt and S. A. Eaton, "Distinct presynaptic metabotropic receptors for L-AP4 and CCG1 on GABAergic terminals: pharmacological evidence using novel $\alpha$-methyl derivative mGluR antagonists, MAP4 and MCCG, in the rat thalamus in vivo," Neuroscience, vol. 65, no. 1, pp. 5-13, 1995.

[256] T. E. Salt and J. P. Turner, "Antagonism of the presumed presynaptic action of L-AP4 on GABAergic transmission in the ventrobasal thalamus by the novel mGluR antagonist MPPG," Neuropharmacology, vol. 35, no. 2, pp. 239-241, 1996.

[257] J. P. Turner and T. E. Salt, "Group II and III metabotropic glutamate receptors and the control of the nucleus reticularis thalami input to rat thalamocortical neurones in vitro," Neuroscience, vol. 122, no. 2, pp. 459-469, 2003.

[258] J. P. Turner and T. E. Salt, "Group III metabotropic glutamate receptors control corticothalamic synaptic transmission in the rat thalamus in vitro," Journal of Physiology, vol. 519, no. 2, pp. 481-491, 1999.

[259] R. T. Ngomba, F. Ferraguti, A. Badura et al., "Positive allosteric modulation of metabotropic glutamate 4 (mGlu4) receptors enhances spontaneous and evoked absence seizures," Neuropharmacology, vol. 54, no. 2, pp. 344-354, 2008.

[260] C. Izzi, A. Barbon, M. R. Toliat et al., "Candidate gene analysis of the human metabotropic glutamate receptor type 4 (GRM4) in patients with juvenile myoclonic epilepsy," The American Journal of Medical Genetics-Neuropsychiatric Genetics, vol.123, no. 1, pp. 59-63, 2003.

[261] C. T. Wong, S. W. Scherer, O. C. Snead III, and D. R. Hampson, "Localization of the human mGluR4 gene within an epilepsy susceptibility locus," Molecular Brain Research, vol. 87, no. 1, pp. 109-116, 2001.

[262] F. Bertaso, C. Zhang, A. Scheschonka et al., "PICK1 uncoupling from mGluR7a causes absence-like seizures," Nature Neuroscience, vol. 11, no. 8, pp. 940-948, 2008.

[263] C. S. Zhang, F. Bertaso, V. Eulenburg et al., "Knock-in mice lacking the PDZ-ligand motif of mGluR7a show impaired PKCdependent autoinhibition of glutamate release, spatial working memory deficits, and increased susceptibility to pentylenetetrazol," Journal of Neuroscience, vol. 28, no. 34, pp. 8604-8614, 2008.

[264] G. D’Arcangelo, M. D’Antuono, V. Tancredi, and M. Avoli, "Neocortical hyperexcitability in a genetic model of absence seizures and its reduction by levetiracetam," Epilepsia, vol. 47, no. 7, pp. 1144-1152, 2006.

[265] N. M. Lorenzon and R. C. Foehring, "Relationship between repetitive firing and afterhyperpolarizations in human neocortical neurons," Journal of Neurophysiology, vol. 67, no. 2, pp. 350363, 1992.

[266] S. W. Kuffler and J. G. Nicholls, From Neuron to Brain, Sinauer Associates, Sunderland, Mass, USA, 1987.

[267] R. H. Roth, M. E. Wolf, and A. Y. Deutch, "Neurochemisry of midbrain dopamine system," in Psychopharmacology the Third Generation of Progress, H. Y. Meltzer, Ed., chapter 9, pp. 81-98, Raven Press, New York, NY, USA, 1987.

[268] R. H. Roth and J. D. Elsworth, "Biochemical pharmacology of midbrain dopamine neurons," in Psychopharmacology: The Fourth Generation of Progress, F. E. Bloom and D. J. Kupfer, Eds., chapter 21, pp. 227-243, Raven Press, New York, NY, USA, 1995. 
[269] A. Björklund and S. B. Dunnett, "Dopamine neuron systems in the brain: an update," Trends in Neurosciences, vol. 30, no. 5, pp. 194-202, 2007.

[270] K. J. Watling, The Sigma-RBI Handbook of Receptor Classification and Signal Transduction, Sigma-Aldrich, 2006.

[271] S. P. H. Alexander, A. Mathie, and J. A. Peters, "Guide to receptors and channels (GRAC), 5th edition," The British Journal of Pharmacology, vol. 164, supplement 1, pp. S1-S324, 2011.

[272] P. Greengard, P. B. Allen, and A. C. Nairn, "Beyond the dopamine receptor: the DARPP-32/protein phosphatase- 1 cascade," Neuron, vol. 23, no. 3, pp. 435-447, 1999.

[273] P. Calabresi, B. Picconi, A. Tozzi, and M. Di Filippo, "Dopamine-mediated regulation of corticostriatal synaptic plasticity," Trends in Neurosciences, vol. 30, no. 5, pp. 211-219, 2007.

[274] J. Lester, S. Fink, N. Aronin, and M. DiFiglia, "Colocalization of D1 and D2 dopamine receptor mRNAs in striatal neurons," Brain Research, vol. 621, no. 1, pp. 106-110, 1993.

[275] C. A. Tamminga and A. Carlsson, "Partial dopamine agonists and dopaminergic stabilizers, in the treatment of psychosis," Current Drug Targets_CNS \& Neurological Disorders, vol. 1, no. 2, pp. 141-147, 2002.

[276] E. N. Pothos, "Regulation of dopamine quantal size in midbrain and hippocampal neurons," Behavioural Brain Research, vol. 130, no. 1-2, pp. 203-207, 2002.

[277] A. S. Bazyan, V. M. Getsova, and N. V. Orlova, "Haloperidol catalepsy consolidation in the rat as a model of neuromodulatory integration," Neuroscience, vol. 99, no. 2, pp. 279-288, 2000.

[278] R. R. Gainetdinov, T. D. Sotnikova, T. V. Grekhova, and K. S. Rayevsky, "In vivo evidence for preferential role of dopamine D3 receptor in the presynaptic regulation of dopamine release but not synthesis," European Journal of Pharmacology, vol. 308, no. 3, pp. 261-269, 1996.

[279] J. W. Mink, “The basal ganglia," in Fundamental Neuroscience, L. R. Scuire, F. T. Bloom, S. C. McConnell, J. L. Roberts, N. C. Spitzer, and M. J. Zigmond, Eds., pp. 815-839, Elsevier Science/Academic Press, 2nd edition, 2003.

[280] A. S. Bazyan, G. A. Grigoryan, and M. E. Joffe, "Regulation of motor behaviour," Uspekhi Fizicheskikh Nauk, vol. 42, no. 3, pp. 65-80, 2011.

[281] O. Hikosaka, Y. Takikawa, and R. Kawagoe, "Role of the basal ganglia in the control of purposive saccadic eye movements," Physiological Reviews, vol. 80, no. 3, pp. 953-978, 2000.

[282] Y. Smith, M. D. Bevan, E. Shink, and J. P. Bolam, "Microcircuitry of the direct and indirect pathways of the basal ganglia," Neuroscience, vol. 86, no. 2, pp. 353-387, 1998.

[283] J. Olds and P. Milner, "Positive reinforcement produced by electrical stimulation of septal area and other regions of rat brain," Journal of Comparative and Physiological Psychology, vol. 47, no. 6, pp. 419-427, 1954.

[284] P. D. Shabanov and A. A. Lebedev, "Participation of GABA- and dopaminergic mechanisms of the bed nucleus of stria terminalis in reinforcing effects of psychotropic drugs mediated via the lateral hypothalamus," Rossiǔskii Fiziologicheskiu Zhurnal Imeni I. M. Sechenova, vol. 97, no. 8, pp. 804-813, 2011.

[285] P. D. Shabanov, A. A. Lebedev, A. V. Liubimov, and V. A. Kornilov, "Significance of CRF and dopamine receptors in amygdala for reinforcing effects of opiates and opioids on selfstimulation of lateral hypothalamus in rats," Eksperimental'naia i Klinicheskaia Farmakologiia, vol. 74, no. 1, pp. 3-8, 2011.

[286] P. Redgrave, "Modulation of intracranial self-stimulation behaviour by local perfusions of dopamine, noradrenaline and serotonin within the caudate nucleus and nucleus accumbens," Brain Research, vol. 155, no. 2, pp. 277-295, 1978.

[287] D. J. Hayes, J. Hoang, and A. J. Greenshaw, "The role of nucleus accumbens shell GABA receptors on ventral tegmental area intracranial self-stimulation and a potential role for the 5-HT2C receptor," Journal of Psychopharmacology, vol. 25, no. 12, pp. 1661-1675, 2011.

[288] F. Mora, D. B. Avrith, and E. T. Rolls, "An electrophysiological and behavioural study of self-stimulation in the orbitofrontal cortex of the rhesus monkey," Brain Research Bulletin, vol. 5, no. 2, pp. 111-115, 1980.

[289] F. Mora, F. Vives, and F. Alba, "Evidence for an involvement of acetylcholine in self-stimulation of the prefrontal cortex in the rat," Experientia, vol. 36, no. 10, pp. 1180-1181, 1980.

[290] A. G. Phillips, F. Mora, and E. T. Rolls, "Intracerebral selfadministration of amphetamine by rhesus monkeys," Neuroscience Letters, vol. 24, no. 1, pp. 81-86, 1981.

[291] F. Mora and J. M. R. Ferrer, "Neurotransmitters, pathways and circuits as the neural substrates of self-stimulation of the prefrontal cortex: facts and speculations," Behavioural Brain Research, vol. 22, no. 2, pp. 127-140, 1986.

[292] K. L. Thomas and B. J. Everitt, "Limbic-cortical-ventral striatal activation during retrieval of a discrete cocaine-associated stimulus: a cellular imaging study with $\gamma$ protein kinase $\mathrm{C}$ expression," Journal of Neuroscience, vol. 21, no. 7, pp. 2526$2535,2001$.

[293] J. M. Allman, A. Hakeem, J. M. Erwin, E. Nimchinsky, and P. Hof, "The anterior cingulate cortex: the evolution of an interface between emotion and cognition," Annals of the New York Academy of Sciences, vol. 935, pp. 107-117, 2001.

[294] K. C. Berridge and M. L. Kringelbach, "Affective neuroscience of pleasure: reward in humans and animals," Psychopharmacology, vol. 199, no. 3, pp. 457-480, 2008.

[295] T. Sharot, T. Shiner, A. C. Brown, J. Fan, and R. J. Dolan, "Dopamine enhances expectation of pleasure in humans," Current Biology, vol. 19, no. 24, pp. 2077-2080, 2009.

[296] K. S. Smith, K. C. Berridge, and J. W. Aldridge, "Disentangling pleasure from incentive salience and learning signals in brain reward circuitry," Proceedings of the National Academy of Sciences of the United States of America, vol. 108, no. 27, pp. E255E264, 2011.

[297] L. M. McClusky, “On making nursing undergraduate human reproductive physiology content meaningful and relevant: discussion of human pleasure in its biological context," Nurse Education Today, vol. 32, no. 1, pp. 101-104, 2012.

[298] J. E. Robinson, E. W. Fish, M. C. Krouse, A. Thorsell, M. Heilig, and C. J. Malanga, "Potentiation of brain stimulation reward by morphine: effects of neurokinin-1 receptor antagonism," Psychopharmacology, vol. 220, no. 1, pp. 215-224, 2012.

[299] A. S. Bazyan, "The mechanisms of neuromodulatory integration actualized the emotional and motivation states," Neurochimia, vol. 16, no. 2, pp. 88-103, 1999.

[300] S. E. Hemby, G. H. Jones, D. B. Neill, and J. B. Justice Jr., "6Hydroxydopamine lesions of the medial prefrontal cortex fail to influence cocaine-induced place conditioning," Behavioural Brain Research, vol. 49, no. 2, pp. 225-230, 1992.

[301] G. A. Higgins, P. Nguyen, and E. M. Sellers, "Morphine place conditioning is differentially affected by CCK(A) and CCK(B) receptor antagonists," Brain Research, vol. 572, no. 1-2, pp. 208215, 1992. 
[302] A. S. Bazyan and G. A. Grigoryan, "Molecular-chemical basis of emotional states and reinforcement," Uspekhi Fiziologicheskikh Nauk, vol. 37, no. 1, pp. 78-83, 2006.

[303] S. R. Bradley, M. J. Marino, M. Wittmann et al., "Activation of group II metabotropic glutamate receptors inhibits synaptic excitation of the substantia nigra pars reticulata," Journal of Neuroscience, vol. 20, no. 9, pp. 3085-3094, 2000.

[304] C. Deransart, V. Riban, B. T. Lê, C. Marescaux, and A. Depaulis, "Dopamine in the striatum modulates seizures in a genetic model of absence epilepsy in the rat," Neuroscience, vol. 100, no. 2, pp. 335-344, 2000.

[305] W. Schultz, P. Dayan, and P. R. Montague, "A neural substrate of prediction and reward," Science, vol. 275, no. 5306, pp. 15931599, 1997.

[306] W. Schultz, "Predictive reward signal of dopamine neurons," Journal of Neurophysiology, vol. 80, no. 1, pp. 1-27, 1998.

[307] W. Schultz and A. Dickinson, "Neuronal coding of prediction errors," Annual Review of Neuroscience, vol. 23, pp. 473-500, 2000.

[308] I. S. Midzianovskaya, "Haloperidol induces changes in the electroencephalogram of rats with genetic absence epilepsy," Zhurnal Vysshei Nervnoi Deiatelnosti Imeni I. P. Pavlova, vol. 48, no. 6, pp. 1111-1114, 1998.

[309] I. S. Midzianovskaia, "Two types of "spike-wave" discharges in the electrocorticogram of WAG/Rij rats, the genetic model of absence epilepsy," Zhurnal Vysshei Nervnoi Deiatelnosti Imeni I. P. Pavlova, vol. 49, no. 5, pp. 855-859, 1999.

[310] N. M. W. J. de Bruin, E. L. J. M. van Luijtelaar, A. R. Cools, and B. A. Ellenbroek, "Dopamine characteristics in rat genotypes with distinct susceptibility to epileptic activity: apomorphineinduced stereotyped gnawing and novelty/amphetamineinduced locomotor stimulation," Behavioural Pharmacology, vol. 12, no. 6-7, pp. 517-525, 2001.

[311] K. Y. Sarkisova, M. A. Kulikov, I. S. Mydzyanovskaya, and A. A. Folomkina, "Dopamine-dependent character of depressivelike behavior in WAG/Rij rats with genetic absence epilepsy," Zhurnal Vysshei Nervnoi Deyatelnosti Imeni I. P. Pavlova, vol. 57, no. 1, pp. 91-102, 2007.

[312] G. D. Kuznetsova, E. V. Petrova, A. M. L. Coenen, and E. L. J. M. van Luijtelaar, "Generalized absence epilepsy and catalepsy in rats," Physiology and Behavior, vol. 60, no. 4, pp. 1165-1169, 1996.

[313] A. R. Cools, R. Brachten, D. Heeren, A. Willemen, and B. Ellenbroek, "Search after neurobiological profile of individualspecific features of Wistar rats," Brain Research Bulletin, vol. 24, no. 1, pp. 49-69, 1990.

[314] A. R. Cools, B. A. Ellenbroek, M. A. Gingras, A. Engbersen, and D. Heeren, "Differences in vulnerability and susceptibility to dexamphetamine in Nijmegen high and low responders to novelty: a dose-effect analysis of spatio-temporal programming of behaviour," Psychopharmacology, vol. 132, no. 2, pp. 181-187, 1997.

[315] B. A. Ellenbroek, F. Sluyter, and A. R. Cools, “The role of genetic and early environmental factors in determining apomorphine susceptibility," Psychopharmacology, vol. 148, no. 2, pp. 124-131, 2000.

[316] A. G. Marshall, Biophysical Chemistry, John Wiley \& Sons, New York, NY, USA, 1978.

[317] T. Momiyama and E. Koga, "Dopamine D2-like receptors selectively block $\mathrm{N}$-type $\mathrm{Ca}^{2+}$ channels to reduce GABA release onto rat striatal cholinergic interneurones," Journal of Physiology, vol. 533, part 2, pp. 479-492, 2001.
[318] A. J. Cooper and I. M. Stanford, "Dopamine D2 receptor mediated presynaptic inhibition of striatopallidal GABA $\mathrm{A}_{\mathrm{A}}$ IPSCs in vitro," Neuropharmacology, vol. 41, no. 1, pp. 62-71, 2001.

[319] B. Dean, T. Hussain, E. Scarr, G. Pavey, and D. L. Copolov, "Extended treatment with typical and atypical antipsychotic drugs: differential effects on the densities of dopamine D2-like and $\mathrm{GABA}_{\mathrm{A}}$ receptors in rat striatum," Life Sciences, vol. 69, no. 11, pp. 1257-1268, 2001.

[320] R. M. Shin, M. Masuda, M. Miura et al., "Dopamine D4 receptor-induced postsynaptic inhibition of GABAergic currents in mouse globus pallidus neurons," Journal of Neuroscience, vol. 23, no. 37, pp. 11662-11672, 2003.

[321] J. J. An, M. H. Bae, S. R. Cho et al., "Altered GABAergic neurotransmission in mice lacking dopamine D2 receptors," Molecular and Cellular Neuroscience, vol. 25, no. 4, pp. 732-741, 2004.

[322] D. Centonze, P. Gubellini, A. Usiello et al., "Differential contribution of dopamine D2S and D2L receptors in the modulation of glutamate and GABA transmission in the striatum," Neuroscience, vol. 129, no. 1, pp. 157-166, 2004.

[323] I. Silva, H. Cortes, E. Escartín et al., "L-DOPA inhibits depolarization-induced $[3 \mathrm{H}] \mathrm{GABA}$ release in the dopaminedenervated globus pallidus of the rat: the effect is dopamine independent and mediated by D2-like receptors," Journal of Neural Transmission, vol. 113, no. 12, pp. 1847-1853, 2006.

[324] Y. Qu, N. R. Swerdlow, M. Weber, D. Stouffer, and L. H. Parsons, "Quinelorane, a dopamine D3/D2 receptor agonist, reduces prepulse inhibition of startle and ventral pallidal GABA efflux: time course studies," Pharmacology Biochemistry and Behavior, vol. 90, no. 4, pp. 686-690, 2008.

[325] J. Acosta-García, N. Hernández-Chan, F. Paz-Bermúdez et al., "D4 and D1 dopamine receptors modulate $\left[{ }^{3} \mathrm{H}\right] \mathrm{GABA}$ release in the substantia nigra pars reticulata of the rat," Neuropharmacology, vol. 57, no. 7-8, pp. 725-730, 2009.

[326] D. Gasca-Martinez, A. Hernandez, A. Sierra et al., "Dopamine inhibits GABA transmission from the globus pallidus to the thalamic reticular nucleus via presynaptic D4 receptors," Neuroscience, vol. 169, no. 4, pp. 1672-1681, 2010.

[327] G. Govindaiah, T. Wang, M. U. Gillette, S. R. Crandall, and C. L. Cox, "Regulation of inhibitory synapses by presynaptic D4 dopamine receptors in thalamus," Journal of Neurophysiology, vol. 104, no. 5, pp. 2757-2765, 2010.

[328] A. S. Bazyan, N. V. Orlova, and V. M. Getsova, "Characterisation of learning and memory in the WAG/Rij rats prone to absence epilepsy," in The WAG/Rij Rats Model of Absence Epilepsy: The Nijmegen-Moscow Research, G. D. Kuznetsova, A. M. L. Coenen, S. A. Chepurnov, and E. L. J. M. van Luijtelaar, Eds., pp. 99-104, Nijmegen University Press, Nijmegen, The Netherlands, 2000.

[329] K. Y. Sarkisova and M. A. Kulikov, "WAG/Rij rats: a new genetically-based model of depression," in The WAG/Rij Rats Model of Absence Epilepsy: The Nijmegen-Moscow Research, G. D. Kuznetsova, A. Coenen, S. A. Chepurnov, and E. L. J. M. van Luijtelar, Eds., pp. 105-112, Nijmegen University Press, Nijmegen, The Netherlands, 2000.

[330] Y. V. Dobryakova, V. A. Dubynin, and G. van Luijtelaar, "Maternal behavior in a genetic animal model of absence epilepsy," Acta Neurobiologiae Experimentalis, vol. 68, no. 4, pp. 502-508, 2008.

[331] Y. V. Dobryakova, V. A. Dubynin, and G. van Luijtelaar, "The effect of haloperidol on maternal behavior in WAG/Rij rats 
and its consequences in the offspring," Acta Neurobiologiae Experimentalis, vol. 71, no. 3, pp. 339-347, 2011.

[332] V. M. Getsova, N. V. Orlova, A. A. Folomkina, and A. S. Bazian, "Low dose of disulfiram and l-dopa evoked synergistic modification in behavior of Wistar and WAG/Rij rats", Zhurnal Vysshei Nervnoi Deiatelnosti Imeni I. P. Pavlova, vol. 53, no. 5, pp. 656-662, 2003.

[333] V. M. Getsova, N. V. Orlova, A. A. Folomkina, and A. S. Bazyan, "The behavioural correlates of dopamine deficit by WAG/Rij rats strain," in The WAG/Rij Model of Absence Epilepsy: The Nijmegan-Russian Federation Papers, G. van Luijtelar, G. D. Kuznetsova, A. Coenen, and S. A. Chepurnov, Eds., pp. 293-304, Nijmegan Institute for Cognition and Information, Nijmegen, The Netherlands, 2004.

[334] R. I. Kruglikov, V. M. Getsova, N. V. Orlova, A. A. Lushkin, and I. R. Feshchenko, "Monoamine changes in the brain: influence on reaction of emotional resonance," Zhurnal Vysshei Nervnoi Deyatelnosti Imeni I. P. Pavlova, vol. 45, no. 3, pp. 551-557, 1995.

[335] A. S. Bazyan, I. S. Midzianovskaya, G. D. Kuznetsova et al., "Possible mechanisms of WAG/Rij rats strain typological behavior actualization," Zhurnal Vysshei Nervnoi Deiatelnosti Imeni I. P. Pavlova, vol. 51, no. 6, pp. 720-727, 2001.

[336] R. A. Wise, "Catecholamine theories of reward: a critical review," Brain Research, vol. 152, no. 2, pp. 215-247, 1978.

[337] R. A. Wise, "Dopamine and reward: the anhedonia hypothesis 30 years on," Neurotoxicity Research, vol. 14, no. 2-3, pp. 169-183, 2008.

[338] R. A. Wise, "Roles for nigrosriatal-not just mesocorticolimbicdopamine in reward and addiction," Trends in Neurosciences, vol. 32, no. 10, pp. 517-524, 2009.

[339] M. H. Joseph, K. Datla, and A. M. J. Young, "The interpretation of the measurement of nucleus accumbens dopamine by in vivo dialysis: the kick, the craving or the cognition?" Neuroscience and Biobehavioral Reviews, vol. 27, no. 6, pp. 527-541, 2003.

[340] W. Schultz, "Behavioral dopamine signals," Trends in Neurosciences, vol. 30, no. 5, pp. 203-210, 2007.

[341] T. Aosaki, H. Tsubokawa, A. Ishida, K. Watanabe, A. M. Graybiel, and M. Kimura, "Responses of tonically active neurons in the primate's striatum undergo systematic changes during behavioral sensorimotor conditioning," Journal of Neuroscience, vol. 14, no. 6, pp. 3969-3984, 1994.

[342] S. Jacques, "Brain stimulation and reward: "pleasure centers" after twenty-five years," Neurosurgery, vol. 5, no. 2, pp. 277-283, 1979.

[343] B. G. Hoebel, "Brain neurotransmitters in food and drug reward," The American Journal of Clinical Nutrition, vol. 42, no. 5, pp. 1133-1150, 1985.

[344] P. Shizgal, "Toward a cellular analysis of intracranial selfstimulation: contributions of collision studies," Neuroscience and Biobehavioral Reviews, vol. 13, no. 2-3, pp. 81-90, 1989.

[345] A. Robertson, "Multiple reward systems and the prefrontal cortex," Neuroscience and Biobehavioral Reviews, vol. 13, no. 2-3, pp. 163-170, 1989.

[346] A. G. Phillips, C. D. Blaha, and H. C. Fibiger, "Neurochemical correlates of brain-stimulation reward measured by ex vivo and in vivo analyses," Neuroscience and Biobehavioral Reviews, vol. 13, no. 2-3, pp. 99-104, 1989.

[347] G. J. Schaefer and R. P. Michael, "Schedule-controlled brain self-stimulation: has it utility for behavioral pharmacology?" Neuroscience and Biobehavioral Reviews, vol. 16, no. 4, pp. 569$583,1992$.
[348] G. Di Chiara, "The role of dopamine in drug abuse viewed from the perspective of its role in motivation," Drug and Alcohol Dependence, vol. 38, no. 2, pp. 95-137, 1995.

[349] S. Nakajima, "Biochemical mechanism of reinforcement: findings in the studies of self-stimulation," Shinrigaku Kenkyu, vol. 66, no. 6, pp. 449-456, 1996.

[350] S. Ikemoto and J. Panksepp, "The role of nucleus accumbens dopamine in motivated behavior: a unifying interpretation with special reference to reward-seeking," Brain Research Reviews, vol. 31, no. 1, pp. 6-41, 1999.

[351] W. Lason, B. Przewlocka, A. Coenen, R. Przewlock, and G. van Luijtelaar, "Effects of $\mu$ and $\delta$ opioid receptor agonists and antagonists on absence epilepsy in WAG/Rij rats," Neuropharmacology, vol. 33, no. 2, pp. 161-166, 1994.

[352] W. Lason, B. Przewlocka, A. M. L. Coenen, R. Przewlocki, and E. L. J. M. van Luijtelaar, "The role of opioid system in absence epilepsy in rats," in Typical Absences and Related Epileptic Syndromes, J. S. Duncan and C. P. Panayiotupolos, Eds., pp. 161-166, Churchill Communications Europe, London, UK, 1995.

[353] B. Przewłocka, W. Lasoń, H. Machelska, G. van Luijtelaar, A. Coenen, and R. Przewłocki, "Kappa opioid receptor agonists suppress absence seizures in WAG/Rij rats," Neuroscience Letters, vol. 186, no. 2-3, pp. 131-134, 1995.

[354] W. Lason, B. Przewlocka, R. Przewlocki, A. M. L. Coenen, and E. L. J. M. van Luijtelaar, "The role of opioid mechanisms in nonconvulsive seizures in WAG/Rij rats," in New Leads in Opioid Research, J. M. van Ree, A. H. Mulder, V. M. Weigamt, and T. van Wimersma Greidanus, Eds., pp. 350-352, Excerpta Medica, Amsterdam, The Netherlands, 1990.

[355] W. Lason, B. Przewlocka, E. L. J. M. van Luijtelaar, A. M. L. Coenen, and R. Przewlocki, "Endogenous opioid peptides in brain and pituitary of rats with absence epilepsy," Neuropeptides, vol. 21, no. 3, pp. 147-152, 1992.

[356] W. Lasoń, B. Przewłocka, G. van Luijtelaar, and A. Coenen, "Proenkephalin and prodynorphin mRNA level in brain of rats with absence epilepsy," Neuropeptides, vol. 27, no. 6, pp. 343-347, 1994.

[357] G. Baranauskas and A. Nistri, "Sensitization of pain pathways in the spinal cord: cellular mechanisms," Progress in Neurobiology, vol. 54, no. 3, pp. 349-365, 1998.

[358] A. S. Bazian, N. V. Orlova, and V. M. Getsova, "Modulation of the activity of monoaminergic brain systems and emotional condition by dalargin in rats during development of emotional resonance response," Zhurnal Vysshei Nervnoi Deyatelnosti Imeni I.P. Pavlova, vol. 50, no. 3, pp. 500-508, 2000.

[359] N. Altier and J. Stewart, "Dopamine receptor antagonists in the nucleus accumbens attenuate analgesia induced by ventral tegmental area substance P or morphine and by nucleus accumbens amphetamine," Journal of Pharmacology and Experimental Therapeutics, vol. 285, no. 1, pp. 208-215, 1998.

[360] N. Altier and J. Stewart, "The role of dopamine in the nucleus accumbens in analgesia," Life Sciences, vol. 65, no. 22, pp. 22692287, 1999.

[361] E. J. Calabrese, “Dopamine: biphasic dose responses," Critical Reviews in Toxicology, vol. 31, no. 4-5, pp. 563-583, 2001.

[362] C. Suaudeau and J. Costentin, "Analgesic effect of the direct D2 dopamine receptor agonist RU 24926 and cross tolerance with morphine," Fundamental and Clinical Pharmacology, vol. 9, no. 2, pp. 147-152, 1995.

[363] C. D. Cook, A. C. Barrett, C. Syvanthong, and M. J. Picker, "Modulatory effects of dopamine D3/2 agonists on kappa 
opioid-induced antinociception and diuresis in the rat," Psychopharmacology, vol. 152, no. 1, pp. 14-23, 2000.

[364] J. E. Magnusson and K. Fisher, "The involvement of dopamine in nociception: the role of $\mathrm{D} 1$ and $\mathrm{D} 2$ receptors in the dorsolateral striatum," Brain Research, vol. 855, no. 2, pp. 260-266, 2000.

[365] X. Gao, Y. Q. Zhang, and G. C. Wu, "Effects of dopaminergic agents on carrageenan hyperalgesia after intrathecal administration to rats," European Journal of Pharmacology, vol. 418, no. 1-2, pp. 73-77, 2001.

[366] N. A. Trekova, L. A. Vetrilé, L. A. Basharova, O. I. Mikovskaya, and T. G. Khlopushina, "Anti-dopamine antibodies: effects on behavior in an "open field," pain sensitivity, CNS monoamine content, and functional activity of immunocytes in C57Bl/6 mice," Neuroscience and Behavioral Physiology, vol. 31, no. 1, pp. 7-13, 2001.

[367] E. L. J. M. van Luijtelaar, R. Dirksen, T. B. Vree, and F. van Haaren, "Effects of acute and chronic cocaine administration on EEG and behaviour in intact and castrated male and intact and ovariectomized female rats," Brain Research Bulletin, vol. 40, no. 1, pp. 43-50, 1996.

[368] J. Glowinski, "Regulation of synthesis and release processes in central catecholaminergic neuron," in Metabolic Components and Neurotransmitters Relation of Brain Structure and Function, pp. 187-203, Pergamon Press, New York, NY, USA, 1975.

[369] N. Weiner, F. L. Lee, E. Dreyer, and E. Barnes, "The activation of tyrosine hydroxylase in noradrenergic neurons during acute nerve stimulation," Life Sciences, vol. 22, no. 13-15, pp. 1197-1216, 1978.

[370] B. Nikodejevic, S. Senoh, J. W. Daly, and C. R. Creveling, "Catechol-O-methyltransferase. II. A new class of inhibitors of catechol-o-methyltransferase; 3,5-dihydroxy-4-methoxybenzoic acid and related compounds," Journal of Pharmacology and Experimental Therapeutics, vol. 174, no. 1, pp. 83-93, 1970.

[371] E. Costa and M. Sandler, Monoamine Oxidase: New Vistas, Raven Press, New York, NY, USA, 1972.

[372] R. J. Ziance, K. Moxley, M. Mullis, and W. Gray, "Influence of $\mathrm{MAO}$ inhibitors on uptake and release of norepinephrine in rat brain in vitro," Archives Internationales de Pharmacodynamie et de Therapie, vol. 228, no. 1, pp. 30-38, 1977.

[373] G. A. R. Johnston, “Transmitter inactivating processes," Proceedings of the Australian Physiological and Pharmacological Society, vol. 9, no. 2, pp. 94-98, 1978.

[374] U. Trendelenburg, "Extraneuronal uptake and metabolism of catecholamines as a site of loss," Life Sciences, vol. 22, no. 13-14, pp. 1217-1222, 1978.

[375] I. S. Midzianovskaya, G. D. Kuznetsova, L. Tuomisto, U. MacDonald, M. A. Kulikov, and A. S. Bazyan, "The dopamine and it metabolites concentration in the different structures of WAG/Rij and Wistar rats strains' brain: the comparative analysis of audiogenic, absence and mixed form epilepsy," Neurokimia, vol. 21, no. 4, pp. 264-270, 2004.

[376] L. M. Birioukova, I. S. Midzyanovskaya, S. Lensu, L. Tuomisto, and G. van Luijtelaar, "Distribution of D1-like and D2-like dopamine receptors in the brain of genetic epileptic WAG/Rij rats," Epilepsy Research, vol. 63, no. 2, pp. 89-96, 2005.

[377] L. M. Birioukova, I. S. Midzyanovskaya, S. Lensu, L. Tuomisto, G. van Luijtelaar, and A. S. Bazyan, "Distribution D1- and D2like dopamine receptors of WAG/Rij and ACI rats brain regions with and without absence epilepsy accordingly," Neurokhimia, vol. 23, no. 3, pp. 234-239, 2006.

[378] K. S. Raevskii, T. D. Sotnikova, and R. R. Gainetdinov, "The brain dopaminergic systems: receptor heterogeneity, functional role and pharmacological regulation," Uspekhi Fiziologicheskikh Nauk, vol. 27, no. 4, pp. 3-29, 1996.

[379] K. Y. Sarkisova and M. A. Kulikov, "Behavioral characteristics of WAG/Rij rats susceptible and non-susceptible to audiogenic seizures," Behavioural Brain Research, vol. 166, no. 1, pp. 9-18, 2006.

[380] A. H. Tran, R. Tamura, T. Uwano, T. Kobayashi, M. Katsuki, and T. Ono, "Dopamine D1 receptors involved in locomotor activity and accumbens neural responses to prediction of reward associated with place," Proceedings of the National Academy of Sciences of the United States of America, vol. 102, no. 6, pp. 21172122, 2005.

[381] A. A. Bari and R. C. Pierce, "D1-like and D2 dopamine receptor antagonists administered into the shell subregion of the rat nucleus accumbens decrease cocaine, but not food, reinforcement," Neuroscience, vol. 135, no. 3, pp. 959-968, 2005.

[382] C. M. Olsen and C. L. Duvauchelle, "Prefrontal cortex D1 modulation of the reinforcing properties of cocaine," Brain Research, vol. 1075, no. 1, pp. 229-235, 2006.

[383] B. A. Sorg, N. Li, W. Wu, and T. M. Bailie, "Activation of dopamine $\mathrm{D} 1$ receptors in the medial prefrontal cortex produces bidirectional effects on cocaine-induced locomotor activity in rats: effects of repeated stress," Neuroscience, vol. 127, no. 1, pp. 187-196, 2004.

[384] K. H. Choi, R. L. H. Clements, and A. J. Greenshaw, "Simultaneous AMPA/kainate receptor blockade and dopamine D2/3 receptor stimulation in the nucleus accumbens decreases brain stimulation reward in rats," Behavioural Brain Research, vol. 158, no. 1, pp. 79-88, 2005.

[385] Z. X. Xi, J. G. Gilbert, A. C. Pak, C. R. Ashby Jr., C. A. Heidbreder, and E. L. Gardner, "Selective dopamine D3 receptor antagonism by SB-277011A attenuates cocaine reinforcement as assessed by progressive-ratio and variable-cost-variablepayoff fixed-ratio cocaine self-administration in rats," European Journal of Neuroscience, vol. 21, no. 12, pp. 3427-3438, 2005.

[386] L. M. Pritchard, A. D. Logue, B. C. Taylor et al., "Relative expression of D3 dopamine receptor and alternative splice variant D3nf mRNA in high and low responders to novelty," Brain Research Bulletin, vol. 70, no. 4-6, pp. 296-303, 2006.

[387] N. M. Richtand, "Behavioral sensitization, alternative splicing, and D3 dopamine receptor-mediated inhibitory function," Neuropsychopharmacology, vol. 31, no. 11, pp. 2368-2375, 2006.

[388] W. J. McBride, J. M. Murphy, and S. Ikemoto, "Localization of brain reinforcement mechanisms: intracranial selfadministration and intracranial place-conditioning studies," Behavioural Brain Research, vol. 101, no. 2, pp. 129-152, 1999.

[389] J. M. Warter, M. Vergnes, A. Depaulis et al., "Effects of drugs affecting dopaminergic neurotransmission in rats with spontaneous petit mal-like seizures," Neuropharmacology, vol. 27, no. 3, pp. 269-274, 1988.

[390] C. Deransart, G. B. Landwehrmeyer, T. J. Feuerstein, and C. H. Lücking, "Up-regulation of D3 dopaminergic receptor mRNA in the core of the nucleus accumbens accompanies the development of seizures in a genetic model of absence-epilepsy in the rat," Molecular Brain Research, vol. 94, no. 1-2, pp. 166-177, 2001.

[391] J. M. Lauder, V. K. M. Han, and P. Henderson, "Prenatal ontogeny oaf the GABAergic system in the rat brain: an immunocytochemical study," Neuroscience, vol. 19, no. 2, pp. 465-493, 1986

[392] J. Liu, A. L. Morrow, L. Devaud, D. R. Grayson, and J. M. Lauder, "GABA $A_{A}$ receptors mediate trophic effects of GABA on 
embryonic brainstem monoamine neurons in vitro," Journal of Neuroscience, vol. 17, no. 7, pp. 2420-2428, 1997.

[393] S. D. Ugarte, G. E. Homanics, and D. L. Hammond, "Effect of embryonic knock-down of $\mathrm{GABA}_{\mathrm{A}}$ receptors on the levels of monoamines and their metabolites in the CNS of the mouse," Brain Research, vol. 904, no. 2, pp. 290-297, 2001.

[394] C. Verney, "Phenotypic expression of monoamines and GABA in the early development of human telencephalon, transient or not transient," Journal of Chemical Neuroanatomy, vol. 26, no. 4, pp. 283-292, 2003.

[395] D. Smith and D. Gallager, "GABA, benzodiazepine and serotonergic receptor development in the dorsal raphe nucleus: electrophysiological studies," Brain Research, vol. 432, no. 2, pp. 191-198, 1987.

[396] J. M. Fritschy, D. Benke, S. Mertens, W. H. Oertel, T. Bachi, and H. Möhler, "Five subtypes of type A $\gamma$-aminobutyric acid receptors identified in neurons by double and triple immunofluorescence staining with subunit- specific antibodies," Proceedings of the National Academy of Sciences of the United States of America, vol. 89, no. 15, pp. 6726-6730, 1992.

[397] L. F. B. Nicholson, R. L. M. Faull, H. J. Waldvogel, and M. Dragunow, "The regional, cellular and subcellular localization of $\mathrm{GABA}_{\mathrm{A}}$ /benzodiazepine receptors in the substantia nigra of the rat," Neuroscience, vol. 50, no. 2, pp. 355-370, 1992.

[398] D. N. Stephens and L. Turski, "Kindling to the benzodiazepine receptor inverse agonist, FG 7142: evidence for involvement of NMDA, but not non-NMDA, glutamatergic receptors," Neuropharmacology, vol. 32, no. 10, pp. 1011-1017, 1993.

[399] G. D. Pratt, M. Kokaia, J. Bengzon et al., "Differential regulation of N-methyl-D-aspartate receptor subunit mesenger RNAs in kindling-induced epileptogenesis," Neuroscience, vol. 57, no. 2, pp. 307-318, 1993.

[400] M. Kokaia, G. D. Pratt, E. Elmer et al., "Biphasic differential changes of $\mathrm{GABA}_{\mathrm{A}}$ receptor subunit mRNA levels in dentate gyrus granule cells following recurrent kindling-induced seizures," Molecular Brain Research, vol. 23, no. 4, pp. 323-332, 1994.

[401] M. S. Evans and K. E. Viola-McCabe, "Midazolam inhibits longterm potentiation through modulation of $\mathrm{GABA}_{\mathrm{A}}$ receptors," Neuropharmacology, vol. 35, no. 3, pp. 347-357, 1996.

[402] M. Higashima, H. Kinoshita, and Y. Koshino, "Differences in the effects of zolpidem and diazepam on recurrent inhibition and long-term potentiation in rat hippocampal slices," Neuroscience Letters, vol. 245, no. 2, pp. 77-80, 1998.

[403] R. W. Stackman, T. J. Walsh, F. H. Brucato, and H. S. Swartzwelder, "Medial septal benzodiazepine receptors modulate hippocampal evoked responses and long-term potentiation," Brain Research, vol. 717, no. 1-2, pp. 12-21, 1996.

[404] G. R. Seabrook, A. Easter, G. R. Dawson, and B. J. Bowery, "Modulation of long-term potentiation in CA1 region of mouse hippocampal brain slices by $\mathrm{GABA}_{\mathrm{A}}$ receptor benzodiazepine site ligands," Neuropharmacology, vol. 36, no. 6, pp. 823-830, 1997.

[405] J. M. Koff, G. A. Pritchard, D. J. Greenblatt, and L. G. Miller, "The NMDA receptor competitive antagonist CPP modulates benzodiazepine tolerance and discontinuation," Pharmacology, vol. 55, no. 5, pp. 217-227, 1997.

[406] G. Shen, M. S. Mohamed, P. Das, and E. I. Tietz, "Positive allosteric activation of $\mathrm{GABA}_{\mathrm{A}}$ receptors bi-directionally modulates hippocampal glutamate plasticity and behaviour," Biochemical Society Transactions, vol. 37, no. 6, pp. 1394-1398, 2009.
[407] G. Shen, B. J. van Sickle, and E. I. Tietz, "Calcium/calmodulindependent protein kinase II mediates hippocampal glutamatergic plasticity during benzodiazepine withdrawal," Neuropsychopharmacology, vol. 35, no. 9, pp. 1897-1909, 2010.

[408] L. P. Niles, L. J. Smith, and C. C. Tenn, "Modulation of cfos expression in the rat striatum by diazepam," Neuroscience Letters, vol. 236, no. 1, pp. 5-8, 1997.

[409] Y. Nomura, Y. Kitamura, T. Ohnuki et al., "Alterations in acetylcholine, NMDA, benzodiazepine receptors and protein kinase $\mathrm{C}$ in the brain of the senescence-accelerated mouse: an animal model useful for studies on cognitive enhancers," Behavioural Brain Research, vol. 83, no. 1-2, pp. 51-55, 1997.

[410] J. D. Johnston, S. A. Price, and D. R. Bristow, "Flunitrazepam rapidly reduces $\mathrm{GABA}_{\mathrm{A}}$ receptor subunit protein expression via a protein kinase C-dependent mechanism," The British Journal of Pharmacology, vol. 124, no. 7, pp. 1338-1340, 1998.

[411] L. Ramdas, B. A. Bunnin, M. J. Plunkett et al., "Benzodiazepine compounds as inhibitors of the Src protein tyrosine kinase: screening of a combinatorial library of 1,4-benzodiazepines," Archives of Biochemistry and Biophysics, vol. 368, no. 2, pp. 394400, 1999.

[412] E. A. Bignante, G. Paglini, and V. A. Molina, "Previous stress exposure enhances both anxiety-like behaviour and p35 levels in the basolateral amygdala complex: modulation by midazolam," European Neuropsychopharmacology, vol. 20, no. 6, pp. 388-397, 2010.

[413] L. Huopaniemi, R. Keist, A. Randolph, U. Certa, and U. Rudolph, "Diazepam-induced adaptive plasticity revealed by $\alpha 1 \mathrm{GABA}_{\mathrm{A}}$ receptor-specific expression profiling," Journal of Neurochemistry, vol. 88, no. 5, pp. 1059-1067, 2004.

[414] S. H. Mellon and L. D. Griffin, "Neurosteroids: biochemistry and clinical significance," Trends in Endocrinology and Metabolism, vol. 13, no. 1, pp. 35-43, 2002.

[415] P. K. Stanton and J. M. Sarvey, "Blockade of norepinephrineinduced long-lasting potentiation in the hippocampal dentate gyrus by an inhibitor of protein synthesis," Brain Research, vol. 361, no. 1-2, pp. 276-283, 1985.

[416] S. A. Deadwyler, T. Dunwiddie, and G. Lynch, "A critical level of protein synthesis is required for long-term potentiation," Synapse, vol. 1, no. 1, pp. 90-95, 1987.

[417] T. Smirnova, S. Laroche, M. L. Errington, A. A. Hicks, T. V. P. Bliss, and J. Mallet, "Transsynaptic expression of a presynaptic glutamate receptor during hippocampal long-term potentiation," Science, vol. 262, no. 5132, pp. 433-436, 1993.

[418] A. R. Brooks-Kayal, M. D. Shumate, H. Jin, T. Y. Rikhter, and D. A. Coulter, "Selective changes in single cell GABA $\mathrm{A}_{\mathrm{A}}$ receptor subunit expression and function in temporal lobe epilepsy," Nature Medicine, vol. 4, no. 10, pp. 1166-1172, 1998.

[419] R. W. Olsen, J. Yang, R. G. King, A. Dilber, G. B. Stauber, and R. W. Ransom, "Barbiturate and benzodiazepine modulation of GABA receptor binding and function," Life Sciences, vol. 39, no. 21, pp. 1969-1976, 1986.

[420] B. A. Pasqualotto, R. A. Lanius, and C. A. Shaw, "Regulation of $\mathrm{GABA}_{\mathrm{A}}$ AMPA receptors by agonist and depolarizing stimulation requires phosphatase or kinase activity," NeuroReport, vol. 4, no. 4, pp. 447-450, 1993.

[421] B. J. Krishek, X. Xie, C. Blackstone, R. L. Huganir, S. J. Moss, and T. G. Smart, "Regulation of $\mathrm{GABA}_{\mathrm{A}}$ receptor function by protein kinase C phosphorylation," Neuron, vol. 12, no. 5, pp. 1081-1095, 1994. 
[422] B. J. McDonald and S. J. Moss, "Differential phosphorylation of intracellular domains of $\gamma$-aminobutyric acid type A receptor subunits by calcium/calmodulin type 2-dependent protein kinase and cGMP-dependent protein kinase," The Journal of Biological Chemistry, vol. 269, no. 27, pp. 18111-18117, 1994.

[423] M. Uusi-Oukari and E. R. Korpi, "Regulation of $\mathrm{GABA}_{\mathrm{A}}$ receptor subunit expression by pharmacological agents," Pharmacological Reviews, vol. 62, no. 1, pp. 97-135, 2010.

[424] J. N. Jovanovic, "Phosphorylation site-specific antibodies as research tools in studies of native $\mathrm{GABA}_{\mathrm{A}}$ receptors," in The Dynamic Synapse: Molecular Methods in Ionotropic Receptor Biology, J. T. Kittler and S. J. Moss, Eds., chapter 4, pp. 57-81, CRC Press, Boca Raton, Fla, USA, 2006, http://www .crcpress.com/.

[425] M. Mayford, T. Abel, and E. R. Kandel, “Transgenic approaches to cognition," Current Opinion in Neurobiology, vol. 5, no. 2, pp. 141-148, 1995.

[426] D. S. Bredt and R. A. Nicoll, "AMPA receptor trafficking at excitatory synapses," Neuron, vol. 40, no. 2, pp. 361-379, 2003.

[427] T. Del'guidice and J. M. Beaulieu, "Messing up with traffic: different effects of antipsychotic agents on glutamate receptor complexes in vivo," Molecular Pharmacology, vol. 73, no. 5, pp. 1339-1342, 2008

[428] J. A. Esteban, "Intracellular machinery for the transport of AMPA receptors," The British Journal of Pharmacology, vol. 153, no. S1, pp. S35-S43, 2008.

[429] I. Bayazitov and A. Kleschevnikov, "Afferent high strength tetanizations favour potentiation of the NMDA versus AMPA receptor-mediated component of field EPSP in CA1 hippocampal slices of rats," Brain Research, vol. 866, no. 1-2, pp. 188-196, 2000.

[430] S. Chen Bo- and K. W. Roche, "Regulation of NMDA receptors by phosphorylation," Neuropharmacology, vol. 53, no. 3, pp. 362-368, 2007.

[431] J. T. Kittler, P. Thomas, V. Tretter et al., "Huntingtin-associated protein 1 regulates inhibitory synaptic transmission by modulating $\gamma$-aminobutyric acid type A receptor membrane trafficking," Proceedings of the National Academy of Sciences of the United States of America, vol. 101, no. 34, pp. 12736-12741, 2004.

[432] R. S. Saliba, G. Michels, T. C. Jacob, M. N. Pangalos, and S. J. Moss, "Activity-dependent ubiquitination of $\mathrm{GABA}_{\mathrm{A}}$ receptors regulates their accumulation at synaptic sites," Journal of Neuroscience, vol. 27, no. 48, pp. 13341-13351, 2007.

[433] V. Tretter and S. J. Moss, "GABA ${ }_{A}$ receptor dynamics and constructing GABAergic synapses," Frontiers in Molecular Neuroscience, vol. 1, article 7, 2008.

[434] M. Amalric, A. Ouagazzal, C. Baunez, and A. Nieoullon, "Functional interactions between glutamate and dopamine in the rat striatum," Neurochemistry International, vol. 25, no. 2, pp. 123-131, 1994.

[435] C. Baunez, A. Nieoullon, and M. Amalric, "N-methyl-Daspartate receptor blockade impairs behavioural performance of rats in a reaction time task: new evidence for glutamatergicdopaminergic interactions in the striatum," Neuroscience, vol. 61, no. 3, pp. 521-531, 1994.

[436] R. Kotter, "Postsynaptic integration of glutamatergic and dopaminergic signals in the striatum," Progress in Neurobiology, vol. 44, no. 2, pp. 163-196, 1994.

[437] M. E. Wolf, S. Mangiavacchi, and X. Sun, "Mechanisms by which dopamine receptors may influence synaptic plasticity," Annals of the New York Academy of Sciences, vol. 1003, pp. 241249, 2003.
[438] J. L. Hu, G. Liu, Y. C. Li, W. J. Gao, and Y. Q. Huang, “Dopamine D1 receptor-mediated NMDA receptor insertion depends on Fyn but not Src kinase pathway in prefrontal cortical neurons," Molecular Brain, vol. 3, no. 1, article 20, 2010.

[439] N. M. Graziane, E. Y. Yuen, and Z. Yan, "Dopamine D4 receptors regulate $\mathrm{GABA}_{\mathrm{A}}$ receptor trafficking via an actin/cofilin/ myosin-dependent mechanism," The Journal of Biological Chemistry, vol. 284, no. 13, pp. 8329-8336, 2009.

[440] Z. Chen, K. I. Ito, S. Fujii et al., "Roles of dopamine receptors in long-term depression: enhancement via D1 receptors and inhibition via D2 receptors," Receptors and Channels, vol. 4, no. 1, pp. 1-8, 1996.

[441] A. S. Bazyan, V. M. Getsova, and N. V. Orlova, "Pharmacological reminders of emotional state facilitate the retrieval of traces from amnesiac memory," Neuroscience and Behavioral Physiology, vol. 31, no. 5, pp. 509-515, 2001.

[442] R. E. See, M. Aravagiri, and G. D. Ellison, "Chronic neuroleptic treatment in rats produces persisting changes in $\mathrm{GABA}_{\mathrm{A}}$ and dopamine D-2, but not dopamine D-1 receptors," Life Sciences, vol. 44, no. 3, pp. 229-236, 1989.

[443] R. E. See, A. W. Toga, and G. Ellison, "Autoradiographic analysis of regional alterations in brain recepors following chronic administration and withdrawal of typical and atypical neuroleptics in rats," Journal of Neural Transmission-General Section, vol. 82, no. 2, pp. 93-109, 1990.

[444] J. J. Soghomonian, "Effects of neonatal 6-hydroxydopamine injections on glutamate decarboxylase, preproenkephalin and dopamine D2 receptor mRNAs in the adult rat striatum," Brain Research, vol. 621, no. 2, pp. 249-259, 1993.

[445] Z. H. Qin and B. Weiss, "Dopamine receptor blockade increases dopamine D2 receptor and glutamic acid decarboxylase mRNAs in mouse substantia nigra," European Journal of Pharmacology, vol. 269, no. 1, pp. 25-33, 1994.

[446] S. M. Anderson and R. C. Pierce, "Cocaine-induced alterations in dopamine receptor signaling: implications for reinforcement and reinstatement," Pharmacology and Therapeutics, vol. 106, no. 3, pp. 389-403, 2005.

[447] N. M. Richtand, Y. Liu, R. Ahlbrand, J. R. Sullivan, A. H. Newman, and R. K. McNamara, "Dopaminergic regulation of dopamine D3 and D3nf receptor mRNA expression," Synapse, vol. 64 , no. 8 , pp. 634-643, 2010. 


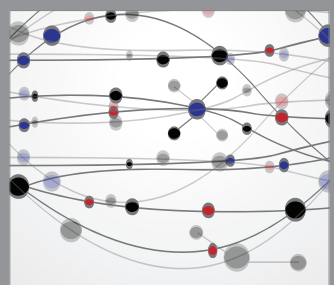

The Scientific World Journal
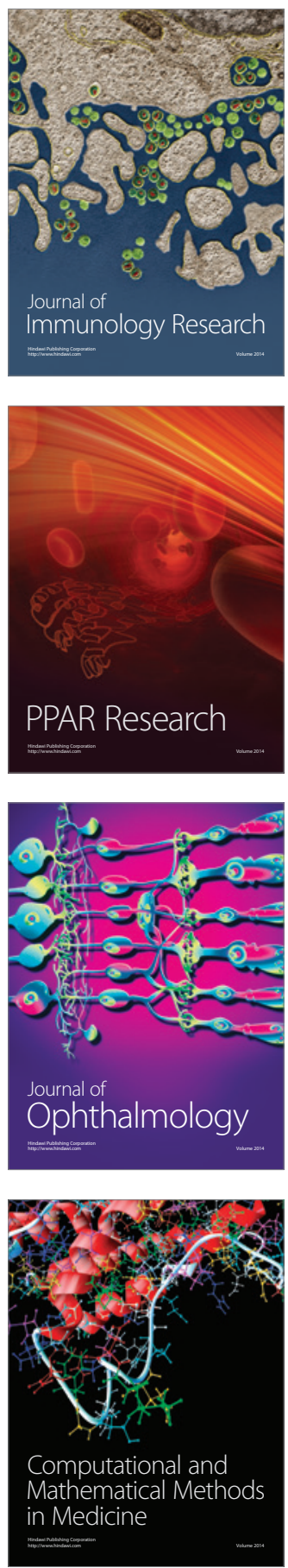

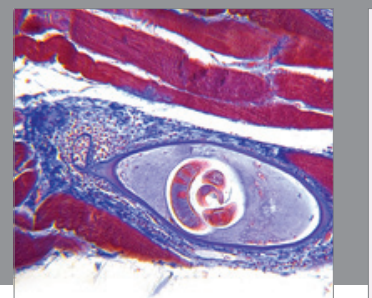

Gastroenterology

Research and Practice
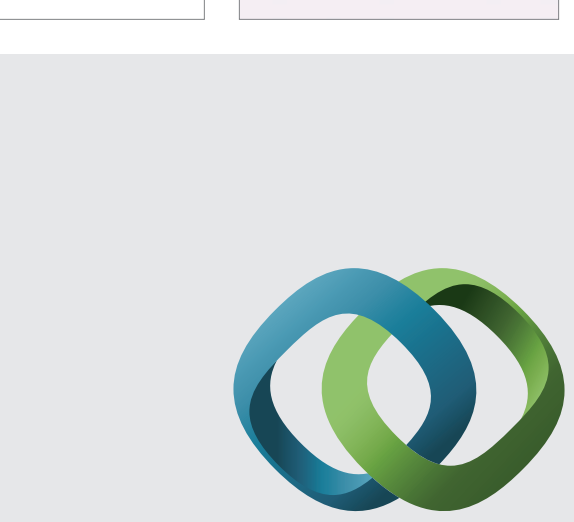

\section{Hindawi}

Submit your manuscripts at

http://www.hindawi.com
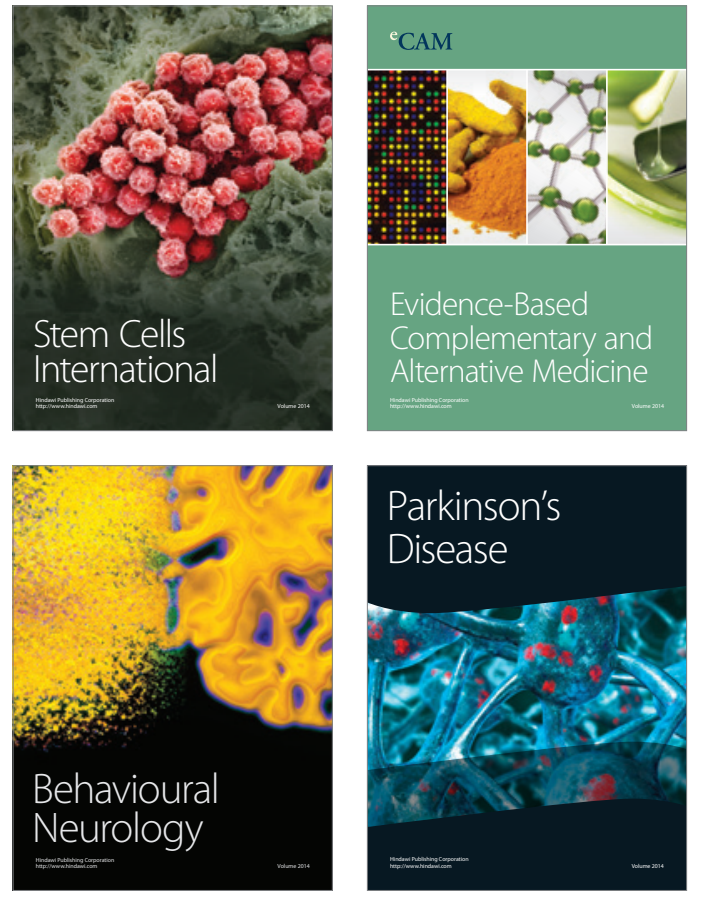
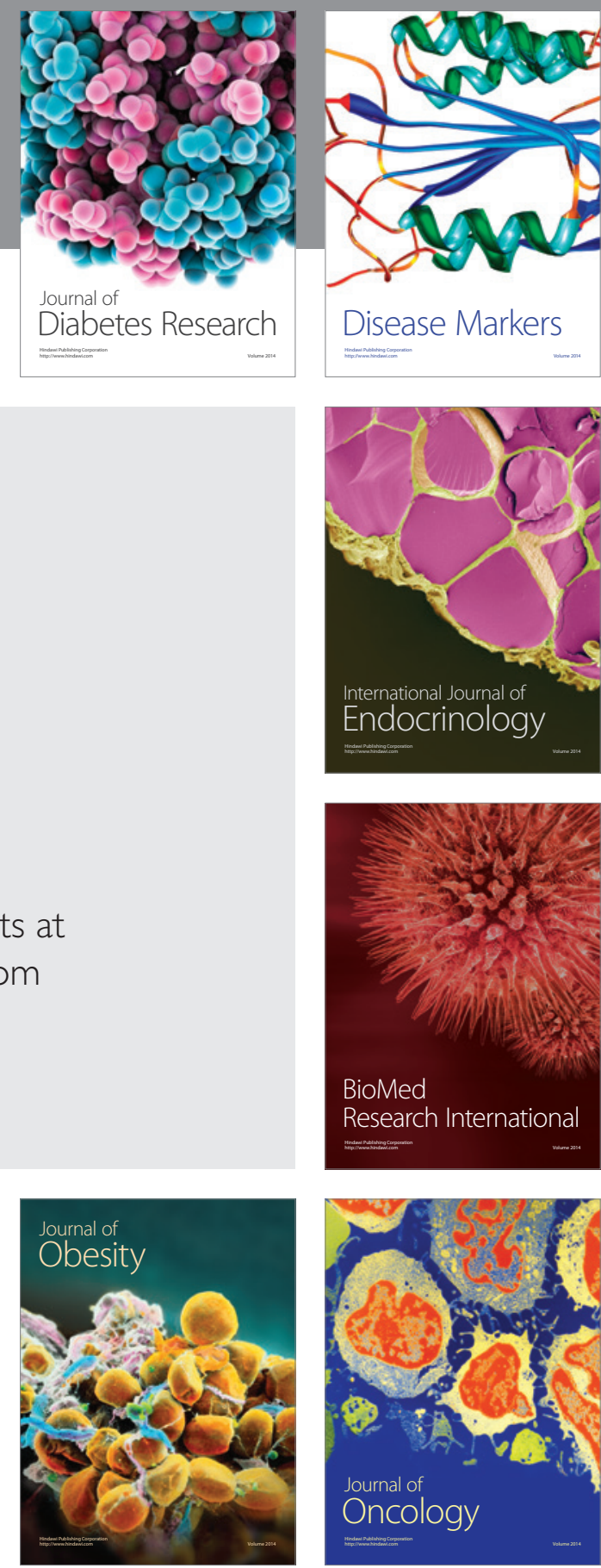

Disease Markers
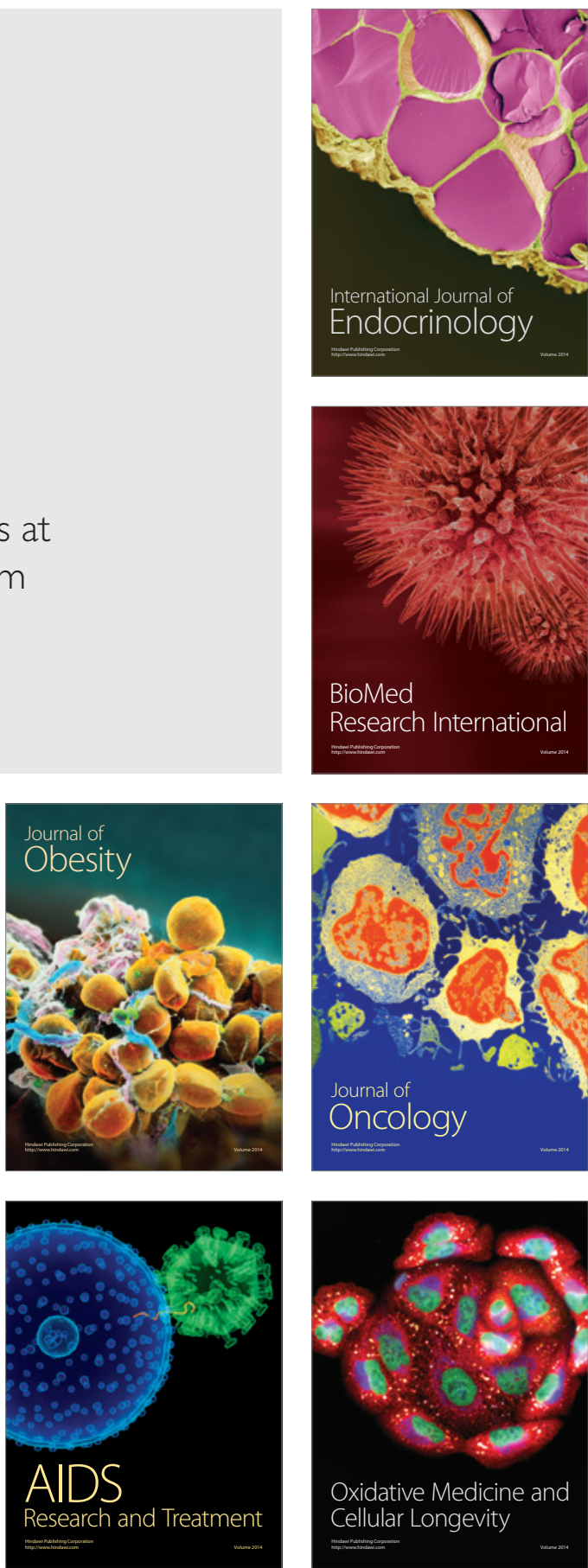